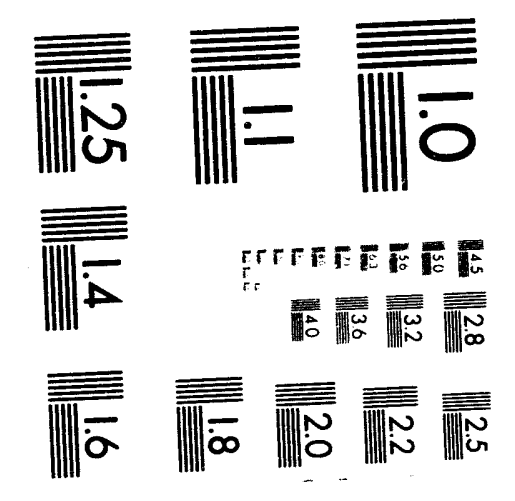



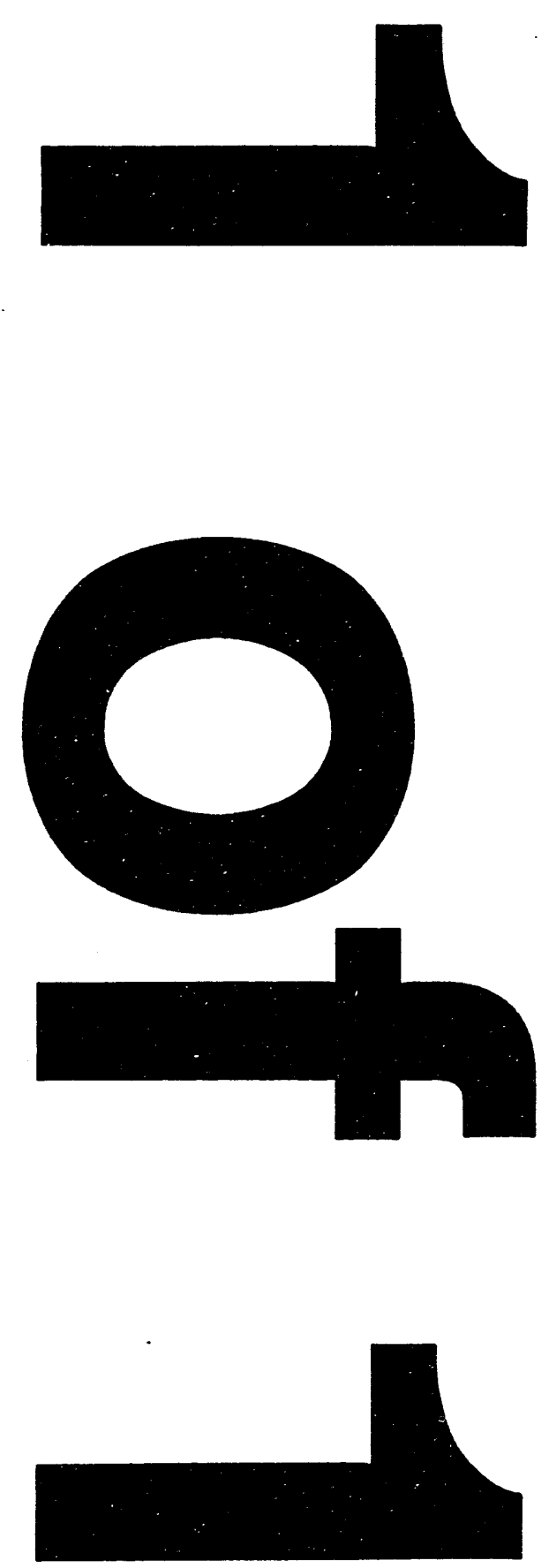
Energy Technology Division Energy Technology Division Energy Technology Division Energy Technology Division Energy Technology Division Energy Technology Division

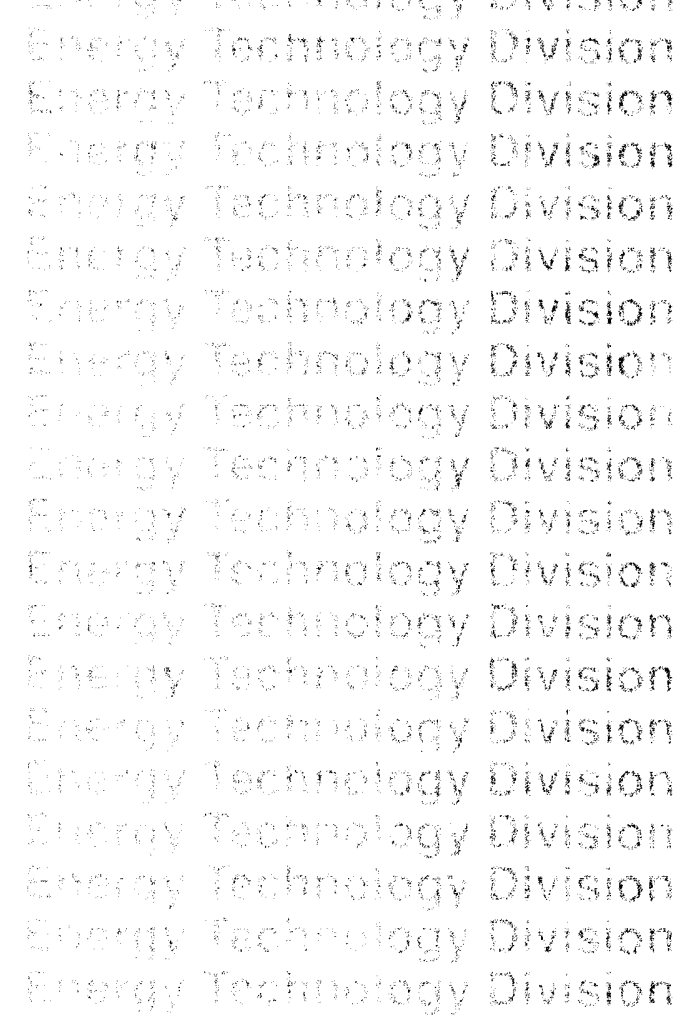

\section{Compatibility of ITER Candidate Structural Materials with Static Gallium}

by P. R. Luebbers, W. F. Michaud, and O. K. Chopra

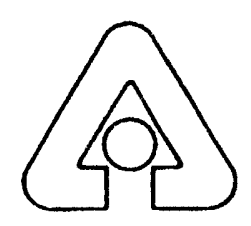

Argonne National Laboratory, Argonne, Illinois 60439

operated by The University of Chicago

for the United States Department of Energy under Contract W-31-109-Eng-38 
Argonne National Laboratory, with facilities in the states of Illinois and Idaho, is owned by the United States government, and operated by The University of Chicago under the provisions of a contract with the Department of Energy.

\section{DISCLAIMER}

This report was prepared as an account of work sponsored by an agency of the United States Government. Neither the United States Government nor any agency thereof, nor any of their employees, makes any warranty, express or implied, or assumes any legal liability or responsibility for the accuracy, completeness, or usefulness of any information, apparatus, product, or process disclosed, or represents that its use would not infringe privately owned rights. Reference herein to any specific commercial product, process, or service by trade name, trademark, manufacturer, or otherwise, does not necessarily constitute or imply its endorsement, recommendation, or favoring by the United States Government or any agency thereof. The views and opinions of authors expressed herein do not necessarily state or reflect those of the United States Government or any agency thereof.

Reproduced from the best available copy.

Available to DOE and DOE contractors from the Office of Scientific and Technical Information P.O. Box 62

Oak Ridge, TN 37831

Prices available from (615) 576-8401

Available to the public from the National Technical Information Service

U.S. Department of Commerce 5285 Port Royal Road Springfield, VA 22161 
Distribution

Category:

Energy Research

(UC-423)

ARGONNE NATIONAL LABORATORY

9700 South Cass Avenue, Argonne, Illinols 60439

\section{ANL-93/31 \\ COMPATIBILITY OF ITER CANDIDATE STRUCTURAL MATERIALS WITH STATIC GALLIUM}

by

P. R. Luebbers, W. F. Michaud, and O. K. Chopra

Energy Technology Division

December 1993

Work Sponsored by

U.S. DEPARTMENT OF ENERGY

Office of Fusion Energy, Washington, DC 20555 


\title{
COMPATIBILITY OF ITER CANDIDATE STRUCTURAL MATERIALS WITH STATIC GALLIUM
}

\author{
by \\ P. R. Luebbers, W. F. Michaud, \\ and O. K. Chopra
}

\begin{abstract}
Tests were conducted on the compatibility of gallium with candidate structural materials for the International Thermonuclear Experimental Reactor, e.g., Type 316 SS, Inconel 625, and Nb-5 Mo-1 $Z_{1}$ alloy, as well as Armco iron, Nickel 270, and pure chromium. Type 316 stainless steel is least resistant to corrosion in static gallium and $\mathrm{Nb}-5 \mathrm{Mo}-1 \mathrm{Zr}$ alloy is most resistant. At $400^{\circ} \mathrm{C}$, corrosion rates are $\approx 4.0,0.5$, and $0.03 \mathrm{~mm} / \mathrm{yr}$ for Type $316 \mathrm{SS}$, Inconel 625 , and $\mathrm{Nb}-$ $5 \mathrm{Mo}-1 \mathrm{Zr}$ alloy, respectively. The pure metals react rapidly with gallium. In contrast to find ings in earlier studies, pure iron shows greater corrosion than nickel. The corrosion rates at $400^{\circ} \mathrm{C}$ are $\geq 88$ and $18 \mathrm{~mm} / \mathrm{yr}$, respectively, for Armco iron and Nickel 270 . The results indicate that at temperatures up to $400^{\circ} \mathrm{C}$, corrosion occurs primarily by dissolution and is accompanied by formation of metal/sallium intermetallic compounds. The solubility data for pure metals and oxygen in gallium are reviewed. The physical, chemical, and radioactive properties of gallium are also presented. The supply and avallability of gallium, as well as price predictions through the year 2020, are summarized.
\end{abstract}




\section{CONTENTS}

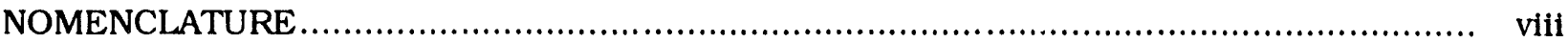

EXECUTIVE SUMMARY ..................................................................................

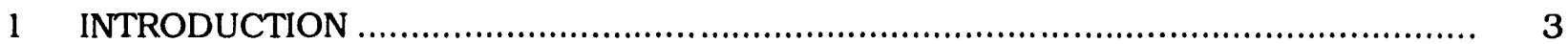

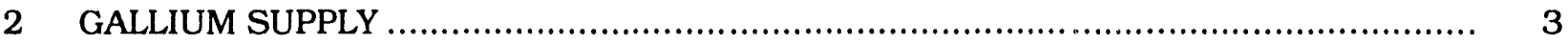

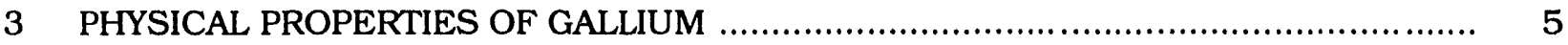

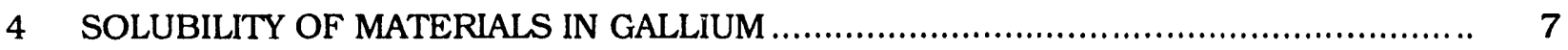

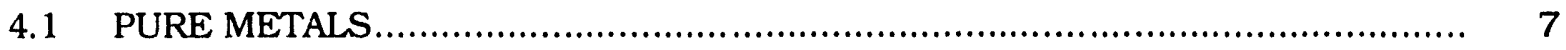

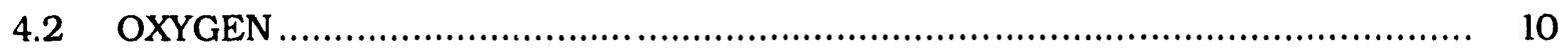

5 COMPATIBILITY OF GALLIUM WITH STRUCTURAL ALLOYS .............................. 12

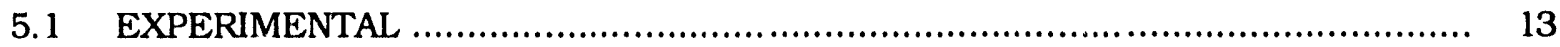

5.1.1 Formation of Gallium Whiskers ............................................. 15

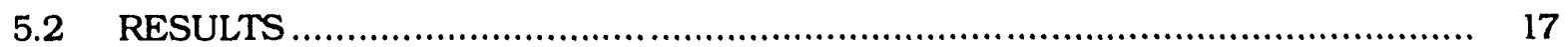

5.2.1 Corrosion Rates ............................................................... 17

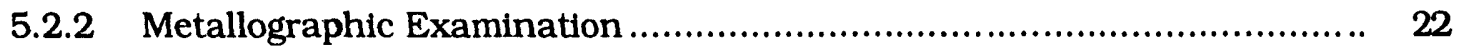

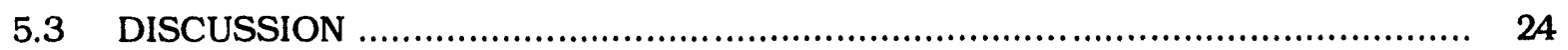

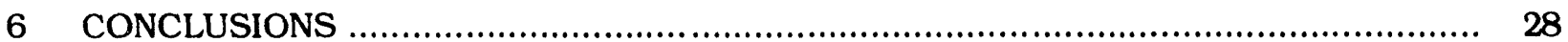

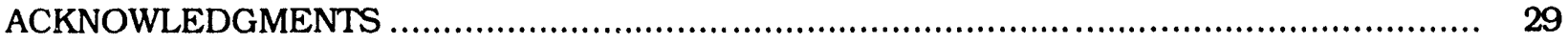

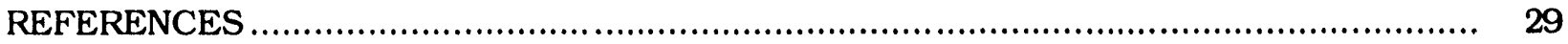

APPENDIX A: COMPOSITE PHOTOMICROGRAPHS FROM METALLOGRAPHIC EXAMINATION

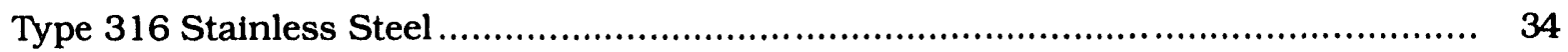

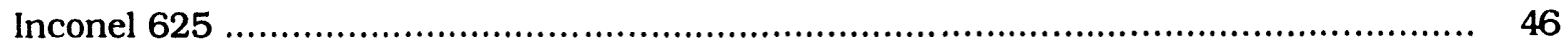

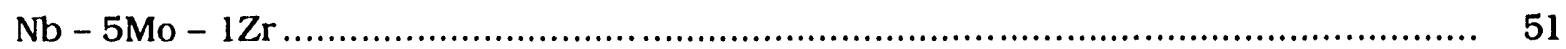

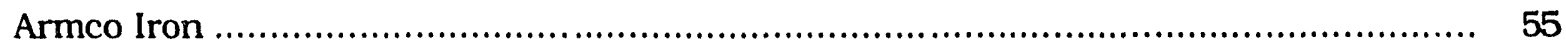


Nickel 270

\section{FIGURES}

1. Long-range (1995-2020) supply and price of crude gallium from bauxite ores .......... 4

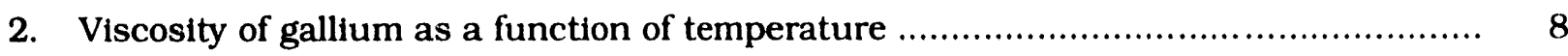

3. Specific heat capacity of gallium as a function of temperature .......................... 8

4. Thermal conductivity of gallium as a function of temperature .......................... 8

5. Solubility of metals in gallium as a function of atomic number for Periods 2-7 of the Atomic Chart of the Elements.

6. Solubility of metals as a function of atomic number for Periods 4 and 5 of the Atomic Chart of the Elements.............................................................. 10

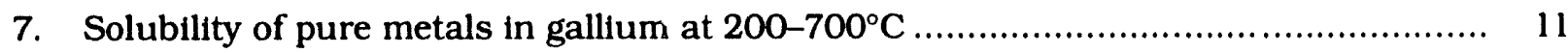

8. Solubility of pure metals in gallium at $200-700^{\circ} \mathrm{C}$, as predicted by equation $5 \ldots \ldots \ldots . \quad 11$

9. Temperature dependence of the minimum oxygen concentration in gallium for oxide formation in metals .............................................................. 13

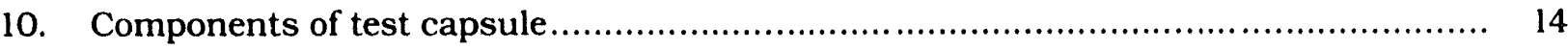

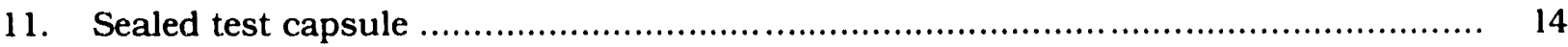

12. Schematic diagram showing typical measurements made to determine corrosion behavior of materials

13. Photomicrographs of a pure gallium whisker and specimen surface after whisker removal.

14. Photomicrographs of pure gallium whiskers, one with a curled end

15. Photomicrograph of a spiral-shaped pure gallium whisker

16. Periodicity of corrosion rate of metals in liquid gallium at $400^{\circ} \mathrm{C}$

17. Corrosion behavior of materials tested at $300^{\circ} \mathrm{C}$ in static gallium

18. Corrosion behavior of materials tested at $400^{\circ} \mathrm{C}$ in static gallium

19. Corrosion behavior of oxddized Type $316 \mathrm{SS}$ tested at $400^{\circ} \mathrm{C}$ in static gallium 
20. $\mathrm{FeGa}_{3}$ and $\mathrm{CrGa}_{4}$ crystals growing from gallium melt, with corresponding EDS

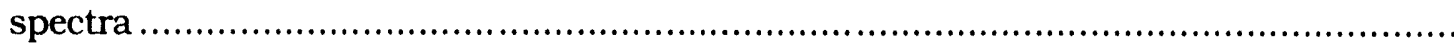

21. $\mathrm{FeGa}_{3}$ and $\mathrm{Ni}_{2} \mathrm{Ga}_{3}$ crystals grown during exposure of Type 316 SS to liquid gallium, together with corresponding EDS spectra

22. NiGa4 crystals grown during exposure of Type 316 SS to liquid gallium, together with EDS spectra of two Ni-Ga phases

23. FeGa3 crystals with silicon imperfections grown during exposure of Type 316 SS to liquid gallium, together with corresponding EDS spectra

24. Arrhenius plot of corrosion rates of various structural metals and alloys

\section{TABLES}

1. Gallium distribution in gallium-bearing resources ..................................

2. Annual capacity of primary gallium-producing countries of the world .................... 5

3. Physical and chemical properties of gallium ............................................ 6

4. Description of radioisotopes of gallium ............................................... 7

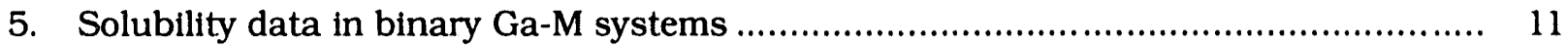

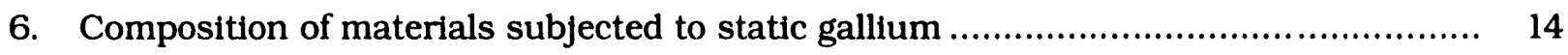

7. Corrosion behavior of Type 316 stainless steel exposed to gallium in sealed alumina capsules

8. Corrosion behavior of various materials exposed to gallium in sealed alumina capsules

A1. Preparation of postexposure specimeris for examination by SEM 


\section{NOMENCLATURE}

T Temperature (K).

$\mathrm{T}_{\mathrm{mp}} \quad$ Melting point (K).

Tbp Boiling point (K).

$Z \quad$ Atomic number.

A Mass number.

$\alpha \quad$ Coefficient of linear thermal expansion $\left(\mathrm{K}^{-1}\right)$.

$\beta \quad$ Coefficient of volumetric (cubic) thermal expansion $\left(\mathrm{K}^{-1}\right)$.

$\rho \quad$ Mass density $\left(\mathrm{g} / \mathrm{cm}^{3}\right)$.

$H_{\mathrm{m}} \quad$ Molar enthalpy $(\mathrm{J} / \mathrm{mol})$.

$S_{\mathrm{m}} \quad$ Molar entropy $(\mathrm{J} / \mathrm{K} \cdot \mathrm{mol})$.

$L_{\mathrm{f}} \quad$ Latent heat of fusion $(\mathrm{J} / \mathrm{mol})$.

$L_{v} \quad$ Latent heat of vaporization $(\mathrm{J} / \mathrm{mol})$.

$\gamma \quad$ Surface tension $(\mathrm{N} / \mathrm{m})$.

$\lambda \quad$ Thermal conductivity $(\mathrm{W} / \mathrm{m} \cdot \mathrm{K})$.

$\mu \quad$ Dynamic viscosity (Pa.s).

$c_{\mathrm{p}} \quad$ Specific heat capacity at constant pressure $(\mathrm{J} / \mathrm{kg} \cdot \mathrm{K})$.

$\rho_{\mathrm{e}} \quad$ Electrical resistivity $(\Omega \cdot \mathrm{m})$.

$c_{\mathrm{m}} \quad$ Concentration of metal in gallium (at.\%).

$c_{0} \quad$ Concentration of oxygen in gallium (at.\%)

$\Delta \mathrm{G}_{0}^{\circ} \quad$ Standard free energy of solution of oxygen in gallium (kJ).

$\Delta \mathrm{G}^{\circ} \quad$ Standard free energy of formation $(\mathrm{kJ})$.

$t_{1 / 2} \quad$ Half-life of radioactive isotope (ks).

PGa Vapor pressure of gallium (Pa).

$\sigma_{\text {absth }}$ Thermal-neutron-capture cross section $\left(\times 10^{-28} \mathrm{~m}^{2}\right)$.

$\sigma_{\text {absf }} \quad$ Fast-neutron-capture cross section $\left(\times 10^{-28} \mathrm{~m}^{2}\right)$. 


\section{EXECUTIVE SUMMARY}

Corrosion tests were conducted on Type 316 stainless steel (SS), Inconel $625, \mathrm{Nb}-5 \mathrm{Mo}-$ $1 \mathrm{Zr}$. Armco Iron, Nickel 270, and pure chromium at exposure temperatures from $200^{\circ} \mathrm{C}$ to $400^{\circ} \mathrm{C}$ and exposure times up to $3,000 \mathrm{~h}$. Contrary to previously reported results, iron-based Type 316 SS was found to be more susceptible to corrosion than nickel-based Inconel 625 in liquid gallium under static conditions. The niobium alloy, under the current test conditions, was not susceptible to attack by liquild gallium, except within cold-worked areas. The pure metals were severely attacked; Armco iron and pure chromium dissolved within $100 \mathrm{~h}$ at $400^{\circ} \mathrm{C}$. Type $316 \mathrm{SS}$ specimens were also oxidized in air at $350^{\circ} \mathrm{C}$ for $100 \mathrm{~h}$ and in water with $6 \mathrm{ppm}$ dissolved oxygen at $290^{\circ} \mathrm{C}$ for $100 \mathrm{~h}$. The specimens that were oxidized in water exhibited a lower corrosion rate than those oxidized in air, and both sets of oxidized specimens exhibited a lower corrosion rate than the nonoxidized Type 316 SS specimens. The corrosion rates at $400^{\circ} \mathrm{C}$ for Type $316 \mathrm{SS}$ as-received, oxidized in air, and oxidized in water were 4.0, 2.7, and $2.2 \mathrm{~mm} / \mathrm{yr}$, respectively. The corrosion rates at $400^{\circ} \mathrm{C}$ for Inconel 625 and $\mathrm{Nb}-5 \mathrm{Mo}-1 \mathrm{Zr}$ were 0.46 and $<0.05 \mathrm{~mm} / \mathrm{yr}$, and rates for Armco iron and Nickel 270 were $\geq 90$ and $17 \mathrm{~mm} / \mathrm{yr}$, re spectively. A corrosion rate was not determined for pure chromium.

Corrosion of metals in liquid gallium occurs by the dissolution of metallic elements into the melt. The dissolved elements then form binary intermetallic phases, typically of the form $\mathrm{MGa}_{3}$ or $\mathrm{MGa}_{4}$, and the dissolved elements are in equilibrium with these phases. The binary intermetallic compounds form at the surface of the exposed specimen, and the reaction continues at this interface as long as dissolved metallic elements are present within the melt. Type 316 SS reacted to form $\mathrm{FeGa}_{3}$, whereas Inconel 625 formed $\mathrm{CrGa}_{4}$, instead of the expected $\mathrm{Ni}_{2} \mathrm{Ga}_{3}$. These compounds are porous and crystalline, and thereby allow the melt to continually reach the reaction zone. It is possible that the rate-controlling parameter may be compound growth rather than dissolution rate.

Formation of the binary intermetallic compounds can be predicted from the solubility data reported by Yatsenko, which is summarized in this report. According to a general linear equation, the relative solubility of structural metals in gallium at temperatures $>300^{\circ} \mathrm{C}$ are: $\mathrm{W}<\mathrm{Nb}<\mathrm{Mo}<\mathrm{Zr}<\mathrm{V}<\mathrm{Ti}<\mathrm{Cr}<\mathrm{Fe}<\mathrm{Co}<\mathrm{Si}<\mathrm{Y}<\mathrm{Ni}<\mathrm{Mn}$. This agrees well with current corrosion data; the niobium alloy, which contains three of the four least-soluble elements listed here, experienced very little corrosion. Solubility data for the pure metals also exhibited a periodicity with atomic number, a phenomenon similar to the solubility behavior of other lowmelting-point metals. The same periodicity has been reported for corrosion rates of pure metals in gallium.

Solubility data for oxygen and $\mathrm{M}_{\mathrm{x}} \mathrm{O}_{\mathrm{y}}$ compounds in gallium are also presented. Most of the metal oxides were more stable than $\beta-\mathrm{Ga}_{2} \mathrm{O}_{3}$, the most stable $\mathrm{Ga}-\mathrm{O}$ compound in liquid gallium that contains excess oxygen. Of the compounds presented, the exceptions are NiO, $\mathrm{FeO}$, and $\mathrm{MoO}_{2}$. Iron [II] chromite $\left(\mathrm{FeCr}_{2} \mathrm{O}_{4}\right)$ was tested experimentally and found to be unstable in gallium.

The physical, chemical, and radioisotope decay properties of gallium are reviewed. Because of its attractive thermal properties, gallium has been considered for use as a heattransport medium in the International Thermonuclear Experimental Reactor (ITER). However, 
gallium exhibits several properties that may preclude its use as a coolant, e.g., a high thermalneutron absorption coefficient and high volumetric expansion upon solidification.

Several recent publications describe the availability, production capacity, and future cost of gallium, based on use primarily in GaAs semiconductors. Gallium constitutes $\approx 1.5 \times 10^{-3}$ mass percent of the earth's crust, but must be extracted as a byproduct from other manufacturing processes. Therefore, if the demand for gallium remains relatively low, the cost of recovering gallium from these processes will continue to remain prohibitively high for use as a heat transport medium in ITER. The current price for ultrapure gallium is $\approx \$ 500 / \mathrm{kg}$.

Based upon current information regarding the stability of advanced alloys in liquid gallium, two ternary alloy systems hold promise for high-temperature containment of the liquid metal. Solubility data predict that alloys of $\mathrm{Zr}-\mathrm{Nb}-\mathrm{Mo}$ and $\mathrm{Ti}-\mathrm{V}-\mathrm{Cr}$ should be stable in liquid gallium at elevated temperatures. Alloys that are susceptible to attack by liquid gallium (i.e., Inconel 625 and Type 316 SS) must be coated with a stable metal oxide to prevent severe liquid-metal corrosion of the alloy. Some alloys may be attacked in cold-worked regions, although the effect of cold-work on liquid-metal compatibility must be investigated further. 


\section{INTRODUCTION}

Gallium is under consideration for use as a liquid-metal heat-transport medium for the International Thermonuclear Experimental Reactor (ITER) because it remains liquid over a wider temperature range than any other metal, i.e., from near room temperature $\left(30^{\circ} \mathrm{C}\right)$ to $\approx 2300^{\circ} \mathrm{C}$, and because it exhibits good thermal conductivity and very low vapor pressure at high temperatures. Its disadvantages include a relatively high thermal-neutron absorption coefficient and a $3.2 \%$ volume increase during solidification. Of all the proposed liquid-metal heattransport media for ITER, gallium has the highest thermal-neutron-capture cross section, i.e.. 2.77 barns $\left(1\right.$ barn $=10^{-28} \mathrm{~m}^{2}$ ) compared with $\approx 40,180$, and 534 mbarns for lithium, lead, and sodium, respectively. Gallium also has a high affinity for most engineering metals and alloys. Pure metals such as aluminum, zinc, and tin disintegrate in liquid gallium at $30^{\circ} \mathrm{C}$. Refractory metals and ceramics are most stable in gallium. Gallium can be contained successfully in beryllium, tantalum, stabilized $\mathrm{ZrO}_{2}$, or Pyrex glass at temperatures up to $450^{\circ} \mathrm{C}$; in tungsten, rhenium, or graphite, at temperatures up to $800^{\circ} \mathrm{C}$; and in reíractory oxides (such as sintered $\mathrm{BeO}$ or $\mathrm{Al}_{2} \mathrm{O}_{3}$ ) and vitreous quartz, at $1,000^{\circ} \mathrm{C}$ or higher. ${ }^{1-3}$

A major concern regarding the use of liquid metals for heat-transport applications is their compatibility with containment materials. Compatibility of structural materials with liquid metals has a major influence on material selection and operating limitations for liquid-metal heat-transport systems. Corrosion in the form of uniform or selective dissolution, intergranular attack, and transfer of interstitial elements to and from the liquid metal can reduce the effective section thickness of structural components. Radioactive mass transfer/deposition of corrosion products may cause severe flow restrictions and excessive accumulation of radioactive material in unshielded regions. Corrosion/dissolution can reduce mechanical integrity, and mass transfer/deposition phenomena can increase pumping-power requirements, decrease the efficiency of energy conversion, and complicate system maintenance.

This report presents results of tests to determine the compatibility of gallium with candidate structural materials for ITER first-wall/blanket systems, e.g., Type 316 stainless steel (SS). Inconel 625, and Nb-5 Mo-1 $\mathrm{Zr}$ alloy. Armco iron. Nickel 270, and pure chromium were included in the study as reference materials. Results of preliminary tests of oxidized Type 316 SS are also presented. The world supply and physical and chemical properties of gallium are described.

\section{GALLIUM SUPPLY}

It has been estimated that gallium constitutes $\approx 1.5 \times 10^{-3}$ mass percent of the earth's crust, and that $5 \times 10^{-4} \mathrm{~g} /$ ton are present in sea water. 4 The primary supply of gallium must be derived as a byproduct from processing of other materials. Naturally occurring pure gallium has not been reported, and gallium-rich mineral ores are scarce. Table 1 lists the approximate gallium supply obtainable from the principal gallium-containing resources.

Bauxite is the most promising source of gallium, which can be extracted by the Bayer process that is used to process alumina from the raw mineral. Sphalerite (zinc ore) contains very little gallium compared with other sources, and would not be a cost-effective choice. The supply in kaolin could be accessed only when extraction of alumina from kaolin becomes 
Table 1. Gallium distribution in gallium-bearing resources (after Katrak \& Agarwal5)

\begin{tabular}{lcc}
\hline Resource & $\begin{array}{c}\text { U.S. } \\
\text { Resources } \\
\left(10^{3} \text { metric tons }\right)\end{array}$ & $\begin{array}{c}\text { World } \\
\text { Resources } \\
\left(10^{3} \text { metric tons }\right)\end{array}$ \\
\hline Bauxitea & 14 & 1,647 \\
Sphalerite & 1.8 & 6.5 \\
Kaolin Clayb & 56 & unknown \\
Coalc & 3,571 & unknown \\
Phosphates & 1,000 & unknown \\
Total & 4,643 & unknown \\
\hline aU.S. bauxite reserves contain 3,000 metric tons of gallium. \\
World reserves contain 1.14 million tons of gallium. \\
bGallium contained in kaolin clay resources in Georgia only. \\
cGallium in coal ashes after combustion.
\end{tabular}

technologically and economically feasible. Gallium is concentrated in ashes from the combustion of coal, but recovery of the metal has not yet been proved economically feasible. Phosphates are an unlikely source of gallium because most phosphates are wet-processed for fertilizer production. 5

Issues of importance to the ITER program are the worldwide availability of gallium and our capacity to produce it. ITER will require approximately $\approx \mathbf{2 5 0 0}$ metric tons of liquid gallium for operation. 6 Figure 1 depicts the supply and corresponding price of gallium on a worldwide basis, based on extraction of gallium from bauxite ores and 1981 statistics for the use of gallium, primarily for GaAs semiconductors. During the time frame for ITER construction, i.e.,

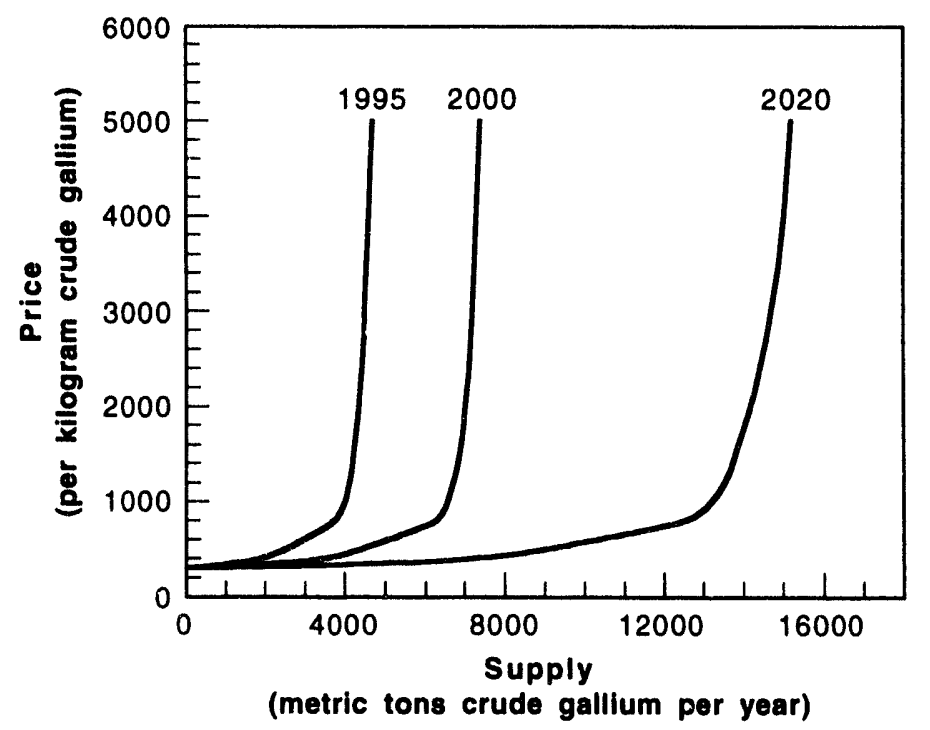

Figure 1. Long-range (1995-2020) supply and price of crude gallium (in 1980 U.S. dollars) from bauxite ores (after Katrak \& Agarwal ${ }^{5}$ ) 
2000-2020, the price to produce a large quantity (e.g., 12.000 metric ton) of crude gallium will be approximately what it currently costs to produce less than a third of that amount. However, the cost of refining crude gallium to the purity required for ITER may still be cost-prohibitive.

As of 1992, electronic components that contain GaAs semiconductors accounted for $95 \%$ of the gallium used in the U.S. The large amount of gallium needed for liquid-metal heattransport in ITER would drastically alter the supply of and demand for gallium. Current production could not satisfy the demand that would be placed on the gallium-refining industry by ITER, while also supplying gallium for semiconductor production. The 2,500 metric tons of gallium needed for ITER far surpasses current world production capacity, which is listed in Table 2.7 The current price is $\approx \$ 200 / \mathrm{kg}$ for $99.99 \%$-pure gallium, $\approx \$ 400 / \mathrm{kg}$ for $99.9999 \%$ pure, and $\approx \$ 500 / \mathrm{kg}$ for $99.999999 \%$-pure gallium. 8 Considering the cost for high-purity gallium and the large amount needed by ITER, gallium may prove to be economically prohibitive as a heat-transport medium.

Table 2. Annual capacity of primary gallium-producing countries of the world (after Kramer ${ }^{7}$ )

\begin{tabular}{lr}
\hline Country & \multicolumn{1}{c}{$\begin{array}{c}\text { Capacitya } \\
(\mathrm{kg})\end{array}$} \\
\hline North America: United States & 12,000 \\
Europe: & 3,000 \\
Czechoslovakia (former) & 20,000 \\
France & 15,000 \\
Germany & 4,000 \\
Hungary & $\underline{5,000}$ \\
Norway & $\underline{47,000}$ \\
Total & \\
Asia: $\quad$ 8,000 \\
China & $\underline{17,000}$ \\
Japan & $\underline{25,000}$ \\
Total & $\underline{50,000}$ \\
Oceania: Australia & 134,000 \\
\hline
\end{tabular}

as of December 31, 1990.

\section{PHYSICAL PROPERTIES OF GALLIUM}

Liquid gallium offers several advantages as a possible heat-transport medium for ITER. With a high thermal conductivity, high boiling point, and the largest liquidus range of any element, gallium appears to be well-suited for this use. The disadvantages include a significant thermal-neutron absorption coefficient and a volumetric expansion of $\approx 3 \%$ upon solidification. The physical and chemical properties of gallium are presented in Table 3 . The radioisotope decay properties ${ }^{9}$ of gallium are listed in Table 4 . 
Table 3. Physical and chemical properties of galliuma

\begin{tabular}{|c|c|c|}
\hline & Property & Value \\
\hline \multirow[t]{4}{*}{$Z$} & Atomic number & 31 \\
\hline & Atomic weight $\left({ }^{12} \mathrm{C}=12\right)$ & 69.717 \\
\hline & Atomic radius $14(\AA)$ & 1.39 \\
\hline & Crystal structure & orthorhombic \\
\hline \multirow[t]{5}{*}{$\rho$} & Density $\left(\mathrm{g} / \mathrm{cm}^{3}\right)$ & \\
\hline & $293 \mathrm{~K}$ & 5.907 \\
\hline & at $T_{\mathrm{mp}}$, solid & 5.9037 \\
\hline & at $T_{m p}$, liquid & 6.0948 \\
\hline & Density change on fusion $10(\%)$ & +3.4 \\
\hline $\mathrm{T}_{\mathrm{mp}}$ & Melting point $\left({ }^{\circ} \mathrm{C}\right)$ & 29.7714 \\
\hline$T_{b p}$ & Boiling point $\left({ }^{\circ} \mathrm{C}\right)$ & $\approx 2200$ \\
\hline$L_{\mathrm{f}}$ & Latent heat of fusion $(\mathrm{kJ} / \mathrm{mol})$ & 5.563 \\
\hline$L_{v}$ & Latent heat of vaporization $16(\mathrm{~kJ} / \mathrm{mol})$ & 1.014 \\
\hline \multirow[t]{5}{*}{$p_{\mathrm{Ga}}$} & Vapor pressure $\left(\mathrm{N} / \mathrm{m}^{2}\right)$ & \\
\hline & $1198 \mathrm{~K}$ & 0.14 \\
\hline & $1249 \mathrm{~K}$ & 0.44 \\
\hline & $1321 \mathrm{~K}$ & 1.74 \\
\hline & $1478 \mathrm{~K}$ & 16.50 \\
\hline$H_{\mathrm{m}}$ & Molar enthalpy 10 at $298 \mathrm{~K}(\mathrm{~kJ} / \mathrm{mol})$ & 557.70 \\
\hline$S_{\mathrm{m}}$ & Molar entropy ${ }^{10}$ at $298 \mathrm{~K}(\mathrm{~J} / \mathrm{K} \cdot \mathrm{mol})$ & 47.90 \\
\hline$c_{\mathrm{p}}$ & $\begin{array}{l}\text { Specific heat capacity at constant pressure }(\mathrm{J} / \mathrm{kg} \cdot \mathrm{K}) \\
\begin{array}{l}256 \mathrm{~K} \\
303 \mathrm{~K}\end{array}\end{array}$ & $\begin{array}{l}361.4 \\
381.5\end{array}$ \\
\hline \multirow[t]{2}{*}{$\lambda$} & $\begin{array}{l}\text { Thermal conductivity }(\mathrm{W} / \mathrm{m} \cdot \mathrm{K}) \\
\text { solid, } 293 \mathrm{~K}\end{array}$ & $\begin{array}{l}\text { axis a: } 88.4 \\
\text { axis b: } 16.0 \\
\text { axis c: } 40.8\end{array}$ \\
\hline & liquid, $350 \mathrm{~K}$ & 28.7 \\
\hline$\beta$ & $\begin{array}{l}\text { Coefficient of volumetric thermal expansion }\left(K^{-1}\right) \\
\text { solid, } 273-293 \mathrm{~K} \\
\text { liquid, } 376 \mathrm{~K}\end{array}$ & $\begin{array}{l}5.95 \times 10^{-5} \\
1.20 \times 10^{-4}\end{array}$ \\
\hline$\rho_{\mathrm{e}}$ & $\begin{array}{l}\text { Electrical resistivity }(\Omega-\mathrm{m}) \\
\text { solid, } 293 \mathrm{~K} \text { (polycrystalline) } \\
\text { liquid, } 303 \mathrm{~K}\end{array}$ & $\begin{array}{l}15.05 \times 10^{-5} \\
25.795 \times 10^{-5}\end{array}$ \\
\hline$\mu$ & Dynamic visrosity $(\mathrm{mPa} \cdot \mathrm{s})$ at $305 \mathrm{~K}$ & 1.810 \\
\hline$\gamma$ & Surface tension $(\mathrm{mN} / \mathrm{m})$ at $303 \mathrm{~K}$ & 709 \\
\hline$\sigma_{\text {absth }}$ & Thermal-neutron absorption cross section $10\left(\times 10^{-28} \mathrm{~m}^{2}\right)$ & $2.77 \pm 0.12$ \\
\hline$\sigma_{\text {abs }}$ & Fast-neutron capture cross section $16\left(\times 10^{-28} \mathrm{~m}^{2}\right)$ & 4 \\
\hline
\end{tabular}

avalues supplied by the Eagle-Picher Corp., unless noted by superscript reference number 
Table 4. Description of radioisotopes of gallium (after Dymov \& Savostin ${ }^{9}$ )

\begin{tabular}{|c|c|c|c|c|}
\hline \multirow[b]{2}{*}{ Isotope } & \multirow[b]{2}{*}{$t_{1 / 2}(\mathrm{ks})$} & \multirow[b]{2}{*}{ Type of radiation ${ }^{a}$} & \multicolumn{2}{|c|}{ Radiation Energy (MeV) } \\
\hline & & & particles & $\gamma$-rays \\
\hline 64 & 2.88 & $\beta^{+}$ & - & - \\
\hline 65 & 0.90 & $K, e^{-}$ & - & $0.54 ; 0.117$ \\
\hline 66 & 33.84 & $\beta^{+}$ & 3.1 & - \\
\hline \multirow[t]{2}{*}{67} & 298.80 & $K, e^{-}$ & - & $0.09 ; 0.18 ; 0.30$ \\
\hline & 280.80 & $K, \gamma, e^{-}$ & - & - \\
\hline \multirow[t]{2}{*}{68} & 4.08 & $\beta^{+}$ & 1.9 & - \\
\hline & & $\beta^{+}, K, \gamma$ & - & - \\
\hline \multirow[t]{2}{*}{70} & 1.22 & $\beta-, \gamma$ & 1.68 & - \\
\hline & 1.26 & $\beta^{-}$ & - & - \\
\hline \multirow[t]{3}{*}{72} & 51.48 & $4 \beta^{-}, 7 \gamma, 2 e^{-}$ & $0.64-3.15$ & $0.63-2.50$ \\
\hline & 51.12 & $\beta^{-}, \gamma$ & - & - \\
\hline & 50.76 & $\beta-, \gamma$ & $0.7 ; 1.0$ & $0.83^{b} ; 2.50^{b} ; 0.63^{b}$ \\
\hline 73 & 18.00 & $\beta^{-}$ & 1.4 & - \\
\hline 74 & 32.40 & $\beta^{-}$ & 8.0 & - \\
\hline
\end{tabular}

$a_{e}-$ internal conversion electrons: $K$ electron capture: $\beta^{+}$positrons; $\beta^{-}$negatrons.

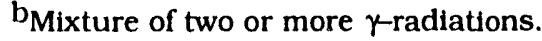

The temperature dependence of viscosity, $4,10,11$ specific heat capacity, 12 and thermal conductivity, ${ }^{13}$ are shown in Figs. 2-4. The change in viscosity, specific heat capacity, and thermal conductivity as a function of temperature (measured in kelvin) are given by Eqs. 1-3.

$$
\begin{array}{lr}
\mu\left(\mathrm{N} \cdot \mathrm{s} / \mathrm{m}^{2}\right)=321.5+\mathrm{T}^{(-0.89)} & (0 \mathrm{~K} \leq \mathrm{T} \leq 200 \mathrm{~K}) \\
c_{\mathrm{p}}(\mathrm{J} / \mathrm{kg} \cdot \mathrm{K})=-395+330 \log [\mathrm{T}] & (200 \mathrm{~K} \leq \mathrm{T} \leq 1400 \mathrm{~K}) \\
c_{\mathrm{p}}(\mathrm{J} / \mathrm{kg} \cdot \mathrm{K})=367.8+0.06 \mathrm{~T} & (302.9 \mathrm{~K} \leq \mathrm{T} \leq 600 \mathrm{~K}) \\
\lambda(\mathrm{W} / \mathrm{m} \cdot \mathrm{K})=-3.17+0.103 \mathrm{~T} &
\end{array}
$$

\section{SOLUBILITY OF MATERIALS IN GALLIUM}

\subsection{PURE METALS}

The solubility and corrosion of pure metals in gallium have been investigated. 14-19 Most pure metals are highly soluble in liquid gallium. Solubility of pure metals in gallium is based on a saturated solution in equilibrium with an intermetallic compound. For most engineering metals, the intermetallic compound is of the form $\mathrm{MGa}_{3}$ or $\mathrm{MGa}_{4}$. Solubility data at a given temperature, e.g., $400^{\circ} \mathrm{C}$, show a periodicity with atomic number, similar to that observed in other low-melting-point metals, e.g., mercury, indium, tin, lead, bismuth, lithium, sodium, or potassium. Although the absolute value of solubility may vary for the various liquid metals, in all cases, a minimum solubility is observed for beryllium, boron, vanadium, niobium. 

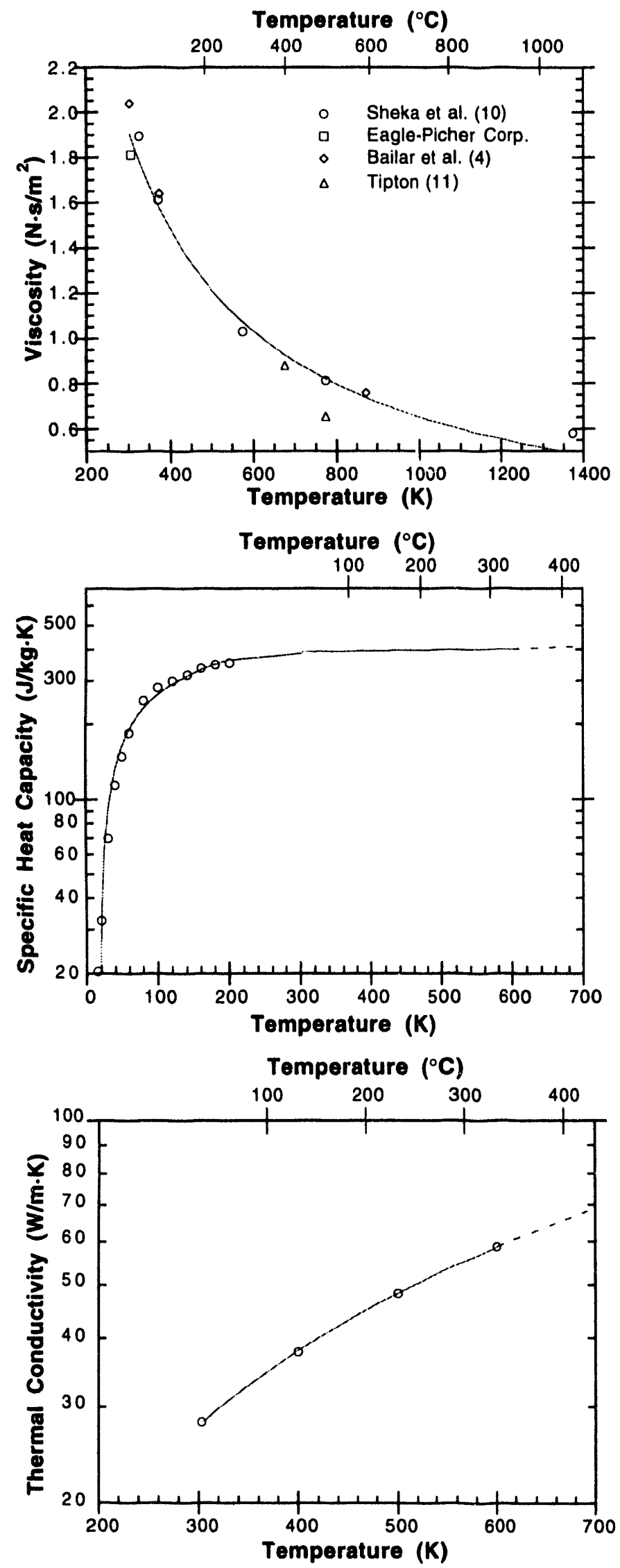

Figure 2.

Viscosity of gallium as a function of temperature

Figure 3.

Specific heat capacity of gallium as a function of temperature

Figure 4.

Thermal conductivity of gallium as a function of temperature 
molybdenum, tantalum, tungsten, rhenium, and osmium.17-19 Figure 5 shows the periodicity of solubility in gallium at 400 and $600^{\circ} \mathrm{C}$ of metals in Periods $2-7$ of the atomic chart of the elements. The metals important to the present work are in Periods 4 and 5, and are shown in more detail in Fig. 6. The elements in Groups 4-6 in Period 4 and the elements in Groups 4-7 in Period 5 exhibit a lower solubility in gallium than the remaining elements of each period. The highest solubilities occur in Groups 11-15. Similar behavior is observed in Period 6, with the lanthanides exhibiting a relatively high solubility.

Assuming that the reported solubility values for a given metal would not change much from a gallium-metal system to a gallium-ternary/quaternary-alloy system, any alloy containing low-solubility elements of Groups 4-6 would be more resistant to gallium attack than alloys composed of elements from other groups. Based upon the presented solubility data, alloys of $\mathrm{Ti}-\mathrm{V}-\mathrm{Cr}$ and $\mathrm{Zr}-\mathrm{Nb}-\mathrm{Mo}$ should be very resistant to attack by gallium at temperatures up to $600^{\circ} \mathrm{C}$. Inconel alloys and austenitic SSs contain highly soluble elements, which could lead to excessive corrosion at higher temperatures.

As mentioned previously, many pure metals are highly soluble in liquid gallium. Yatsenko et al. 14-17.20.21 have reported the variation in solubility of selected pure metals in gallium as a function of temperature; the solubilities of some of these metals are shown in Fig. 7. The discontinuities in the solubilities of manganese, nickel, and vanadium at the

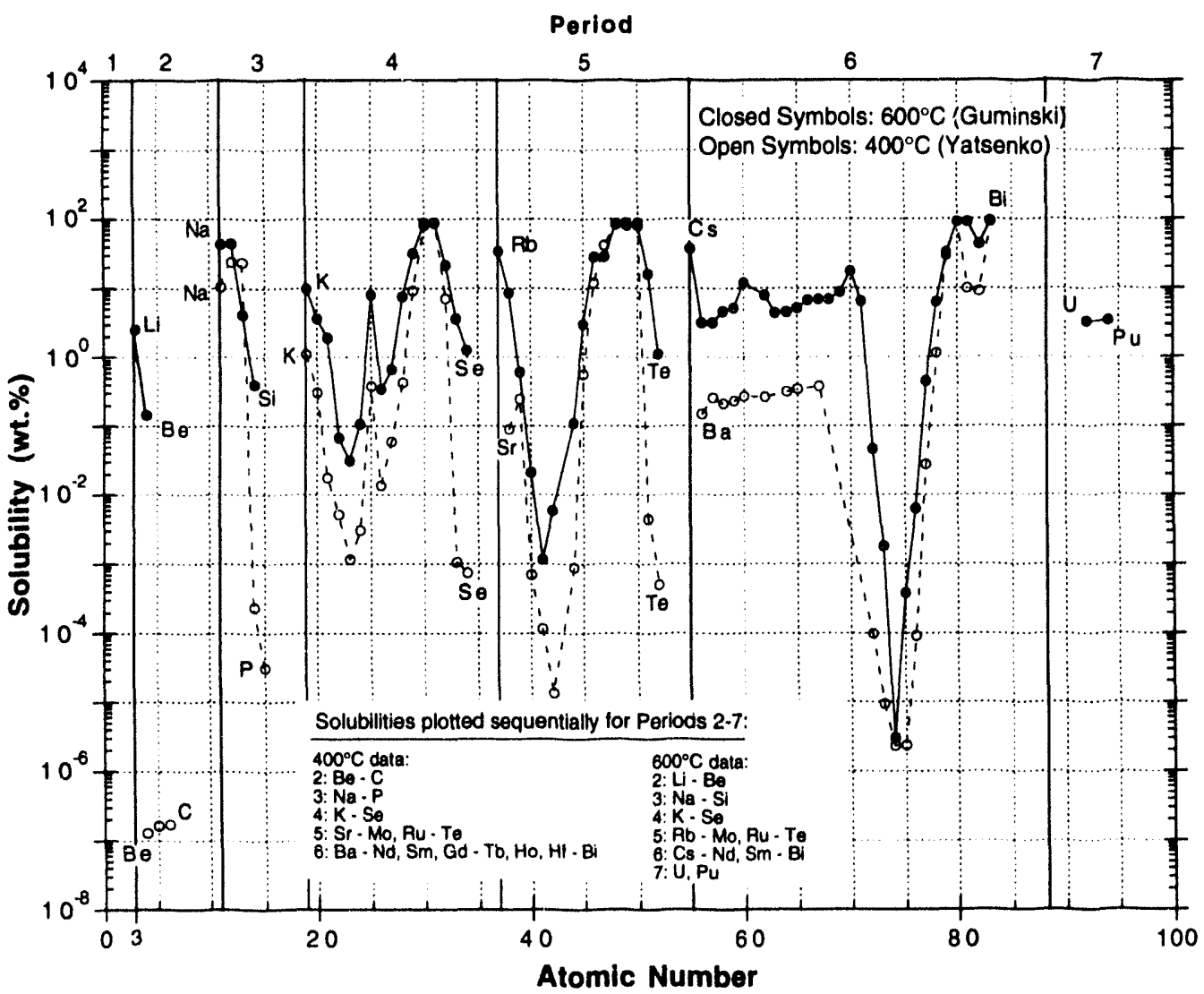

Figure 5. Solubility of metals in gallium as a function of atomic number for Periods 2-7 of the atomic chart of the elements (after Guminskil 18 and Yatsenko 17,19) 


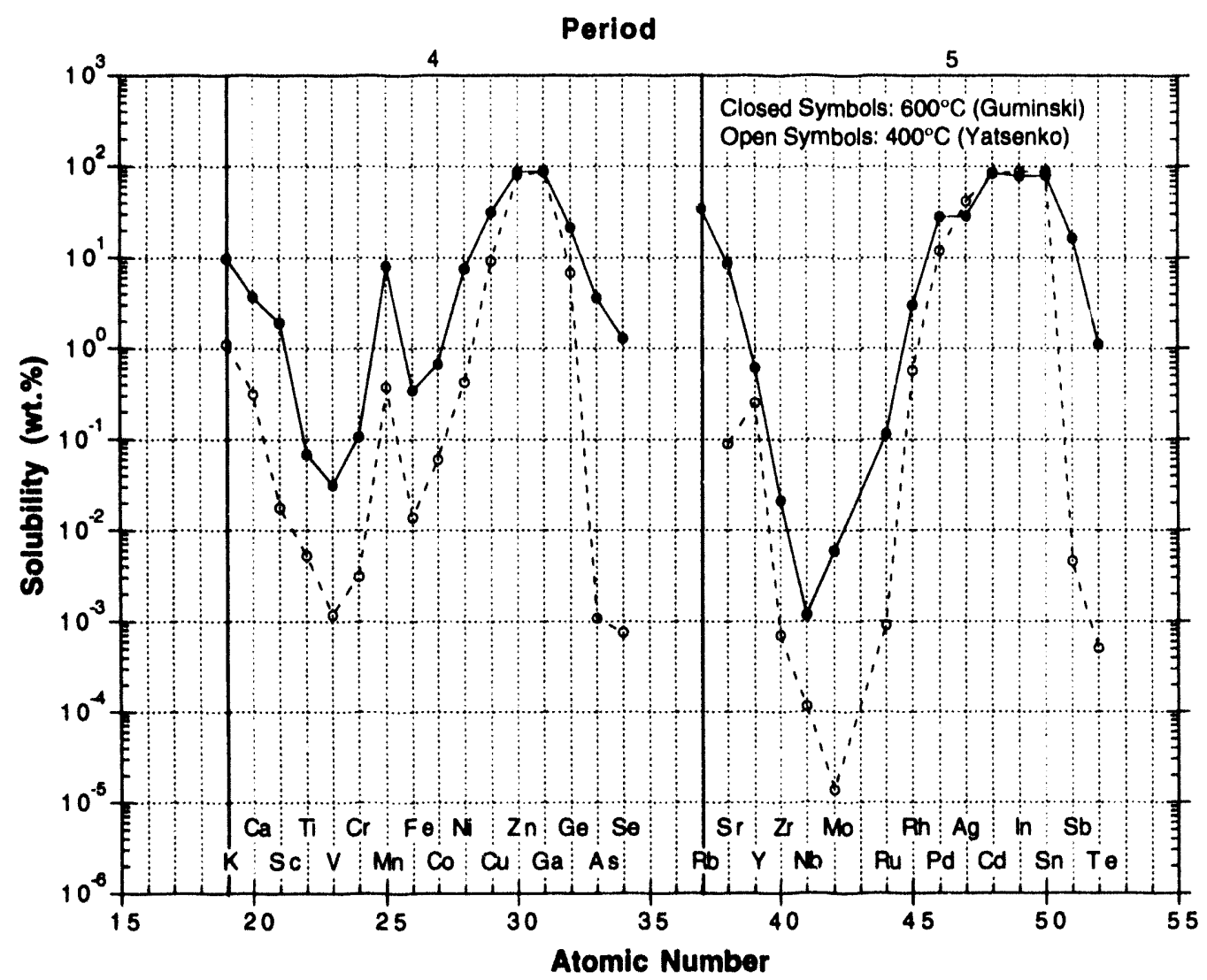

Figure 6. Solubility of metals as a function of atomic number for Periods 4 and 5 of the Atomic Chart of the Elements (after Guminski18 and Yatsenko 17.19)

temperatures indicated represent reported phase changes in each gallium-metal system. Even though chromlum undergoes no phase changes between 200 and $700^{\circ} \mathrm{C}$, its solubility is represented by a curve. The logarithm of the solubility of titanium in gallium from 350 to $700^{\circ} \mathrm{C}$ increases linearly with reciprocal temperature. This behavior is observed for many of the pure metals; consequently, the solubility of pure metals in gallium can be represented 19 by

$$
\log \left[c_{m}\right]=A-\frac{B}{T}
$$

where $c_{m}$ is concentration in atomic percent, $A$ and $B$ are coefficients, and $T$ is in kelvin. Values for $A$ and $B$ are presented in Table 5 . This equation is valid in the solubility range from $10^{-2}$ to 2 at.\% for pure metals. In Fig. 8, the solubility curves, with concentrations converted to weight percent, are plotted as a function of reciprocal temperature. The solid phases listed in Table 5 were cross referenced with the latest published phase diagrams. 22

\section{OXYGEN}

Oxygen reacts with gallium to form three compounds: the oxdde $\mathrm{GaO}$, the suboxdde $\mathrm{Ga}_{2} \mathrm{O}$, and the sesquioxide $\mathrm{Ga}_{2} \mathrm{O}_{3}$. The allotrope $\beta-\mathrm{Ga}_{2} \mathrm{O}_{3}$ is the most stable. Alcock and Jacob ${ }^{23}$ have reported the following equations for the solubility of oxygen in gallium $\left(c_{0}\right)$, the standard 


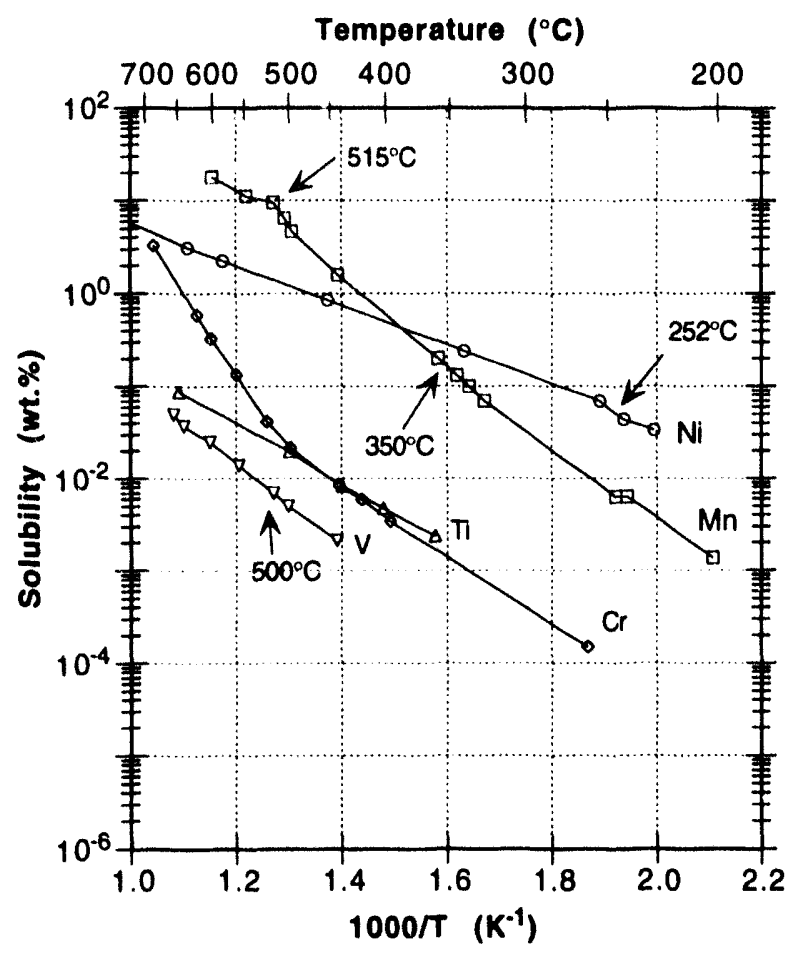

Figure 7. Solubility of pure metals in gallium at $200-700^{\circ} \mathrm{C}$

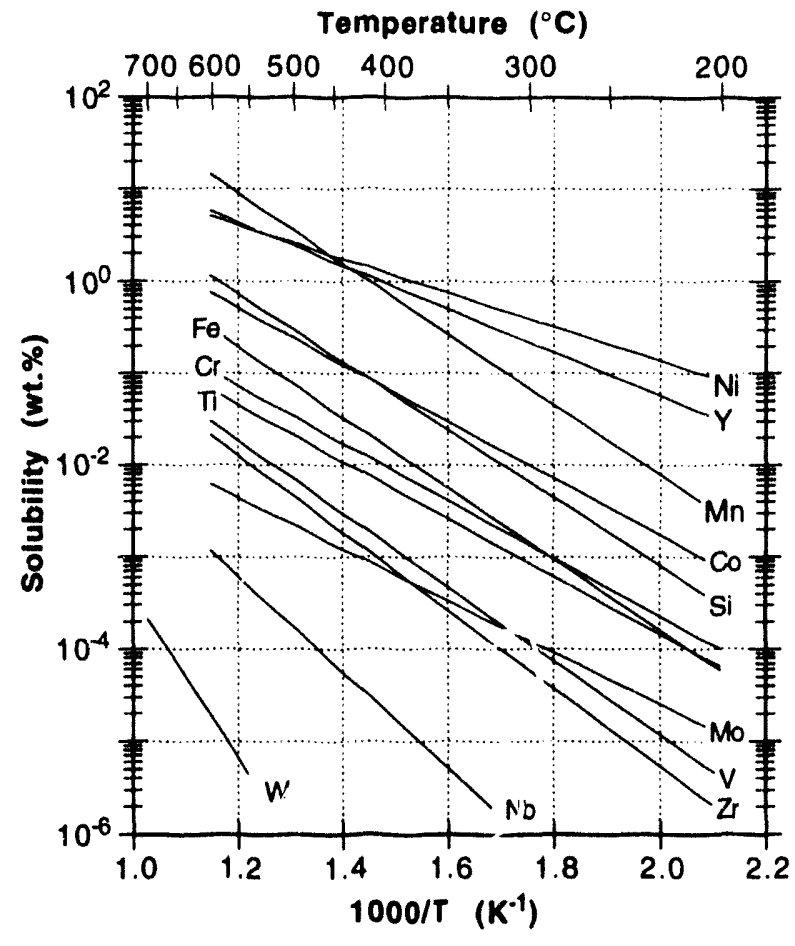

Figure 8. Solubility of pure metals in gallium at $200-700^{\circ} \mathrm{C}$ as predicted by Eq. 5

Table 5. Solubility data in binary Ga-M systems (after Yatsenko 19)

\begin{tabular}{|c|c|c|c|c|}
\hline \multirow[b]{2}{*}{ Pure metal } & \multicolumn{2}{|c|}{ Coefficients of Equation 5} & \multirow[b]{2}{*}{ Solid phase } & \multirow{2}{*}{$\begin{array}{l}\text { Phase stability range } \\
\text { (K) }\end{array}$} \\
\hline & A & $\mathrm{B} \cdot 10^{-3}$ & & \\
\hline $\mathrm{Co}$ & 3.50 & 3.10 & $\mathrm{CoGa}_{3}$ & $\leq 298-1,128$ \\
\hline $\mathrm{Cr}$ & 2.74 & 3.13 & $\mathrm{CrGa}_{4}$ & $\leq 298-973$ \\
\hline $\mathrm{Fe}$ & 4.00 & 3.85 & FeGa3 & $\leq 298-1097$ \\
\hline Mn & 5.40 & 3.90 & $\mathrm{MnGa}_{6}$ & $\leq 298-683$ \\
\hline Mo & 0.86 & 2.80 & $\mathrm{MoGa}_{3}$ & $\mathbf{a}$ \\
\hline $\mathrm{Nb}$ & 2.90 & 5.20 & $\mathrm{NbGa}_{3}$ & $\mathbf{a}$ \\
\hline \multirow[t]{2}{*}{$\mathrm{Ni}$} & 2.52 & 1.85 & $\mathrm{NiGa}_{4}$ & $\leq 298-525$ \\
\hline & & & $\mathrm{Ni}_{2} \mathrm{Ga}_{3}$ & $525-1,168$ \\
\hline $\mathrm{Si}$ & 4.30 & 3.70 & $\mathrm{Si}$ & $\leq 298-1.687^{a}$ \\
\hline $\mathrm{TI}$ & 2.56 & 3.12 & $\mathrm{TIGa}_{3}$ & $\leq 298-1,748$ \\
\hline V & 3.20 & 4.00 & $\mathrm{VGa}_{4}$ & $\mathbf{a}$ \\
\hline W & 4.90 & 8.75 & WGa4 & $\leq 298-3,683^{b}$ \\
\hline $\mathrm{Y}$ & 3.00 & 2.37 & $\mathrm{YGa}_{2}$ & $\leq 298-1,623$ \\
\hline $\mathbf{Z r}$ & 3.05 & 4.22 & $\mathrm{ZrGa}_{3}$ & $\mathbf{a}$ \\
\hline
\end{tabular}

aphase listed could not be cross referenced; therefore, the presence of this phase and the temperature stability range cannot be confirmed.

bPhase is stable up to the melting point of pure metal: pure metal exists in solution with liquid gallium. 
free energy of solution of oxygen in gallium $\left(\Delta \mathrm{G}_{\mathrm{O}}^{\circ}\right)$, and the standard free energy of formation of $\beta-\mathrm{Ga}_{2} \mathrm{O}_{3}\left(\Delta \mathrm{G}^{\circ}\right)$ :

$$
\begin{gathered}
\log \left[c_{\mathrm{o}}\right]=4.264-\frac{7380}{\mathrm{~T}} \quad(1048 \mathrm{~K} \leq \mathrm{T} \leq 1398 \mathrm{~K}) \\
\frac{1}{2} \mathrm{O}_{2(\mathrm{~g})} \rightarrow \mathrm{O}_{\mathrm{Ga}} \\
\Delta \mathrm{G}_{\mathrm{o}}^{\circ}=-220.73+0.0274 \mathrm{~T}( \pm 0.84) \mathrm{kJ} \\
2 \mathrm{Ga}_{(1)}+\frac{3}{2} \mathrm{O}_{2(\mathrm{~g})} \rightarrow \beta-\mathrm{Ga}_{2} \mathrm{O}_{3} \\
\Delta \mathrm{G}^{\circ}=-1086.63+0.3273 \mathrm{~T}( \pm 1.26) \mathrm{kJ}
\end{gathered}
$$

Natesan 24 has complled thermodynamic data on the free energy of formation of oxides and the solubility of oxygen in liquid-alkali metals and structural metals. This information has been adapted to the case of liquid gallium by using the above equations for oxygen in gallium. Results that are relevant for ITER applications are shown in Fig. 9.23-25 Based on free energy of forrnation alone, all of the metal oxides shown, except for $\mathrm{MoO}_{2}, \mathrm{FeO}$, and $\mathrm{NiO}$, should be stable in the presence of $\mathrm{Ga}_{2} \mathrm{O}_{3}$. Iron(II) chromite $\left(\mathrm{FeCr}_{2} \mathrm{O}_{4}\right)$ may be stable at elevated temperatures.

Figure 9 shows that oxides such as $\mathrm{Cr}_{2} \mathrm{O}_{3}, \mathrm{Al}_{2} \mathrm{O}_{3}$, and $\mathrm{SiO}_{2}$ should protect coated structural alloys against corrosion in liquid gallium. Unstable compounds, such as $\mathrm{FeO}$ and $\mathrm{NiO}$. dissociate in liquid gallium to form $\beta-\mathrm{Ga}_{2} \mathrm{O}_{3}$. Upon dissociation, corrosion of the substrate would occur by dissolution of metallic elements and formation of metal/gallium intermetallic compounds.

\section{COMPATIBILITY OF GALLIUM WITH STRUCTURAL ALLOYS}

Corrosion occurs primarily by dissolution due to the solubility of metals in gallium, which results in metal recession and weight loss, and at higher temperatures, by diffusion into the metal, which leads to formation of surface scale and weight gain. For most metals, dissolution is accompanied by formation of metal/gallium intermetallic compounds from the saturated solution.

Corrosion data correlate well with solubility. 1.e., metals with high solubility show poor corrosion resistance. At $400^{\circ} \mathrm{C}$, the solubility and corrosion of nickel in gallium are greater by more than one order of magnitude than the solubility and corrosion of iron. ${ }^{17.19}$ Various highalloy ferritic and martensitic steels and austenitic SSs show fair resistance to corrosion in gallium at temperatures up to $400^{\circ} \mathrm{C}$, i.e., a corrosion rate of $\leq 1 \mathrm{~mm} / \mathrm{yr}$. ${ }^{19}$ In general, corrosion rates of high-alloy steels decrease with increasing chromium content, whereas changes in nickel content have little or no effect on corrosion. Additions of aluminum to nickel-chromium steels increase and titanium additions decrease corrosion rates in gallium. 19

This report describes an investigation of the compatibility of gallium with candidate structural materials, e.g.. Type $316 \mathrm{SS}$, Inconel 625 , and $\mathrm{Nb}-5 \mathrm{Mo}-1 \mathrm{Zr}$ alloy, for ITER first- 


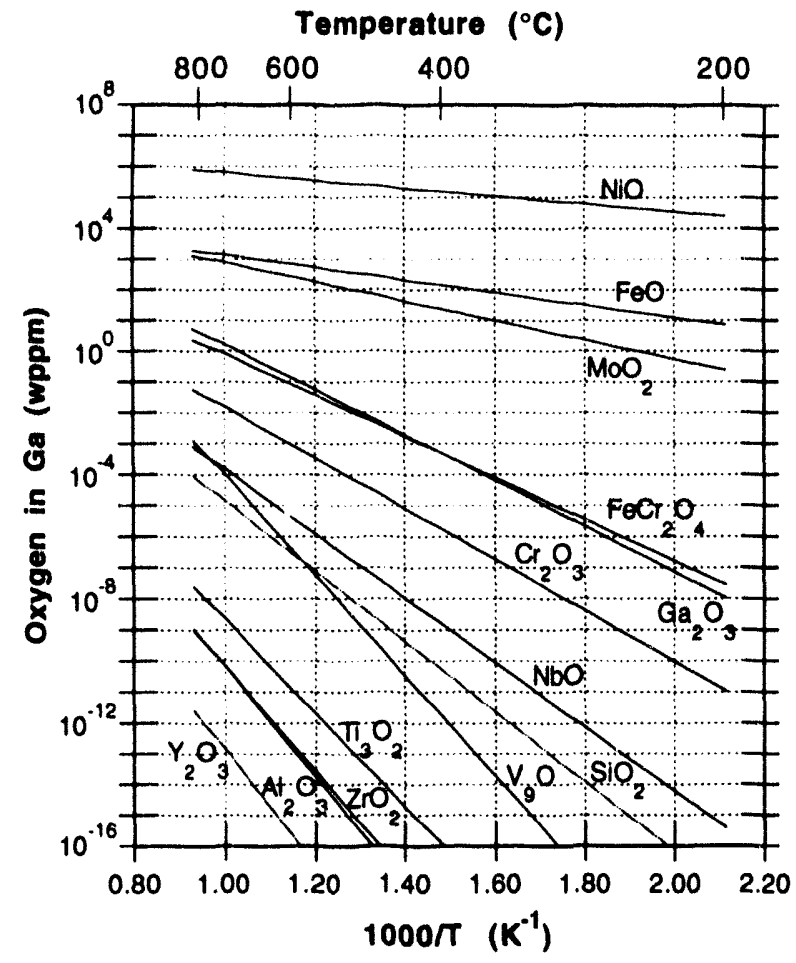

Figure 9.

Temperature dependence of minimum oxygen concentration in gallium necessary for axide formation in metals

wall/blanket systems, and presents the results thereof. Pure metals such as Armco iron, Nickel 270, and chromium were included in the study as reference materials.

\subsection{EXPERIMENTAL}

Corrosion tests were conducted in alumina capsules $\approx 11 \mathrm{~mm}$ in inner diameter and $254 \mathrm{~mm}$ long) with a threaded metal fitting at the top end for sealing. Before the tests, the capsules were baked for $24 \mathrm{~h}$ at $425^{\circ} \mathrm{C}$. Each capsule contained a single test specimen. The capsules were filled with $\approx 11 \mathrm{~cm}^{3}(\approx 65 \mathrm{~g})$ of gallium, and an alumina rod $(6.5 \mathrm{~mm}$ in diameter and $150 \mathrm{~mm}$ long) was placed in each capsule to ensure that the corrosion coupon would remain immersed in gallium and to keep the specimen in place when the capsules were inverted during cooling. The capsules were capped and sealed in a high-purity-argon environment. All components of the capsule unit are shown in Fig. 10. A sealed capsule is shown in Fig. 11. The sealed capsules were placed in an upright position during testing. Corrosion coupons $\approx 10 \times 20$ $x$ 0.4-1.1 mm) were prepared from Type $316 \mathrm{SS}$, Inconel 625, Nb-5 Mo-1 Zr alloy, Nickel 270. Armco iron, and pure chromium. The compositions of these materials are given in Table 6. The coupons were bent into a $U$ shape to study the effect of cold work. Dimensions and weights of the specimens were recorded after degreasing and cleaning.

Two sets of Type 316 SS specimens were prepared and oxddized; four specimens were oxIdized in delonized water with $6 \mathrm{ppm}$ dissolved oxygen at $290^{\circ} \mathrm{C}$ for $100 \mathrm{~h}$, and four were oxddized in air at $350^{\circ} \mathrm{C}$ for $100 \mathrm{~h}$. The oxide coating that formed on the Type $316 \mathrm{SS}$ specimens was identifled by $\mathrm{X}$-ray diffraction (XRD) as the single-phase spinel compound $\mathrm{FeCr}_{2} \mathrm{O}_{4}$ (Iron (II] chromite). The thickness of the oxide coatings formed in water and in air was 0.3 and $\leq 0.1 \mu \mathrm{m}$, respectively. Corrosion tests were conducted at $400^{\circ} \mathrm{C}$ for up to $3,000 \mathrm{~h}$ for the oxddized 


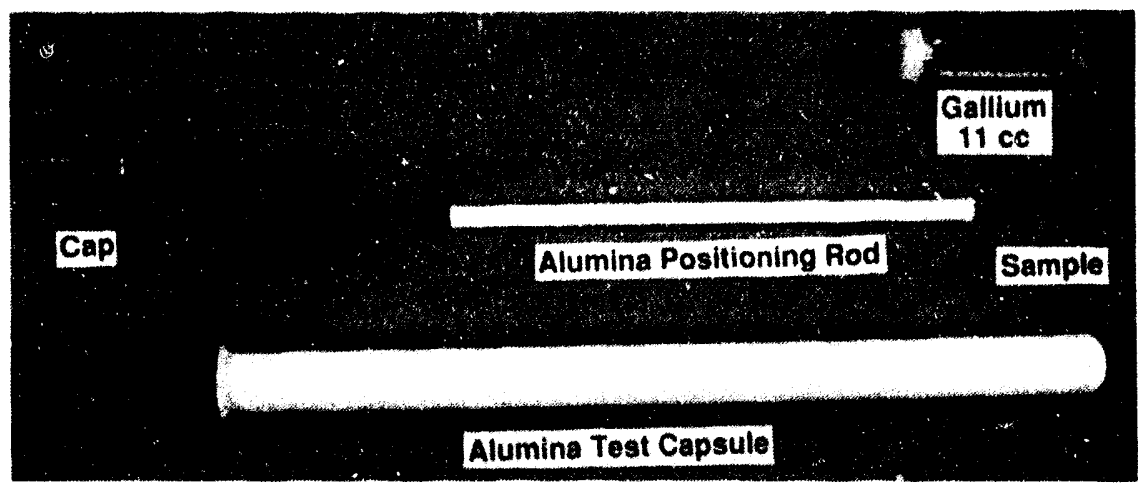

Figure 10. Components of test capsule

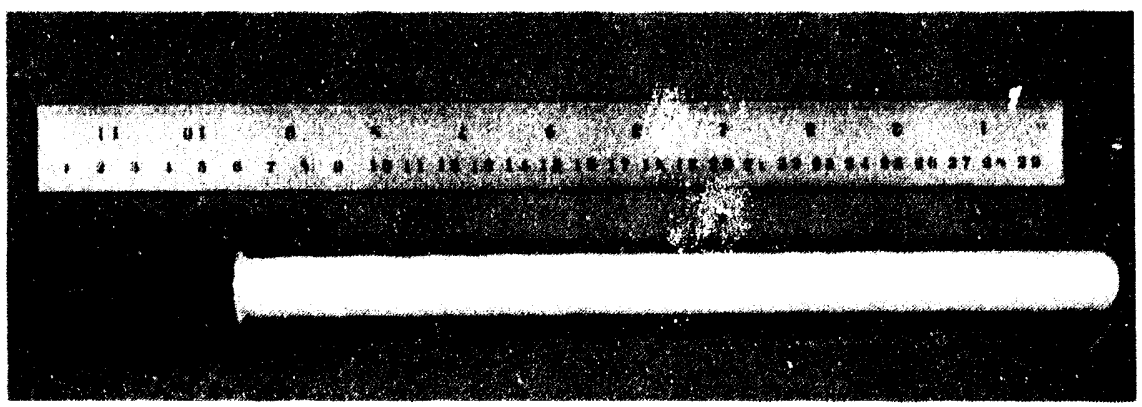

Figure 11. Sealed test capsule

Table 6. Composition of materials subjected to static gallium

\begin{tabular}{|c|c|c|c|c|c|c|c|c|c|c|c|}
\hline \multirow[b]{2}{*}{ Alloy } & \multicolumn{11}{|c|}{ Composition (wt.\%) } \\
\hline & $\mathrm{Fe}$ & $\mathrm{Ni}$ & $\mathrm{Cr}$ & Mo & Mn & SI & $\mathrm{C}$ & $\mathrm{TI}$ & $\mathrm{Nb}$ & $\mathrm{Zr}$ & Other \\
\hline Type 316 SS & 65.0 & 13.0 & 17.0 & 2.50 & $\leq 2.0$ & 0.75 & 0.08 & - & - & - & $\begin{array}{c}0.045 \mathrm{P} . \\
0.03 \mathrm{~S}\end{array}$ \\
\hline Inconel 625 & 2.5 & 61.0 & 21.5 & 9.00 & 0.25 & 0.25 & 0.05 & 0.2 & - & - & $\begin{array}{c}0.2 \mathrm{Al} \\
3.65 \mathrm{Nb}+\mathrm{Ta}\end{array}$ \\
\hline $\begin{array}{l}\mathrm{Nb}-5 \mathrm{Mo}- \\
1 \mathrm{Zr}\end{array}$ & - & - & - & 4.86 & - & 0.0001 & - & 0.0001 & bal & 0.81 & $\begin{array}{l}0.0002 \mathrm{O} \\
0.0001 \mathrm{Ta}\end{array}$ \\
\hline Nickel 270 & 0.0005 & 99.995 & 0.0003 & - & $<0.001$ & $<0.001$ & 0.003 & - & - & - & $\begin{array}{l}<0.001 \mathrm{~S} \\
<0.001 \mathrm{Cu}\end{array}$ \\
\hline
\end{tabular}

specimens, and for up to $1076 \mathrm{~h}$ for as-recelved specimens. After testing, the capsules were inverted and the gallium drained from the specimens to prevent possible deposition of corrosion products on the specimen surface during cooling. Corrosion coupons were washed in a warm solution of soap and water to remove gallium. If needed, a rubber scrubber was used to scrape any gallium adhering to the surface. The coupons were also ultrasonically cleaned in ethanol. and then in acetone, to ensure complete cleaning. Specimen weight and dimensions were recorded after rinsing and drying. All specimens were examined metallographically to determine metal loss and thickness of the reaction layer. A schematic representation of the corrosion behavior is shown in Fig. 12. Metal loss for each surface was determined from the initial thickness of the corrosion coupon and sound metal remaining after the test. 


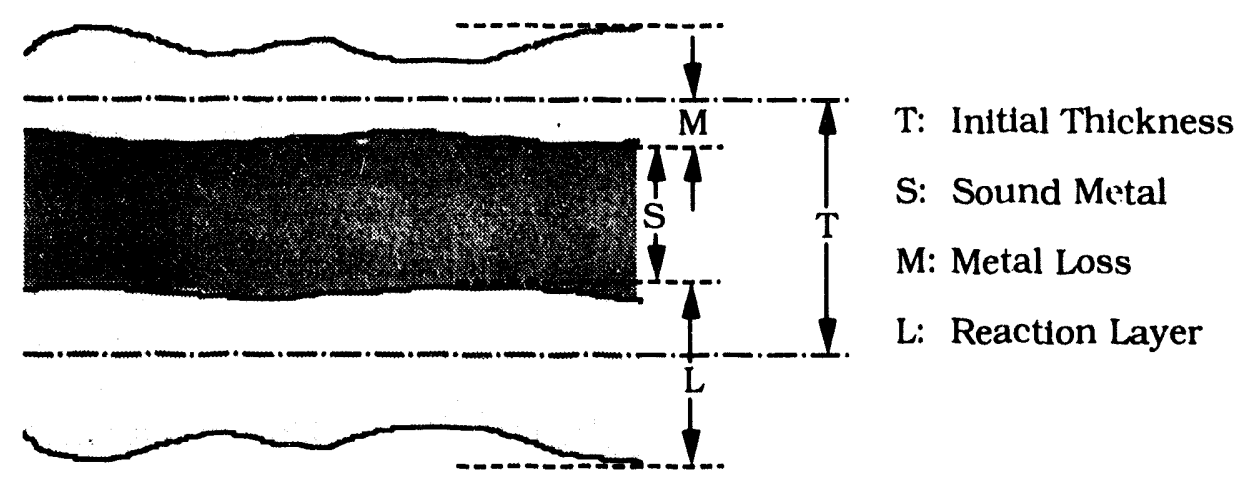

Figure 12. Schematic diagram showing typical measurements made to determine corrosion behavior of materials

\subsubsection{Formation of Gallium Whiskers}

While examining mounted cross sections of specimens, an unusual phenomenon occurred. Specimens that developed an $\mathrm{FeGa}_{3}$ surface layer during the compatibility test, e.g., Type 316 SS and Armco iron, subsequently developed what appeared to be extruded wires or whiskers of pure gallium "growing" on the surface of mounted cross sections. These wires were 0.1-0.5 mm thick and grew to varying lengths up to $50 \mathrm{~mm}$. Energy dispersive spectroscopy (EDS) indicated that these wires were pure gallium. A typical wire growing out of the reaction scale on a Type 316 SS specimen is shown in Fig. 13A. A photomicrograph of the same region but with the wire removed is shown in Fig. 13B. The fine surface markings observed on all of the wires suggest that they are being extruded from the material. The fine parallel lines on the top flat surface of the gallium wire (Fig. 13A) exactly match the lamellae observed in the surrounding region. Most likely these lamellae create the parallel markings on the sides of the wires. Also, the ridges on the top surface of the wire shown in Fig. 13A are indicative of a polycrystalline structure in the wire. However, Fig. 13B shows that there are no cavities or galliumrich regions beneath these wires. They appear to be growing from the surface of the reaction scale. Region (a) in Fig. 13B was identified by EDS as FeGa3. The composition of Region (b), which was at the base of the wire, was the same as that of Region (a). Only Region (c) consisted of pure gallium; most likely this region was part of the wire that remained after the bulk of the wire was removed. Photomicrographs of whiskers from other specimens are shown in Figs. 14 and 15. The whiskers in Fig. 14 appear to have curled near the tip, whereas the one shown in Fig. 15 formed a continuous spiral. The spiraling may be caused by slight temperature fluctuations during whisker growth, or by a diffusion flux gradient along the whisker's base, leading to unequal growth rates along the base.

A similar phenomenon has been reported for several metals by the electronic component manufacturing industry. 26-33 Tin, cadmium, molybdenum, tungsten, aluminum, indium, and lead exhibit spontaneous whisker growth at room temperature and atmospheric pressure. Whisker growth can be categorized in terms of two distinct growth mechanisms: one occurring at the tip and the other occurring at the base. Growth at the tip occurs primarily by vapor deposition at the whisker tip; 29 base-oriented growth may occur by electromigration 30.31 and/or to relieve internal stresses. 27.28 The mechanism important in the growth of gallium whiskers involves the relief of internal stresses. 

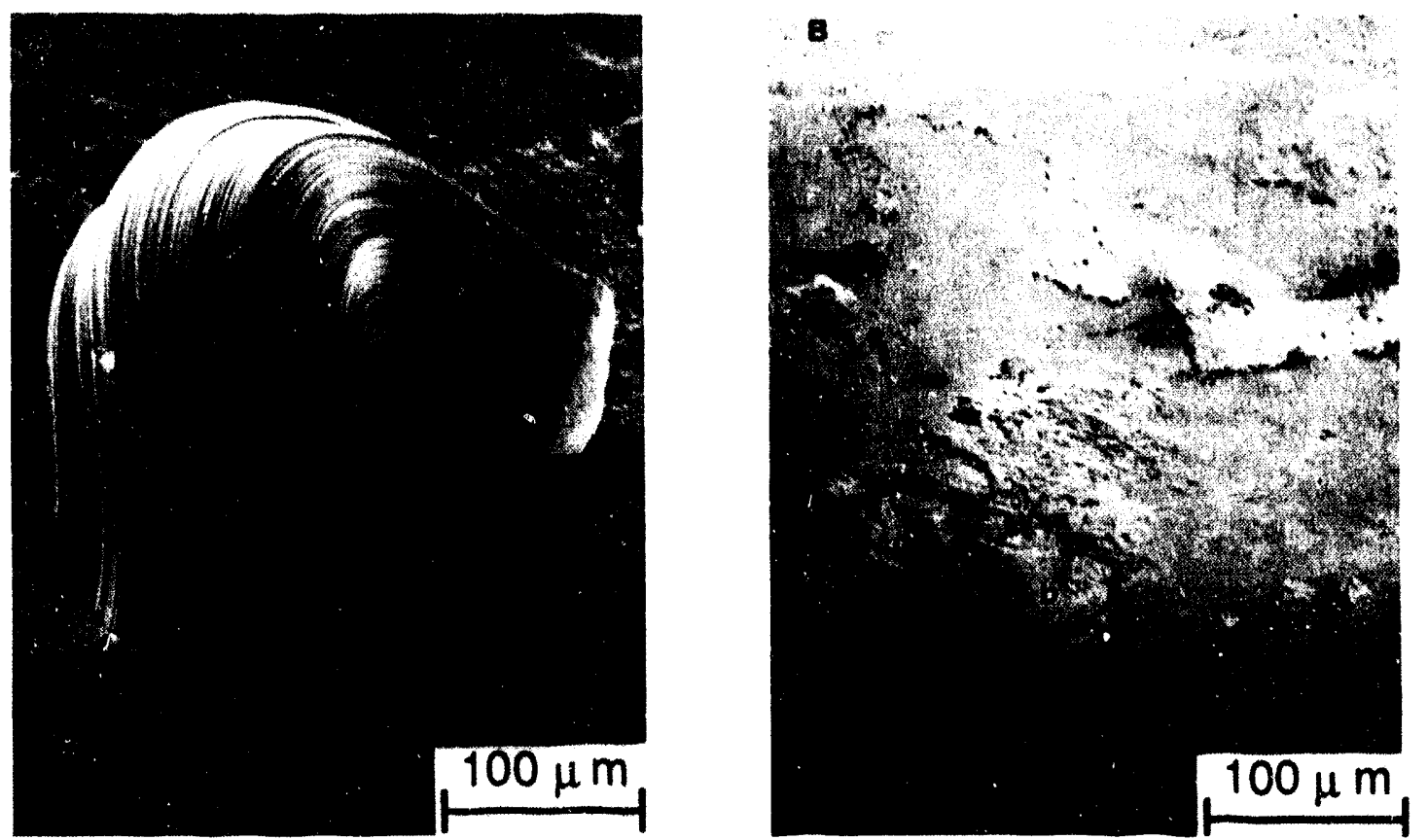

Figure 13. Photomicrographs of (A) a pure gallium whisker and (B) specimen surface after whisker removal. Regions $a, b$, and $c$ are described in the text
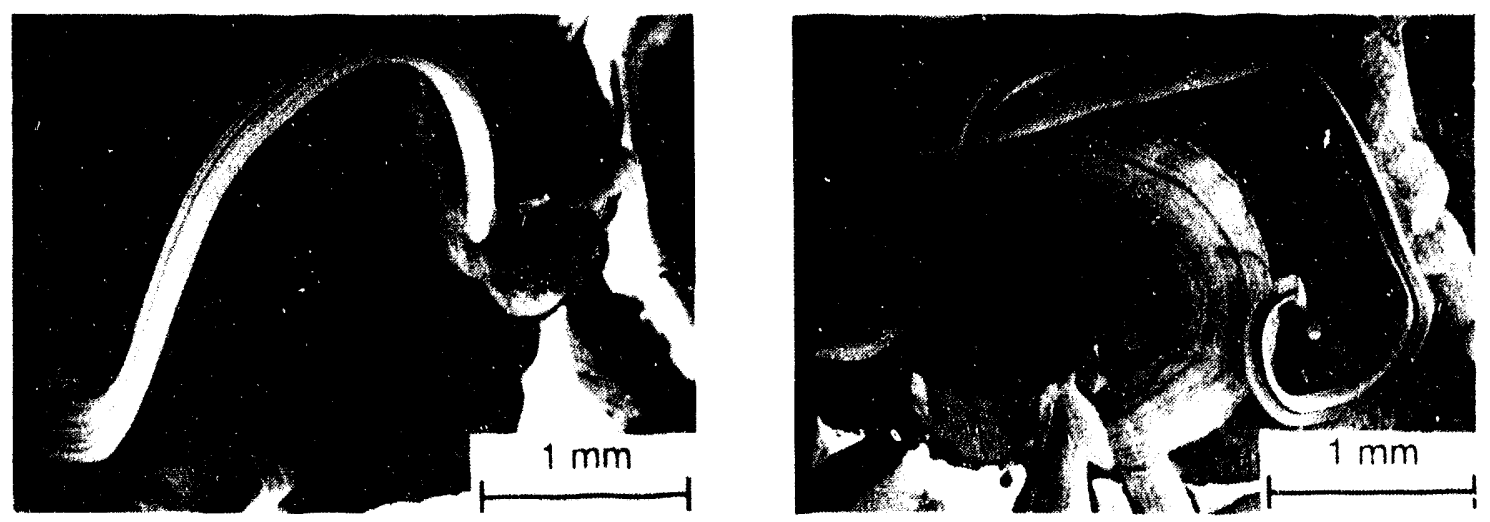

Figure 14. Photomicrographs of pure gallium whiskers, one with a curled end

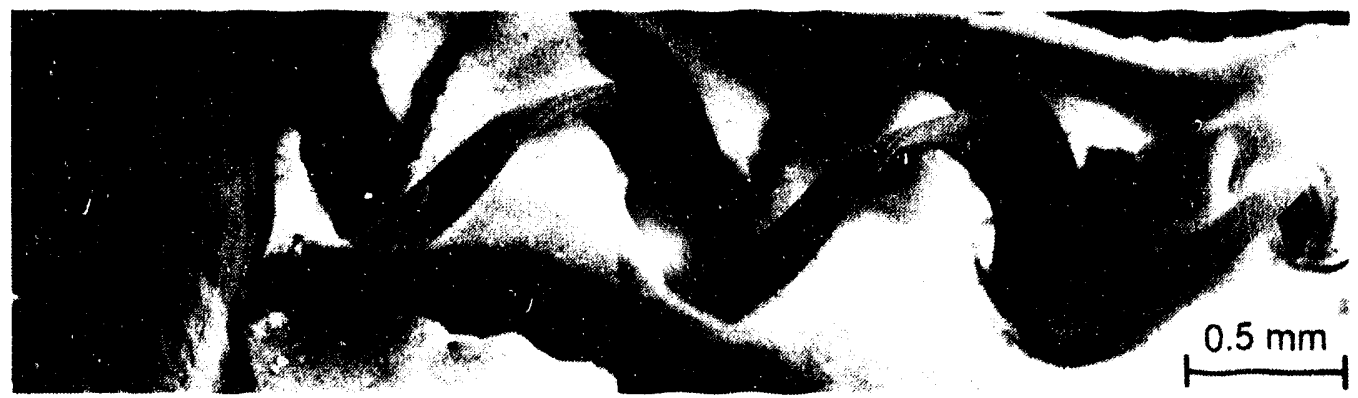

Figure 15. Photomicrograph of a spiral-shaped pure gallium whisker 
The growth of gallium whiskers is very similar to that observed in tin. Fisher et al.28 have reported three stages in the development of tin whiskers: (a) an induction/incubation stage, (b) a stage of constant growth rate, and (c) a stage of abrupt deceleration of growth rate. Current observations indicate that gallium whiskers exhibit all three growth stages. Frank ${ }^{27}$ reported that the mechanism for base-oriented whisker growth is a dislocation in the substrate that travels continuously around the base of the whisker. The process is initiated by a reduction of surface energy by oxidation at the point of initial whisker growth. Fisher et al. 28 indicated that the free energy required for whisker initiation could be provided by another source. In the case of gallium whiskers, strains caused by possible room-temperature phase transformations may provide the necessary energy. However, this cannot be confirmed, because the room-temperature regime of the iron-gallium phase diagram is not well defined.

Assuming that the necessary energy for whisker initiation has been provided, we postu late that gallium whisker growth can be explained by the same mechanism that occurs in tin. Gallium diffuses from a high-pressure region through a pressure gradient to the whisker base, at which point the whisker is projected outward from the substrate by means of the whiskerproducing dislocation mechanism. FeGa3 is crystalline and diffusion most likely occurs along the grain boundaries. The incubation stage is defined as the time needed for phase transformation and pressure gradient formation to occur in the substrate. A constant growth rate would exist as long as the pressure gradient within the substrate provides the necessary energy for whisker growth. When pressure within the substrate is equalized, the growth slows and eventually ceases. 27,28

The room-temperature regime of the nickel-gallium system is not well defined, and similar conditions may exist within this system to provide for whisker growth. Whisker growth near a nickel-gallium compound, possibly $\mathrm{Ni}_{2} \mathrm{Ga}_{3}$, has been observed in the present study.

\subsection{RESULTS}

\subsubsection{Corrosion Rates}

The corrosion of metals in gallium is directly related to their solubility in gallium.17,19 $\mathrm{A}$ minimum corrosion rate at $400^{\circ} \mathrm{C}$ is observed for elements in Groups 4-8 of Periods 4-6; the only exceptions occur in Period 4. The corrosion trends shown in Fig. 16 closely follow the solubility trends shown in Fig. 5. High corrosion rates are observed for metals in higher numbered groups, thus, they follow the solubility trend. In the second period, beryllium, boron, and carbon are not affected by exposure to liquid gallium.

Corrosion test results for the various materials are given in Tables 7 and 8 . Nearly all of the corrosion coupons gained weight after exposure; only the $\mathrm{Nb}-5 \mathrm{Mo}-1 \mathrm{Zr}$ alloy exposed at $400^{\circ} \mathrm{C}$ for 300 and $1.076 \mathrm{~h}$ lost weight. Pure metals react rapidly with gallium at $400^{\circ} \mathrm{C}$. An $\approx 0.5-\mathrm{mm}$-thick iron specimen reacted completely within $24 \mathrm{~h}$, and an $\approx 0.3-\mathrm{mm}$-thick

chromium specimen disintegrated within $100 \mathrm{~h}$. In contrast to the results of Yatsenko, 17.19 shown in Fig. 16, pure iron shows more corrosion than nickel. The corrosion rates at $400^{\circ} \mathrm{C}$ were estimated to be $\geq 10$ and $2 \mu \mathrm{m} / \mathrm{h}$ for Armco iron and Nickel 270, respectively. These values correspond to metal losses $\geq 88$ and $\approx 18 \mathrm{~mm} / \mathrm{yr}$ or mass transfer $\geq 7.9$ and $1.8 \mathrm{mg} / \mathrm{cm}^{2} \cdot \mathrm{h}$ for pure iron and nickel, respectively. A corrosion rate for chromium cannot be estimated 


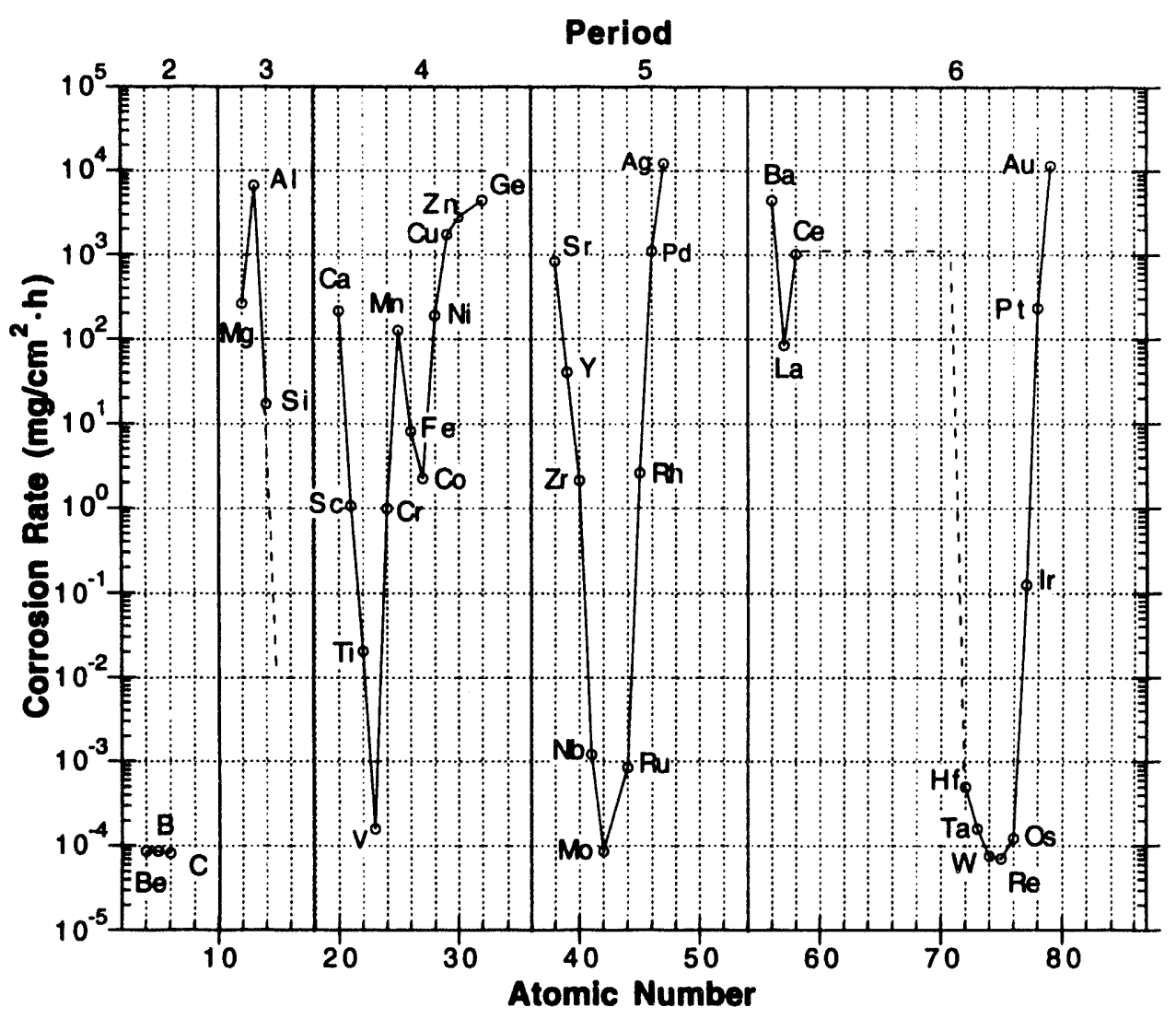

Figure 16. Periodicity of corrosion rate of metals in liquid gallium at $400^{\circ} \mathrm{C}$ (after Yatsenko ${ }^{17.19}$ )

Table 7. Corrosion behavior of Type 316 stainless steel exposed to gallium in sealed alumina capsules

\begin{tabular}{|c|c|c|c|c|c|c|c|}
\hline \multirow[b]{2}{*}{ Specimen } & \multicolumn{2}{|c|}{ Exposure } & \multicolumn{2}{|c|}{ Before Exposure } & \multirow{2}{*}{$\begin{array}{c}\text { Weight } \\
\text { Change } \\
\left(\mathrm{mg} / \mathrm{cm}^{2}\right)\end{array}$} & \multirow{2}{*}{$\begin{array}{c}\text { Metal } \\
\text { Loss }^{a} \\
(\mu \mathrm{m})\end{array}$} & \multirow{2}{*}{$\begin{array}{c}\text { Reaction } \\
\text { Layer } \\
(\mu \mathrm{m})\end{array}$} \\
\hline & $\begin{array}{l}\text { Temp. } \\
\left({ }^{\circ} \mathrm{C}\right)\end{array}$ & $\begin{array}{c}\text { Time } \\
\text { (h) }\end{array}$ & $\begin{array}{l}\text { Mass } \\
\text { (mg) }\end{array}$ & $\begin{array}{l}\text { Thickness } \\
\text { (mm) }\end{array}$ & & & \\
\hline SS-4A & 400 & 24 & 860.6 & $0.5 \overline{405}$ & 31.2 & 21.3 & 90.2 \\
\hline SS $-4 \mathrm{~F}$ & 400 & 48 & 854.1 & 0.5135 & 19.8 & -3.0 & 37.1 \\
\hline SS- $4 B$ & 400 & 100 & 900.1 & 0.5405 & 36.5 & 60.5 & 280.3 \\
\hline SS $-4 \mathrm{C}$ & 400 & 300 & 834.2 & 0.5675 & 362.6 & 130.0 & 620.2 \\
\hline$S S-4 E$ & 400 & 1076 & 770.0 & 0.5675 & 394.5 & 160.1 & 802.2 \\
\hline SS-3C-D & 375 & 300 & 893.9 & 0.5135 & 169.3 & 48.3 & 274.2 \\
\hline SS $-3 C-C$ & 350 & 300 & 937.3 & 0.5135 & 30.7 & 3.7 & 68.3 \\
\hline SS- $-3 C-B$ & 320 & 300 & 899.7 & 0.5135 & 2.7 & -11.6 & - \\
\hline SS-3B & 300 & 100 & 806.7 & 0.5135 & 2.7 & -11.4 & - \\
\hline SS-3C-A & 300 & 300 & 792.5 & 0.5405 & 0.3 & 4.1 & - \\
\hline SS-3D & 300 & 1008 & 845.5 & 0.5135 & 4.7 & -7.4 & 8.9 \\
\hline SS-3E & 300 & 3000 & 820.1 & 0.5405 & 8.4 & 9.6 & 23.3 \\
\hline SS-2C & 200 & 300 & 743.2 & 0.5540 & - & 9.0 & - \\
\hline SS-2D & 200 & 1000 & 870.1 & 0.5135 & - & -13.9 & - \\
\hline SS-2E & 200 & 3000 & 742.0 & 0.5675 & 0.1 & 11.5 & - \\
\hline SS-24Cb & 200 & 300 & 856.5 & 0.5540 & 61.5 & 32.8 & 113.0 \\
\hline SS-24D $b$ & 200 & 1008 & 928.6 & $0.5: 35$ & 69.9 & 18.4 & 122.7 \\
\hline SS-24E & 200 & 3000 & 792.6 & 0.5540 & 59.1 & 34.4 & 122.4 \\
\hline
\end{tabular}

a Negative values represent an increase in thickness. Accuracy of measurements $\pm 10 \mu \mathrm{m}$.

b Specimens exposed at $400^{\circ} \mathrm{C}$ for $24 \mathrm{~h}$ to ensure complete wetting prior to the exposure at $200^{\circ} \mathrm{C}$. 
Table 8. Corrosion behavior of various materials exposed to gallium in sealed alumina capsules

\begin{tabular}{|c|c|c|c|c|c|c|c|}
\hline \multirow[b]{2}{*}{ Specimen } & \multicolumn{2}{|c|}{ Exposure } & \multicolumn{2}{|c|}{ Before Exposure } & \multirow{2}{*}{$\begin{array}{l}\text { Weight } \\
\text { Change } \\
\left(\mathrm{mg} / \mathrm{cm}^{2}\right)\end{array}$} & \multirow{2}{*}{$\begin{array}{l}\text { Metal } \\
\text { Loss }^{a} \\
(\mu \mathrm{m})\end{array}$} & \multirow{2}{*}{$\begin{array}{l}\text { Reaction } \\
\text { Layer } \\
(\mu \mathrm{m})\end{array}$} \\
\hline & $\begin{array}{c}\text { Temp. } \\
\left({ }^{\circ} \mathrm{C}\right)\end{array}$ & $\begin{array}{l}\text { Time } \\
\text { (h) }\end{array}$ & $\begin{array}{l}\text { Mass } \\
\text { (mg) }\end{array}$ & $\begin{array}{c}\text { Thickness } \\
\text { (mm) }\end{array}$ & & & \\
\hline \multicolumn{8}{|c|}{ Inconel 625} \\
\hline IN-4A & 400 & 24 & 2515.2 & 1.3696 & 17.4 & -3.9 & 8.0 \\
\hline IN $-4 \mathrm{~F}$ & 400 & 48 & 2465.4 & 1.3825 & 2.9 & 3.8 & 9.6 \\
\hline IN-4B & 400 & 100 & 2441.1 & 1.3825 & 4.1 & 6.6 & 11.0 \\
\hline IN-4C & 400 & 300 & 2471.0 & 1.3696 & 27.9 & 14.3 & 56.0 \\
\hline IN-4E & 400 & 1076 & 2508.0 & 1.3567 & 82.9 & 56.5 & 203.4 \\
\hline IN-3B & 300 & 100 & 2414.5 & 1.3825 & 4.6 & -0.3 & - \\
\hline IN-3C & 300 & 300 & 2447.7 & 1.3825 & - & 0.3 & - \\
\hline IN-3D & 300 & 1008 & 2443.3 & 1.3825 & 1.8 & 8.8 & - \\
\hline IN-3E & 300 & 3000 & 2427.8 & 1.3825 & 1.0 & -5.8 & - \\
\hline \multicolumn{8}{|c|}{ Nb-5 Mo-1 Zr Alloy } \\
\hline$N B-4 F$ & 400 & 24 & 1560.7 & 0.8602 & 1.0 & 5.3 & - \\
\hline$N B-4 B$ & 400 & 100 & 1750.2 & 0.8602 & 3.9 & -1.2 & - \\
\hline $\mathrm{NB}-4 \mathrm{C}$ & 400 & 300 & 1746.2 & 0.8736 & -0.1 & 3.2 & - \\
\hline NB-4E & 400 & 1076 & 1704.7 & 0.8602 & -5.1 & 3.6 & - \\
\hline NB-3B & 300 & 100 & 1550.7 & 0.8602 & 0.8 & 2.9 & - \\
\hline NB-3C & 300 & 300 & 1701.7 & 0.8602 & 3.1 & -0.9 & - \\
\hline NB-3D & 300 & 1008 & 1714.2 & 0.8602 & 1.2 & 0.1 & - \\
\hline NB-3E & 300 & 3000 & 1874.7 & 0.8602 & 0.6 & -6.2 & - \\
\hline \multicolumn{8}{|c|}{ Armco Iron } \\
\hline$F E-4 F$ & 400 & 24 & 771.0 & 0.4324 & \multirow{4}{*}{\multicolumn{3}{|c|}{$\begin{array}{l}\text { reacted completely to form } \mathrm{FeGa}_{3} \\
\text { reacted completely to form } \mathrm{FeGa} 3 \\
\text { reacted completely to form } \mathrm{FeGa}_{3} \\
\text { reacted completely to form } \mathrm{FeGa}_{3}\end{array}$}} \\
\hline$F E-4 B$ & 400 & 100 & 772.0 & 0.4459 & & & \\
\hline $\mathrm{FE}-4 \mathrm{C}$ & 400 & 300 & 727.2 & 0.4324 & & & \\
\hline$F E-4 E$ & 400 & 1076 & 765.2 & 0.4459 & & & \\
\hline $\mathrm{FE}-3 \mathrm{~B}$ & 300 & 100 & 765.0 & 0.4594 & 150.9 & 47.1 & 250.3 \\
\hline $\mathrm{FE}-3 \mathrm{C}$ & 300 & 300 & 758.2 & 0.4594 & 346.4 & 129.5 & 713.5 \\
\hline FE-3D & 300 & 1008 & 785.5 & 0.4459 & \multirow{2}{*}{\multicolumn{3}{|c|}{$\begin{array}{l}\text { reacted completely to form } \mathrm{FeGa}_{3} \\
\text { reacted completely to form } \mathrm{FeGa}_{3}\end{array}$}} \\
\hline FE-3E & 300 & 3000 & 749.3 & 0.4459 & & & \\
\hline \multicolumn{8}{|l|}{ Nickel 270} \\
\hline $\mathrm{Nl}-4 \mathrm{~B}$ & 400 & 100 & 1320.3 & 0.7155 & 277.7 & 201.2 & 663.9 \\
\hline \multicolumn{8}{|c|}{ Pure Chromium } \\
\hline CR-4B & 400 & 100 & 488.6 & 0.2921 & \multicolumn{3}{|c|}{ disintegrated into $\mathrm{CrGa}_{4}$ crystals } \\
\hline \multicolumn{8}{|c|}{ Type 316 SS Oxidized in Air at $350^{\circ} \mathrm{C}$ for 100 hours } \\
\hline$S S A-4 B$ & 400 & 100 & 757.5 & 0.5405 & 27.2 & 23.3 & 73.4 \\
\hline SSA-4C & 400 & 300 & 732.2 & 0.5405 & 107.3 & 94.9 & 508.7 \\
\hline SSA-4D & 400 & 1000 & 792.0 & 0.5135 & b & 215.6 & 1275.3 \\
\hline SSA-4E & 400 & 3000 & 756.8 & 0.5270 & b & \multicolumn{2}{|c|}{ complete reaction $\mathrm{c}$} \\
\hline \multicolumn{8}{|c|}{ Type 316 SS Oxidized in Water $\left(6 \mathrm{ppm}\right.$ dissolved $\left.\mathrm{O}_{2}\right)$ at $290^{\circ} \mathrm{C}$ for 100 hours } \\
\hline SSW-4B & 400 & 100 & 702.4 & 0.5135 & 83.8 & 26.2 & 189.1 \\
\hline SSW-4C & 400 & 300 & 721.3 & 0.5135 & 135.8 & 76.3 & 465.8 \\
\hline SSW-4D & 400 & 1000 & 761.6 & 0.5135 & b & 173.6 & 998.6 \\
\hline SSW-4E & 400 & 3000 & 810.6 & 0.5135 & $\mathrm{cb}$ & \multicolumn{2}{|c|}{ complete reaction $\mathrm{c}$} \\
\hline
\end{tabular}

\footnotetext{
a Negative values represent an increase in thickness. Accuracy of measurements $\pm 10 \mu \mathrm{m}$.

bpostexposure specimen could not be cleaned; therefore, final masses were not recorded.

c Complete reaction to form intermetallic compounds $\mathrm{FeGa}_{3}, \mathrm{CrGa}_{4}, \mathrm{Ni}_{2} \mathrm{Ca}_{3}$, and $\mathrm{NiGa}_{4}$.
}

accurately because the actual time required for the specimen to dissolve in gallium could not be established. The $100-\mathrm{h}$ result yields an approximate value of $\geq 1.5 \mu \mathrm{m} / \mathrm{h}$ (1.e., $\geq 13 \mathrm{~mm} / \mathrm{yr}$ or $\left.\geq 1 \mathrm{mg} / \mathrm{cm}^{2} \cdot \mathrm{h}\right)$. The corrosion rates for iron and chromium are consistent with the values reported by Yatsenko (Fig. 16), but the rate for nickel is lower by two orders of magnitude. 
Elements of an alloy dissolve in liquid metals because their concentrations in the liquid are lower than their solubilities. Under isothermal conditions, this process will continue at a constant rate orily when experimental conditions stay the same during the test. In capsule tests with a limited volume of liquid metal, dissolution will become slower and stop completely when the liquid metal becomes saturated. However, metallographic examination of the corrosion specimens, discussed in the next section, indicates that, at the test temperatures, corrosion of iron, chromium, and nickel occurs by dissolution and is accompanied by formation of metal-gallium intermetallic compounds. Consequently, dissolution can occur after saturation by formation of intermetallic compounds from the saturated solution of gallium. The growth of these compounds may control the overall rate of corrosion for some metals and alloys. Corrosion of metals and alloys may proceed at a constant rate when the formation of compounds is faster than dissolution of metal elements. The difference in corrosion rate for nickel observed in this study and that reported earlier ${ }^{19}$ may be attributed to a different rate-controlling process; in the present study, the corrosion rate for nickel could be controlled by the rate of formation of nickel-gallium compounds.

Metal losses for the various alloys and pure metals exposed to gallium at 300 and $400^{\circ} \mathrm{C}$ are plotted as a function of time in Figs. 17 and 18, respectively. Corrosion rates for the alloys are lower than those for the pure metals. The $\mathrm{Nb}-5 \mathrm{Mo}-1 \mathrm{Zr}$ alloy showed no measurable corrosion at 300 or $400^{\circ} \mathrm{C}$. Type $316 \mathrm{SS}$ and Inconel 625 specimens show significant corrosion at $400^{\circ} \mathrm{C}$ and little or no corrosion at $300^{\circ} \mathrm{C}$. The iron-based Type $316 \mathrm{SS}$ exhibits more corrosion than nickel-based Inconel 625 . At $400^{\circ} \mathrm{C}$, the corrosion rate of Type $316 \mathrm{SS}$ is nearly one order of magnitude greater than that of Inconel 625.

Corrosion rates for Type 316 SS exposed at $400^{\circ} \mathrm{C}$ decrease with time because of the limited quantity of gallium used in the experiments, i.e., the supply of gallium is exhausted, or because of specimen geometry. For example, corrosion on the inner surface of a U-shaped coupon will stop when the space between the two sides of the specimen fills with reaction layer. This behavior was observed in the Type 316 specimen exposed at $400^{\circ} \mathrm{C}$ for $1.076 \mathrm{~h}$, and in the oxidized specimens exposed at $400^{\circ} \mathrm{C}$ for $1,000 \mathrm{~h}$. Consequently, only values of metal loss up to $300 \mathrm{~h}$ were used to determine the corrosion rate of Type $316 \mathrm{SS}$ at $400^{\circ} \mathrm{C}$. Short-term (300-h)

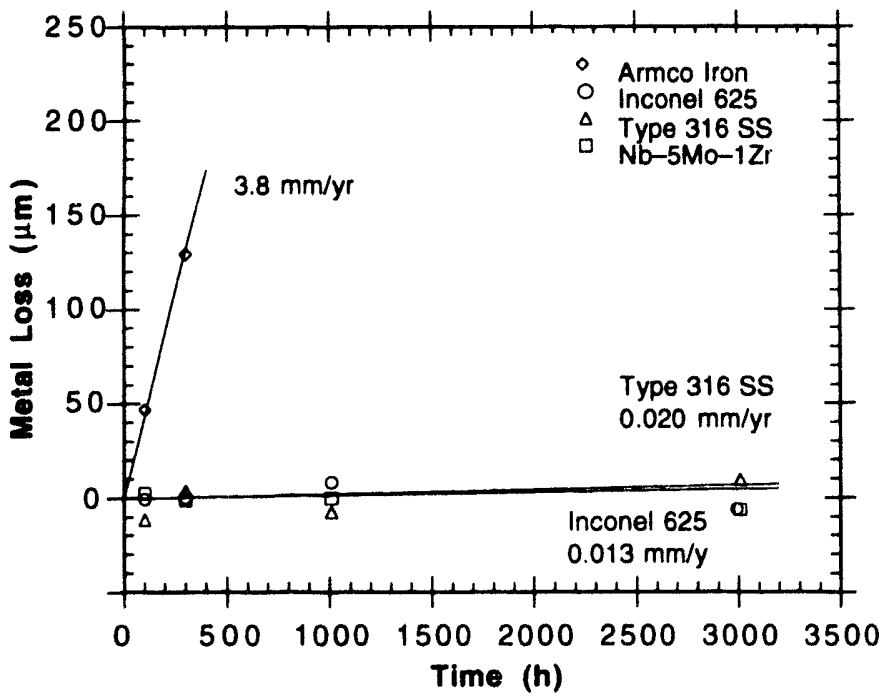

Figure 17. Corrosion behavior of materials tested at $300^{\circ} \mathrm{C}$ in static gallium 

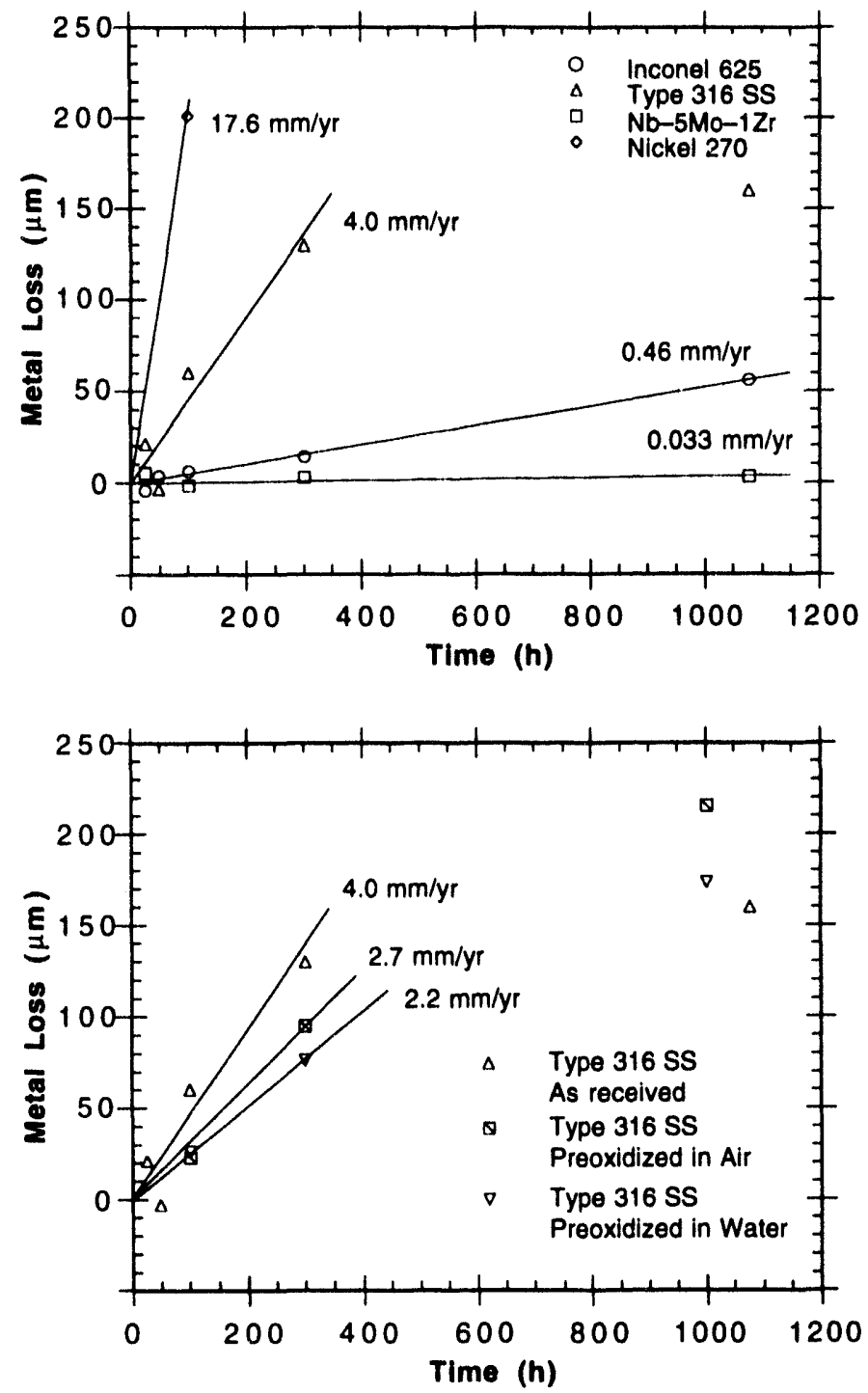

Figure 18.

Corrosion behavior of materials tested at $400^{\circ} \mathrm{C}$ in static gallium
Figure 19.

Corrosion behavior of oxidized Type 316

SS tested at $400^{\circ} \mathrm{C}$ in static gallium

corrosion tests were conducted at 375,350 , and $320^{\circ} \mathrm{C}$ to better establish the temperature dependence of the corrosion rate of Type $316 \mathrm{SS}$. The results show excellent agreement with $300-\mathrm{h}$ tests at 300 and $400^{\circ} \mathrm{C}$. Only approximate estimates of corrosion rates could be obtained for the alloys at $300^{\circ} \mathrm{C}$, because of very low metal loss; long-term $(>3,000-\mathrm{h})$ corrosion data are needed for accurate estimates.

Metal losses for Type 316 SS specimens that were oxidized in air and water and then exposed to gallium at $400^{\circ} \mathrm{C}$ are plotted as a function of time in Fig. 19. The corrosion rates of the oxidized Type 316 SS specimens were lower than those of the as-received specimens. The estimated corrosion rates at $400^{\circ} \mathrm{C}$ were 0.25 and $0.31 \mu \mathrm{m} / \mathrm{h}$ for specimens oxidized in water and air, respectively, and $0.46 \mu \mathrm{m} / \mathrm{h}$ for as-received Type $316 \mathrm{SS}$. These rates, although lower than those for pure metal, would result in $>2 \mathrm{~mm} / \mathrm{yr}$ metal loss. 


\subsubsection{Metallographic Examination}

After exposure to gallium, the specinens were sectioned, mounted, and polished for metallographic examination. Some of the samples were etched to reveal signs of grain boundary at tack. The photomicrographs of the samples are complled in Appendix A.

\section{Pure Metals}

Three pure metals, Armco iron, Nickel 270, and chromium, were evaluated for compatibility with liquid gallium. Armco iron showed significant corrosion even at $300^{\circ} \mathrm{C}$. The specimen developed a very porous and thick reaction layer that was identifled by XRD analysis as FeGa with gallium metal present in the pores. Cross-sectional photomicrographs of specimens exposed to gallium for 100 and $300 \mathrm{~h}$ at $300^{\circ} \mathrm{C}$ are shown in Figs. A42 and A43, respectively. Both specimens exhibited uniform corrosion in both cold-worked and noncold-worked regions, with no intergranular attack. Similar corrosion behavior was observed for Nickel 270, in which the reaction layer primarily consists of $\mathrm{Ni}_{2} \mathrm{Ga}_{3}$ and contains small amounts of $\mathrm{NiGa}_{4}$ in the region in contact with gallium. Most likely, the NiGa4 formed during cooling. XRD also revealed an unidentified phase (' $X$ ' phase), with $d$-spacing lines at $2.71,2.13$, and $1.92 \AA$. We assumed that this phase was a nickel-gallium compound. Upon etching, the porous structure of the reaction layer could easily be seen to contain a large quantity of gallium in the region close to the base metal. Figure A44 shows the cross section of Nickel 270 exposed for $100 \mathrm{~h}$ at $400^{\circ} \mathrm{C}$. Again, intergranular attack was not observed.

A somewhat different behavior was observed for chromium metal; the specimen disintegrated into small crystals. The crystals were identifled as $\mathrm{CrGa}_{4}$ by $\mathrm{XRD}$ analysis, indicating that the mechanism for corrosion of chromium is basically the same as that for nickel or iron, with the difference that the $\mathrm{CrGa}_{4}$ phase in equilibrium with the saturated solution of gallium did not adhere to the metal surface.

Metallographic examination of the reaction layers indicated that at the test temperatures. corrosion of nickel, chromium, and iron occurred entirely by dissolution, accompanied by formation of metal-gallium intermetallic compounds from the saturated solution of gallium. Corrosion can occur only with the growth of intermetallic compounds. For nickel and iron. the reaction proceeds at the metal surface, and an adherent but extremely porous reaction layer grows outward into the melt. The process continues as long as gallium can reach the reaction zone.

$\mathrm{Nb}-5 \mathrm{Mo-1} \mathrm{Zr}$ Alloy

The $\mathrm{Nb}-5 \mathrm{Mo}-1 \mathrm{Zr}$ alloy showed no measurable corrosion at 300 or $400^{\circ} \mathrm{C}$, although there appeared to be significant attack of the cold-worked region. Composite photomicrographs of these specimens are shown in Figs. A34-A41. The surface of the specimens after exposure was smooth, with very little formation of intermetallic compound. XRD analysis identified the sparse surface compound formations as $\mathrm{NbGa}_{3}$. This compound could not be detected by EDS during examination of specimen cross sections.

All specimens exhibited significant intergranular attack in cold-worked regions. Backscatter electron microscopy of postexposure specimens indicated that gallium was present at 
the crack tip. Although a few 10-20- $\mu$ m-long cracks, which were created when the U-bend was made, were observed in the cold-worked region of the specimen before exposure, cracking in this alloy was enhanced by liquid gallium. Some postexposure cracks showed significant branching, with lengths in excess of $60 \mu \mathrm{m}$ (Figs. A37, A40). Metallographic examination indicated that the degree of attack was not significantly different at 300 and $400^{\circ} \mathrm{C}$; the specimens exposed for $100 \mathrm{~h}$ at 300 and $400^{\circ} \mathrm{C}$ showed similar attack. However, intergranular attack increased with time; specimens exposed for $\geq 300 \mathrm{~h}$ exhibited significant crack growth and crack tip widening (Figs. A35-A37, A40, A41).

Inconel 625 Alloy

Inconel 625 specimens showed significant corrosion at $400^{\circ} \mathrm{C}$, and little or no corrosion at $300^{\circ} \mathrm{C}$. The specimens exposed for $24-3,000 \mathrm{~h}$ at $300^{\circ} \mathrm{C}$ exhibited no reaction layer growth; however, the metal surface was etched by the liquid metal, revealing that some attack occurred at this temperature. These specimens are shown in Figs. A27-A30. At $400^{\circ} \mathrm{C}$, metal loss and reaction layer growth was evident, and increased with exposure time. The photomicrographs in Figs. A29-A33 reveal that layer growth occurred evenly on the exposed surface, without intergranular attack. There was no distinction between attack of cold-worked and noncold-worked regions. The reaction layer, identified by $\mathrm{XRD}$, contained $\mathrm{CrGa}_{4}$ and gallium across the entire thickness. XRD also identified the presence of the ' $X$ ' phase observed in the Nickel 270 specimen. It appears that the ' $\mathrm{X}$ ' phase occurred primarlly near clusters of intermetallic compounds adhering to the surface of the specimens.

Type 316 SS

The specimens exposed at $200^{\circ} \mathrm{C}$ exhibited minimal corrosion and formed no reaction layer. Photomicrographs of these specimens are shown in Figs. A1-A3. There are no signs of intergranular attack, and it appears that gallium did not wet the specimens during exposure. Three specimens were initially exposed for $24 \mathrm{~h}$ at $400^{\circ} \mathrm{C}$ to ensure wetting of the specimens by the liquid metal; they were then exposed at $200^{\circ} \mathrm{C}$ for 300,1000 , and $3000 \mathrm{~h}$. The corrosion behavior of these specimens was nearly identical to that of the specimen that was only exposed for $24 \mathrm{~h}$ at $400^{\circ} \mathrm{C}$. The reaction layer was porous and evenly distributed on the specimen surface, indicating that there was no corrosion of Type $316 \mathrm{SS}$ at $200^{\circ} \mathrm{C}$, even after wetting. Corrosion of the prewetted specimens occurred only during the initial 24-h exposure at $400^{\circ} \mathrm{C}$. Photomicrographs of prewetted specimens are shown in Figs. A4-A6. The specimens do not exhibit intergranular attack.

Type $316 \mathrm{SS}$ specimens exposed at $300^{\circ} \mathrm{C}$ displayed little corrosion and reaction layer formation. These specimens are shown in Figs. A7-A10. After 100- and 300-h tests, the specimens did not develop a reaction layer; however, the metal surface exposed to gallium was attacked slightly. Reaction layers formed on the entire specimen during 1008- and 3000-h exposures. Three Type $316 \mathrm{SS}$ specimens were exposed for $300 \mathrm{~h}$ at $320^{\circ} \mathrm{C}, 350^{\circ} \mathrm{C}$, and $375^{\circ} \mathrm{C}$. The photomicrographs of these specimens, Figs. A11-A13, indicate that the thickness of the layer increased linearly with temperature. The reaction layer was similar to that observed after exposure for 1000 or $3000 \mathrm{~h}$ at $300^{\circ} \mathrm{C}$.

The specimens exposed at $400^{\circ} \mathrm{C}$ exhibited significant corrosion and formation of a thick, porous reaction layer. Although significant corrosion occurred, the specimens were not prefer- 
entially attacked along the grain boundartes. The reaction layer. shown in cross section in Figs. A14-A18, appears to be stıtated, with alternating light and dark regions. The larger dark regions are most likely open pores. Exposure to gallium at $400^{\circ} \mathrm{C}$ for extended test times $(1000 \mathrm{~h})$ led to separation of the specimen at the bend, resulting in accelerated corrosion at the sample ends (Fig. A18). XRD analysis confirmed that the reaction layer on Type 316 SS consisted primartly of $\mathrm{FeGa}_{3}$ and gallium, with some $\mathrm{CrGa}_{4}$ in the region next to the steel surface: nickel-gallium compounds were not detected. It is possible that ternary and quaternary compounds of iron, chromlum, nickel, and gallium also formed. More detalled studies of the complex behavior of this four-component system are necessary to accurately identify such compounds.

\section{Preoxidized Type 316 SS}

Two sets of Type 316 SS specimens were oxidized in either water or air prior to exposure in static gallium. Both sets of specimens were heavlly attacked by gallium. The specimens oxidized in air are shown in Figs. A19-A21 and those oxidized in water are shown in Figs. A22A24. The general appearance of oxidized and as-received specimens was similar; however, the corrosion rates of the oxidized specimens were somewhat lower. Examination of the specimens exposed for $100 \mathrm{~h}$ at $400^{\circ} \mathrm{C}$ (Figs. A19, A22) revealed that the marginally lower corrosion rates of the oxidized specimens were caused by lack of wetting of the specimen and/or dissociation of the surface oxdde during the initial 100-h exposure.

$\mathrm{XRD}$ analysis of the oxidized specimens after exposure revealed at least two phases, one nearly amorphous spinel-type phase of the form $\mathrm{NiFeGaO}_{4}$ and another unidentifled phase. with $\mathrm{d}$-spacing lines at $2.67,2.43$, and $1.495 \AA$. The results indicate that, at $400^{\circ} \mathrm{C}$, an iron chromite coating does not provide protection against corrosion. The coating dissociates to form a spinel-type phase, and corrosion of the alloy proceeds by dissolution, accompanied by formation of $\mathrm{FeGa}_{3}$ and other gallium-metal compounds. The specimens tested for $1000 \mathrm{~h}$ (Figs. A21, A24) were nearly identical to the as-received sample tested for $1076 \mathrm{~h}$ (Fig. A18), and $3000-\mathrm{h}$ test specimens were heavily attacked by gallium. B th sets of specimens completely dissolved to form $\mathrm{FeGa}_{3}$.

\subsection{DISCUSSION}

Corrosion of structural alloys occurs primarily by dissolution of elements in liquid gallium. After an initial incubation period to allow wetting, gallium dissolves the elements of the alloys. Intermetallic compounds, typically $\mathrm{MGa}_{3}$ or $\mathrm{MGa}_{4}$, form on the surface of the specimen when the gallium becomes saturated with the metals. Crystalline binary intermetallic phases grow from the melt. A photomicrograph of crystals emerging from a solidified iron-gallium solution during a test on Type 316 SS is shown in Fig. 20. Corresponding EDS spectra are also shown. Note that a crystal of $\mathrm{CrGa}_{4}$ is present with the FeGa3 crystals. Because a significant amount of gallium was detected in the pores of the reaction layer near the base metal, we postulate that the primary reactions and crystal formation occur at the metal surface. Fresh gallium is transported through the lattice of the reaction layer to the reaction zone. The dissolution reaction proceeds as long as fresh gallium can reach the reaction zone. Crystal growth. leading to scale formation, proceeds as more base metal is dissolved. 

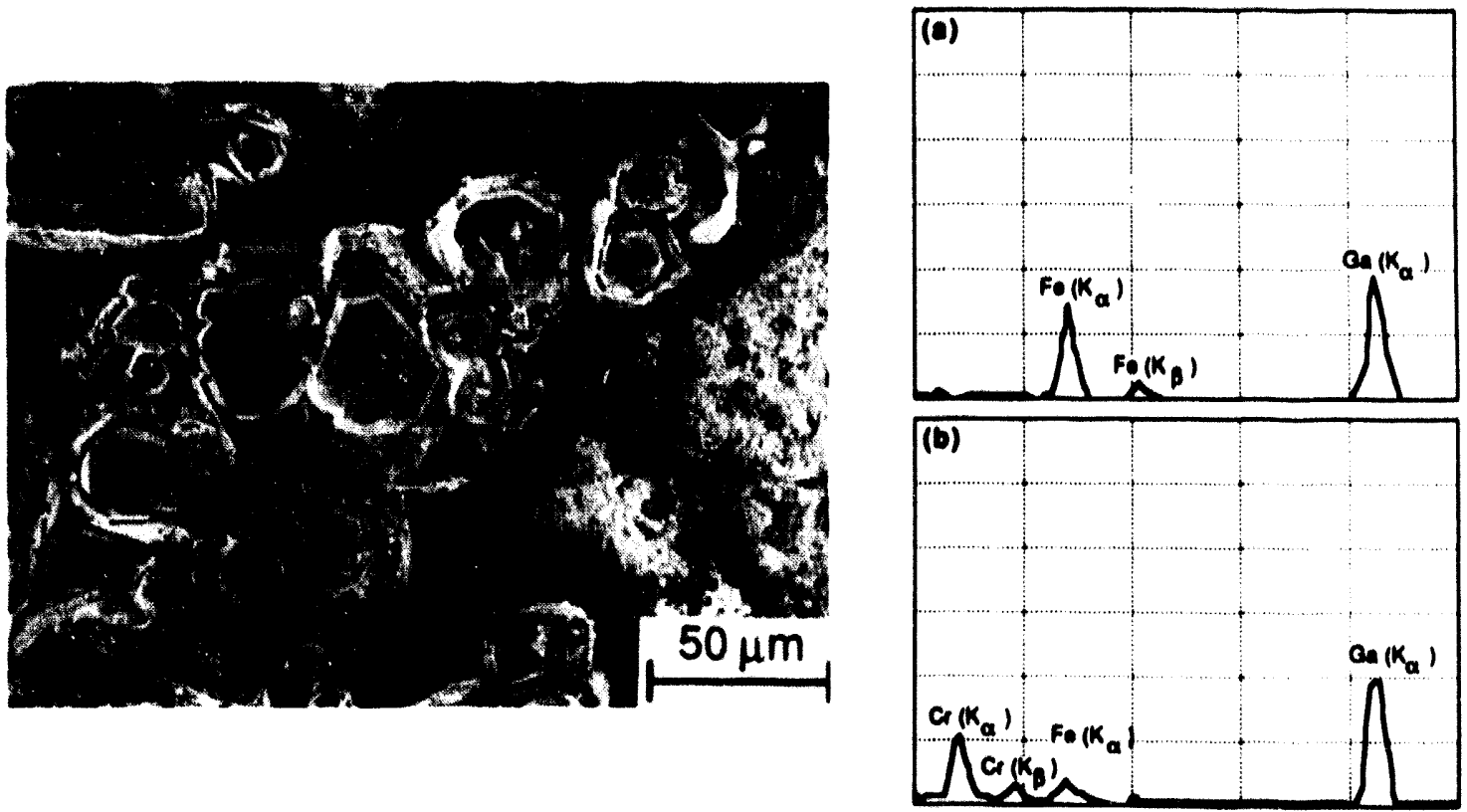

Figure 20. FeGa 3 (a) and $\mathrm{CrGa}_{4}$ (b) crystals growing from gallium melt, with corresponding EDS spectra

The most complex intermetallic formation occurred on Type 316 SS. Dissolution of the primary constituent elements, iron, nickel, and chromium, led to the formation of several intermetallic compounds. XRD analysis of the reaction layer on Type 316 SS indicated the presence of $\mathrm{FeGa}_{3}$ and $\mathrm{CrGa}_{4}$. Nickel compounds were detected by scanning electron microscopy/EDS away from the specimen. Figure 21 shows photomicrographs and EDS spectra of iron-gallium and nickel-gallium crystals. The large, faceted crystals in Fig. $21 \mathrm{~A}$ were identified as $\mathrm{FeGa}_{3}$. The small platelets, shown at higher magnification in Fig. 21B, are most likely $\mathrm{Ni}_{2} \mathrm{Ga}_{3}$. Figure 22 shows a nickel-gallium compound with a somewhat different composition and morphology than that shown in Fig. 21B. The EDS spectra of the two nickel-gallium phases indicate that the large platelets in Fig. 22 contain less nickel; they may be the ' $X$ ' phase identified by XRD of the Nickel 270 and Inconel 625 specimens. The nickel-gallium phase diagram indicates that $\mathrm{Ni}_{2} \mathrm{Ga}_{3}$ was the only stable compound in contact with gallium.

Figure 23 shows photomicrographs of $\mathrm{FeGa}_{3}$ crystals from a test on Type $316 \mathrm{SS}$. In Fig. 23A, most of the surface area of the large faceted crystal appears to be pitted. This is typical of most of the $\mathrm{FeGa}_{3}$ crystals that were observed. The high-magnification view shown in Fig. 23B reveals that these pits are actually crystal imperfections centered upon darker regions. The EDS spectra indicate that these darker regions contain silicon.

Referring to Fig. 8 in Section 4.1, in which the solubility of pure metals is discussed, we noted that the solubilities of iron, chromium, nickel, and niobium follow the sequence $\mathrm{Ni}>\mathrm{Fe}>\mathrm{Cr}>\mathrm{Nb}$ at temperatures above $300^{\circ} \mathrm{C}$, with the solubilities of iron, nickel, and chromium greater by several orders of magnitude than the solubility of niobium at any given temperature. This explains the difference between the corrosion rates of Type $316 \mathrm{SS}$, Inconel 625, and $\mathrm{Nb}-5 \mathrm{Mo}-1 \mathrm{Zr}$. The corrosion rate of Type $316 \mathrm{SS}$ was greater than that of the nickel-based Inconel 625 alloy. However, XRD analysis confirmed that the major reaction layers on Type 316 SS and Inconel 625 were $\mathrm{FeGa}_{3}$ and $\mathrm{CrGa}_{4}$, respectively. Chromium from Inconel 625 dissolves before the highly soluble nickel, resulting in a lower corrosion rate for the 

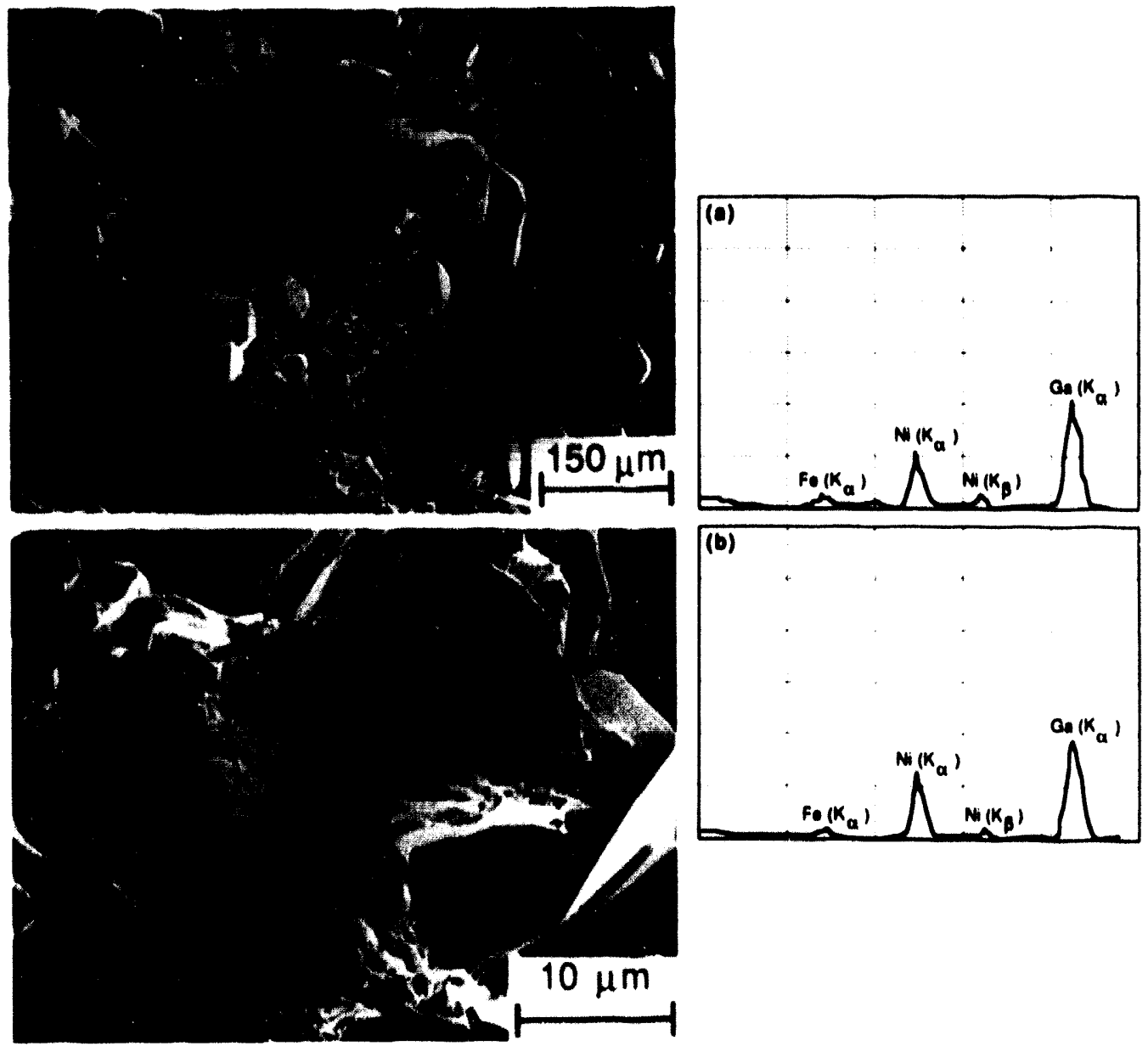

Figure 21. $\mathrm{FeGa}_{3}$ and $\mathrm{Ni}_{2} \mathrm{Ga}_{3}$ crystals grown during exposure of Type $316 \mathrm{SS}$ to liquid gallium, together with corresponding EDS spectra

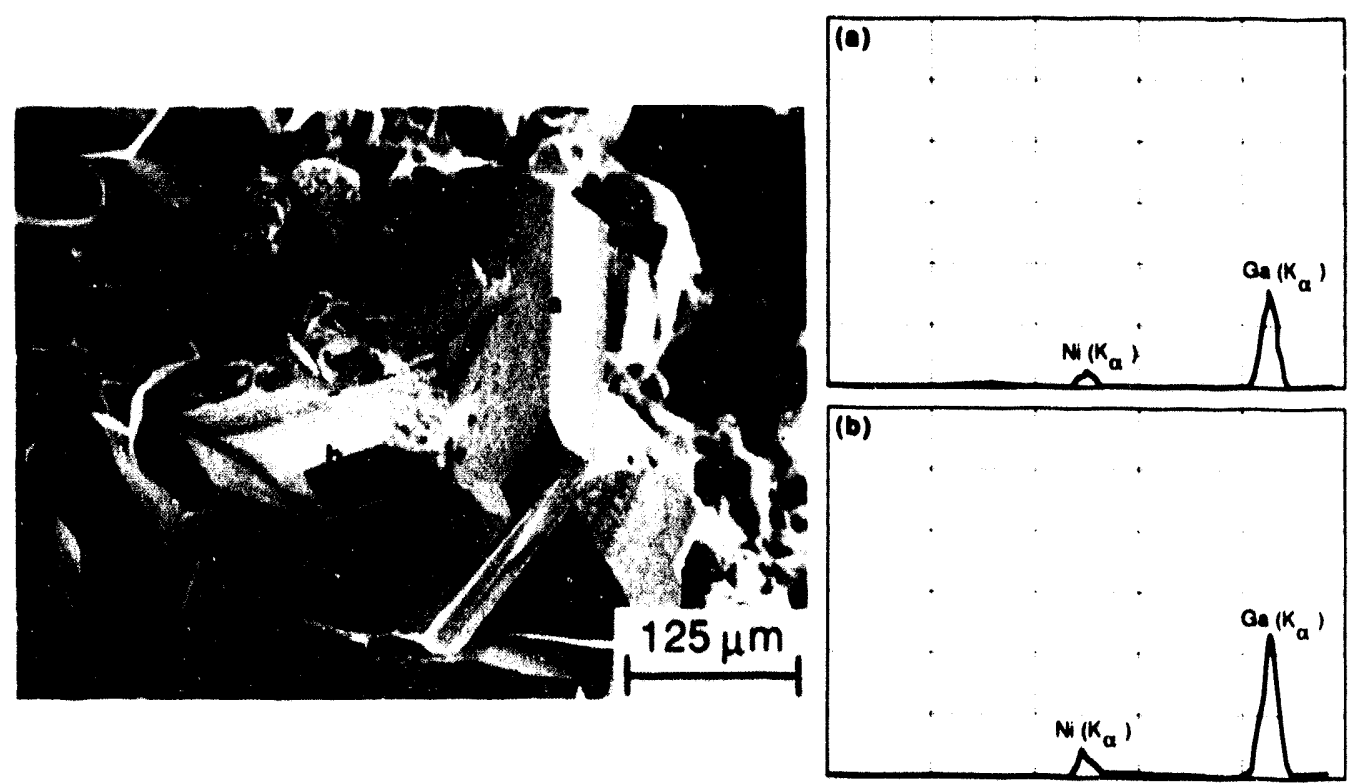

Flgure 22. NiGa 4 crystals grown during exposure of Type 316 SS to liquid gallium, together with corresponding EDS spectra 

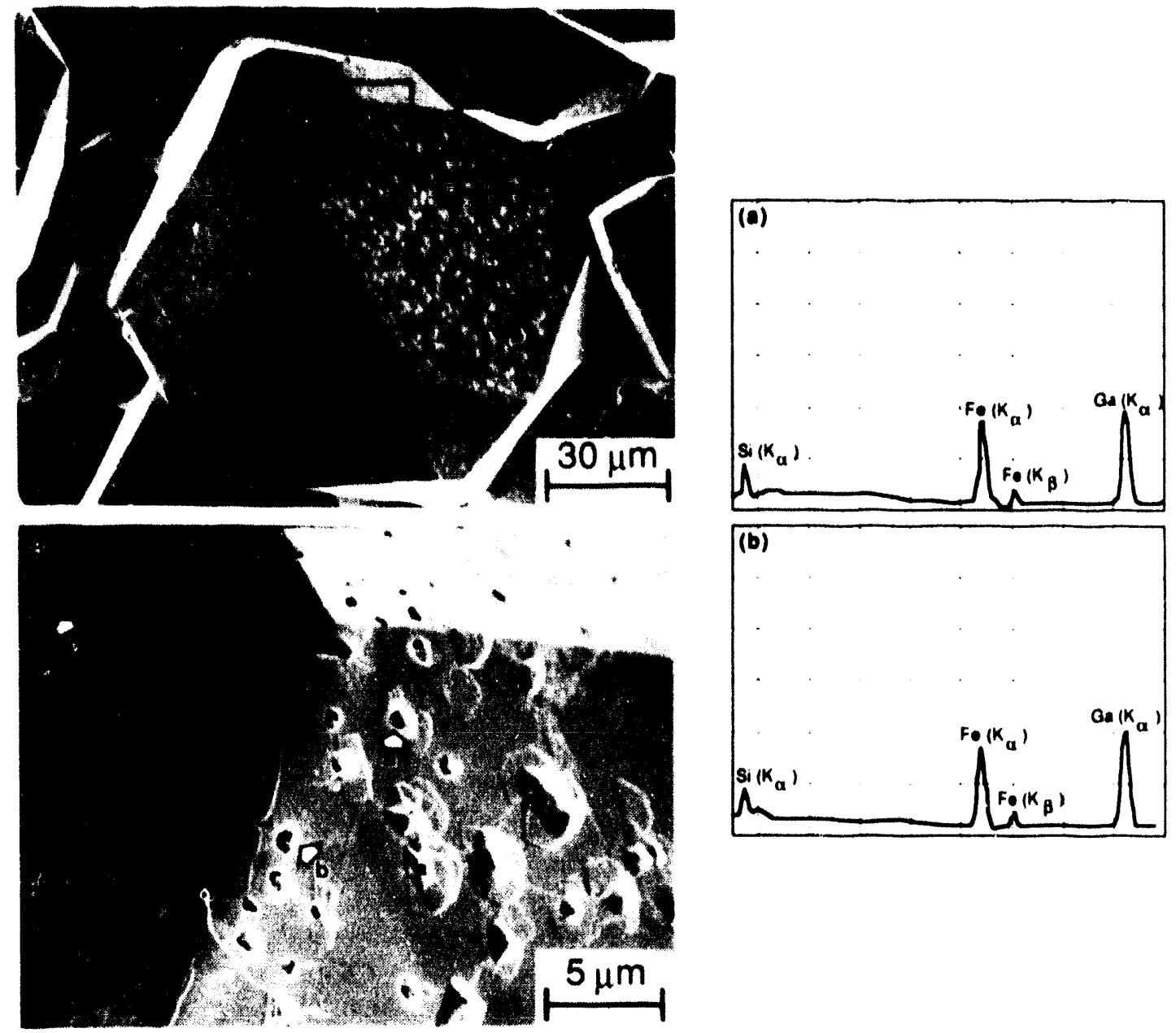

Figure 23. FeGa 3 crystals with silicon imperfections grown during exposure of Type 316 SS to liquid gallium, together with corresponding EDS spectra

Inconel alloy than for the stainless steel. The solubility of nioblum, molybdenum, and zirconium in gallium is relatively low, and it is expected that the niobium alloy will experience little or no measurable corrosion at the present exposure times and temperatures.

An Arrhenius plot of the corrosion rates of various metals and alloys is shown in Fig. 24. In all cases, linear-rate-law for metal loss was assumed to determine the corrosion rates. These values may represent a conservative estimate of corrosion. Results of Yatsenko ${ }^{19}$ for high-alloy steels Kh18N9T (Fe-18 Cr-9 Ni-0.6 Ti) and KhN77TYu (Ni-21 Cr-2.6 Ti-0.8 Al) ex posed to gallium under dynamic conditions $\left(0.15 \mathrm{~m} / \mathrm{s}\right.$ flow velocity) at 250 and $400^{\circ} \mathrm{C}$ are also included in the figure. Corrosion rates of Inconel 625 and Type $316 \mathrm{SS}$ at $400^{\circ} \mathrm{C}$ are comparable to those of Kh18N9T and KhN77TYu but show lower values at $250^{\circ} \mathrm{C}$. The differences are most likely due to velocity effects.

Figure 24 can be used to establish the maximum temperature limit for gallium/structural alloy systems. A maximum corrosion rate is first defined on the basis of either the allowable change in section thickness of the component or allowable mass transfer in the liquid metal system. The maximum operating temperature corresponding to the maximum corrosion rate is then obtained from Fig. 24 for a specific alloy/gallium system. For example, the maximum 


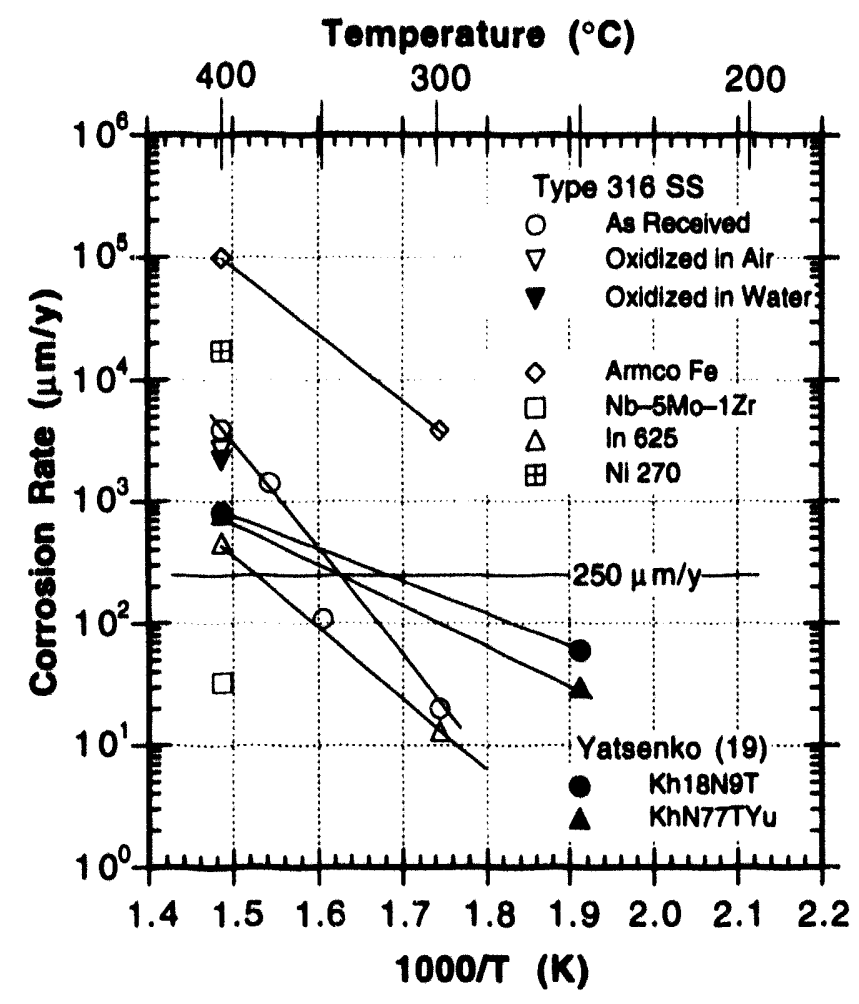

Figure 24.

Arrhenius plot of corrosion rates of various structural metals and alloys

surface temperature of a Type 316 SS component must be $<350^{\circ} \mathrm{C}$ to keep corrosion rates below $250 \mu \mathrm{m} / \mathrm{yr}$. The niloblum alloy can operate at higher temperatures for the same corrosion criterion. Figure 24 does not include the effects of system variables such as velocity and $\Delta \mathrm{T}$ on corrosion mass transfer.

\section{CONCLUSIONS}

Tests were conducted to determine the compatibility of gallium with candidate structural materlals for ITER, 1.e., Type 316 SS, Inconel 625, and $\mathrm{Nb}-5 \mathrm{Mo}-1 \mathrm{Zr}$ alloy, as well as Armco Iron. Nickel 270, and pure chromium. The pure metals reacted rapidly with gallium. In contrast to earlier studies, pure iron showed greater corrosion than nickel. The corrosion rates for Armco iron and Nickel 270 at $400^{\circ} \mathrm{C}$ were $\geq 88$ and $18 \mathrm{~mm} / \mathrm{yr}$, respectively. Corrosion of ironbased Type $316 \mathrm{SS}$ was greater than that of nickel-base Inconel 625 . The $\mathrm{Nb}-5 \mathrm{Mo}-1 \mathrm{Zr}$ alloy was most resistant to corrosion in static gallium. At $400^{\circ} \mathrm{C}$, corrosion rates were $\approx 4.0,0.5$, and $0.03 \mathrm{~mm} / \mathrm{yr}$ for Type $316 \mathrm{SS}$, Inconel 625 , and $\mathrm{Nb}-5 \mathrm{Mo}-1 \mathrm{Zr}$, respectively. However, inter granular attack of the cold-worked region in the nioblum alloy was observed. The results indicate that, at temperatures up to $400^{\circ} \mathrm{C}$, corrosion occurred primarlly by dissolution, accompanied by formation of metal/gailium intermetallic compounds. The growth of intermetallic compounds may control the overall rate of corrosion. The formation of an $\mathrm{FeCr}_{2} \mathrm{O}_{4}$ compound on the surface of Type 316 SS before exposure to liquid gallium did not provide protection against corrosion. The oxdde coating dissociated to form a spinel-type oxide of the form $\mathrm{NiFeGaO}_{4}$, and corrosion of the alloy proceeded by dissolution and formation of intermetallic compounds. 


\section{ACKNOWLEDGMENTS}

The authors thank C. B. Reed, P. M. Dombrowski, and R. C. Clark for contributing to the experimental effort, B. S. Tani for performing $\mathrm{X}$-ray diffraction analyses, and T. F. Kassner for helpful discussions.

\section{REFERENCES}

1. L. R. Kelman, W. D. Wilkinson, and F. L. Yaggee, Resistance of Materials to Attack by Liquid Metals, Argonne National Laboratory Report ANL-4417 (July 1950).

2. W. D. Wilkinson, Effects of Gallium on Materials at Elevated Temperatures, Argonne National Laboratory Report ANL-5027 (August 1953).

3. W. D. Wilkinson, Effects of Gallium on Materials at Elevated Temperatures Supplementary Report, Argonne National Laboratory Report ANL-4582 (Aug. 1953).

4. J. C. Ballar, H. J. Emeléus, R. Nyholm, and A. F. Trotman-Dickenson, Comprehensive Inorganic Chemistry, Pergamon Press, Oxford, U.K., 993-1007 (1973).

5. F. E. Katrak and J. C. Agarwal, Gallium: Long-Run Supply, J. Met., 33, 33-36 (1981).

6. T. Q. Hua, Argonne National Laboratory, Engineering Physics Division, Personal Communication, 1993.

7. D. A. Kramer, Gallium, in Minerals Yearbook, Bureau of Mines, U.S. Dept. of the Interior, 463-467 (1990).

8. M. C. Munson, Events and Trends in Metal and Mineral Commodities, J. Met., 45, 22-28 (1993).

9. A. M. Dymov and A. P. Savostin, Analytical Chemistry of the Elements: Gallium, Ann Arbor Science Publishers, Ann Arbor, MI (1970).

10. I. A. Sheka, I. S. Chaus, and T. T. Mityureva, The Chemistry of Gallium, Elsevier Publishing Co., Amsterdam (1966).

11. C. R. Tipton, Jr., Reactor Handbook, 2nd Ed., Intersciences Publishers, Inc., New York (1960).

12. Y. S. Touloukian and E. H. Buyco, Thermophysical Properties of Matter, Vol. 4: Specific Heat, IFI/Plenum, New York (1970).

13. Y. S. Touloukian, R. W. Powell, C. Y. Ho, and P. G. Klemens, Thermophysical Properties of Matter. Vol. 1: Thermal Conductivity, IFI/Plenum, New York (1970).

14. S. P Yatsenko and Yu. A. Anikin, Solubility of Metals of the Fyfth Period in Liquid Gallium. Sov. Mater. Scl., 6, 333-337. (1970). 
15. S. P. Yatsenko and Yu. A. Anikin, Solubility of Metals of the Fourth Period in Liquid Gallum, Russ. Metall., 4, 118-123 (1970).

16. S. P. Yatsenko, L. N. Rykova, Yu. A. Anikin, and E. N. Dieva, The Corrosion of Group VIII Metals in Liquid Gallium, Sov. Mater. Scl., 8, 310-313 (1972).

17. S. P. Yatsenko, Correlation Between the Physical Properties of Pure Solid Metals with Their Stability in Liquid Ga Metal, Russ. J. Phys. Chem., 45, 1095-1098 (1971).

18. C. Guminski, Solubility of Metals in Liquid Low-Melting Metals. Z. Metallkd., 81, 105-110 (1990).

19. S. P. Yatsenko, Gallium. Its Interaction With Metals, Nauka, Moscow (1974).

20. S. P. Yatsenko and Yu. A. Anikin, Determination of Limiting Heats of Mixing From Solubility Data in Liquid Metals, Russ. J. Phys. Chem., 45, 1104-1 106 (1971).

21. S. P. Yatsenko, E. N. Dieva, and B. N. Zagrebin. The State of Some Impurities in Liquid Gallium, Russ. Metall., 3, 77-82 (1972).

22. T. B. Massalski, ed., Binary Alloy Phase Diagrams, 2nd Ed., ASM International (1990).

23. C. B. Alcock and K. T. Jacob, Solubility and Activity of Oxygen in Liquid Gallium and Gallium-Copper Alloys, J. Less-Comm. Met., 53, 211-222 (1977).

24. K. Natesan, Influence of Nonmetallic Elements on the Compatibility of Structural Materials with Liquid Alkali Metals, J. Nucl. Mater., 116, 251-262 (1983).

25. O. Kubaschewski, E. LL. Evans, and C. B. Alcock, Metallurgical Thermochemistry, 4th Ed., Pergamon Press, New York 421-429 (1967).

26. K. G. Compton, A. Mendizza, and S. M. Arnold, Fylamentary Growth on Metal Surfaces"Whiskers," Corrosion, 7, 327-334 (1951).

27. F. C. Frank, On Tin Whiskers, Phil. Mag., 44, 854-860 (1953).

28. R. M. Fisher, L. S. Darken, and K. G. Carroll, Accelerated Growth of Tin Whiskers, Acta Mettal., 2. 368-373 (1954).

29. B. D. Dunn, Metallurgical Assessment of Spacecraft Parts and Materials, John Wiley \& Sons, New York, 316-348 (1989).

30. K. Mizuishi, Some Aspects of Bonding-Solder Deterioration Observed in Long-Lived Semiconductor Lasers: Solder Migration and Whisker Growth. J. Appl. Phys., 56, 289-295 (1984). 
31. G. M. Bouton and W. G. Bader, Migration and Whisker Growths of Tin and Solders Induced on Thin Metal Films by Direct Current and Heat. IEEE 1968 Electronic Components Conference, May 8-10, 1968, pp.135-140.

32. Y. Takeuchi and K. Fujiwara, Pb Whisker Growth from Liquid Phase and Pb-alloy Josephson Device Chips, J. Appl. Phys, 54, 6053-6054 (1983).

33. T. E. Turner and R. D. Parsons, A New Failure Mechanism: Al-Si Bond Pad Whisker Growth During Life Test, IEEE Transactions on Components Hybrids and Manuf. Technol., 5 431-435 (1982). 


\section{APPENDIX A: \\ COMPOSITE PHOTOMICROGRAPHS FROM METALLOGRAPHIC EXAMINATION}

After cleaning, each specimen was sectioned, mounted in copper-filled epoxy, and polished. Some of the specimens were etched to reveal signs of grain-boundary attack. Table Al describes the preparation methods used for each material tested. The composite photomicrographs shown in this appendix are all displayed the same way. A low-magnification view of the specimen cross section is shown at the bottom of each figure. A high-magnification view of the reaction interface in the cold-worked area of the specimen is shown in the upper left, and in the upper right is a high-magnification view of the reaction interface in a noncold-worked area. The photomicrographs are presented according to increasing exposure time within each exposure temperature. The specimen identification number (within parentheses) refers directly to the specimen number in the first column of Tables 7 and 8.

Table A1. Preparation of postexposure specimens for examination by SEM

\begin{tabular}{|c|c|c|}
\hline \multirow[b]{2}{*}{ Material } & \multicolumn{2}{|c|}{ Grain-boundary etch procedure } \\
\hline & Etchant & Conditions \\
\hline Type 316 SS & $\begin{array}{l}\text { electrolytic etch with } 10 \% \text { oxalic acid } \\
\text { solution; immersed specimen }\end{array}$ & $\approx 30 \mathrm{~s}$ at $15 \mathrm{~V} ;$ Pt cathode \\
\hline Inconel 625 & $\begin{array}{l}\text { electrolytic etch with } 10 \% \text { oxalic acid } \\
\text { solution: immersed specimen }\end{array}$ & $\approx 5 \mathrm{~s}$ at $5-10 \mathrm{~V}:$ Pt cathode \\
\hline Armco Iron & $\begin{array}{l}\text { solution of } 1 \mathrm{~mL} \mathrm{HNO}_{3} \text { and } \\
40 \mathrm{~mL} \mathrm{H}_{2} \mathrm{O}\end{array}$ & immerse specimen for $15 \mathrm{~s}$ \\
\hline Nickel 270 & $\begin{array}{l}\text { solution of } 10 \mathrm{~g} \mathrm{CuSO}_{4} .50 \mathrm{~mL} \mathrm{HCl} \text {. } \\
50 \mathrm{~mL} \mathrm{H} \mathrm{H}_{2} \mathrm{O} \approx 1 \mathrm{~mL} \mathrm{H}_{2} \mathrm{SO}_{4}\end{array}$ & immerse specimen for $\approx 5 \mathrm{~min}$ \\
\hline $\mathrm{Nb}-5 \mathrm{Mo}-1 \mathrm{Zr} \mathrm{r}^{\mathrm{a}}$ & $\begin{array}{l}\text { solution of } 20 \mathrm{~mL} \mathrm{HF}, 15 \mathrm{~mL} \mathrm{H}_{2} \mathrm{SO}_{4} \text {, } \\
10 \mathrm{~mL} \mathrm{HNO}, 50 \mathrm{~mL} \mathrm{H} \mathrm{H}_{2} \mathrm{O}\end{array}$ & $\begin{array}{l}\text { swab on polishing cloth with } \approx 2 \text { drops } \\
\text { solution for } \approx 30 \mathrm{~s}\end{array}$ \\
\hline
\end{tabular}

a The niobium-based alloy was vibratory-polished with $0.05 \mu \mathrm{m}$ suspended alumina for $48 \mathrm{~h}$ after initial polishing with SiC paper. 
Type 316 Stainless Steel

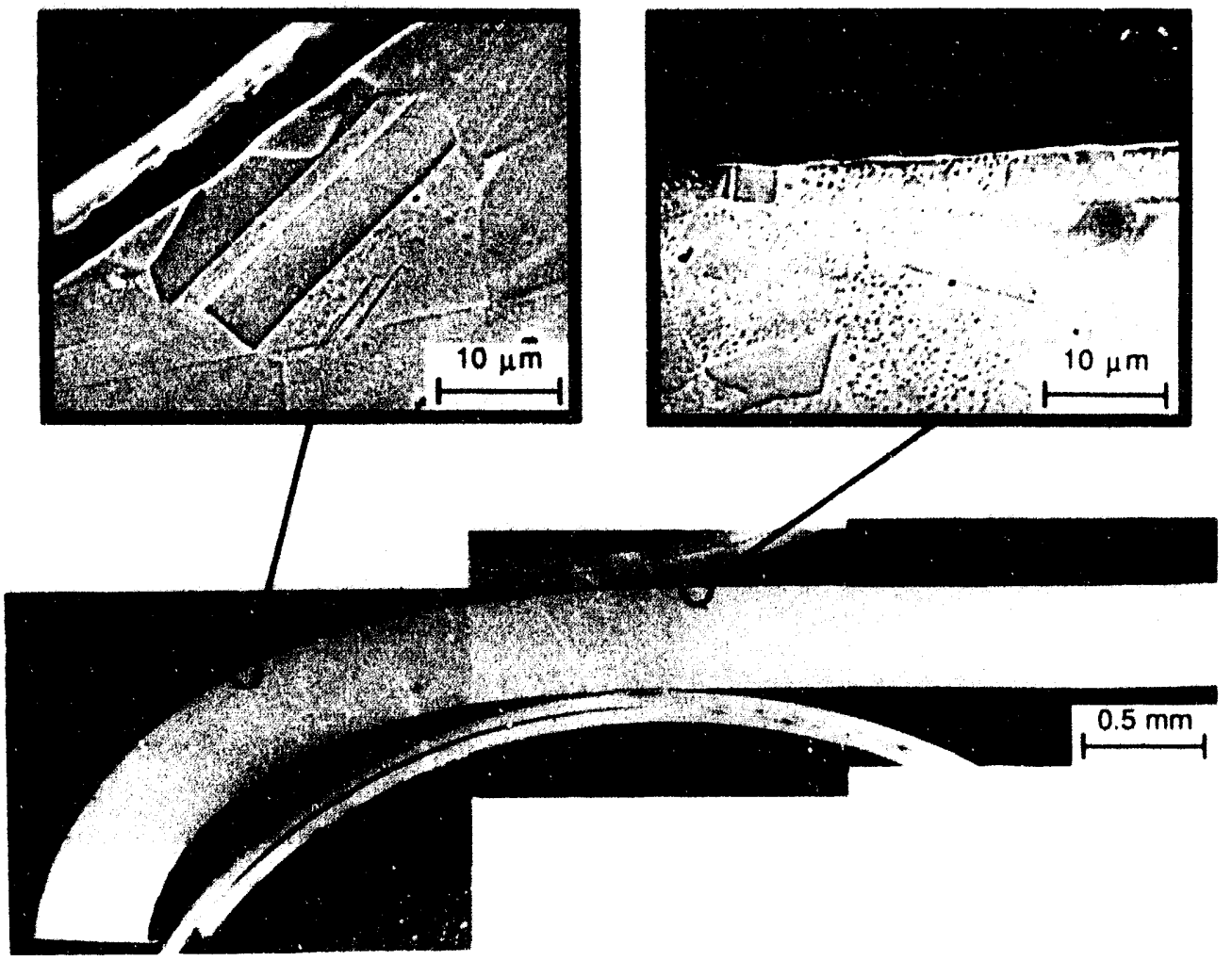

Figure A1. Type $316 \mathrm{SS}$ exposed in gallium for $300 \mathrm{~h}$ at $200^{\circ} \mathrm{C}$ (SS-2C)

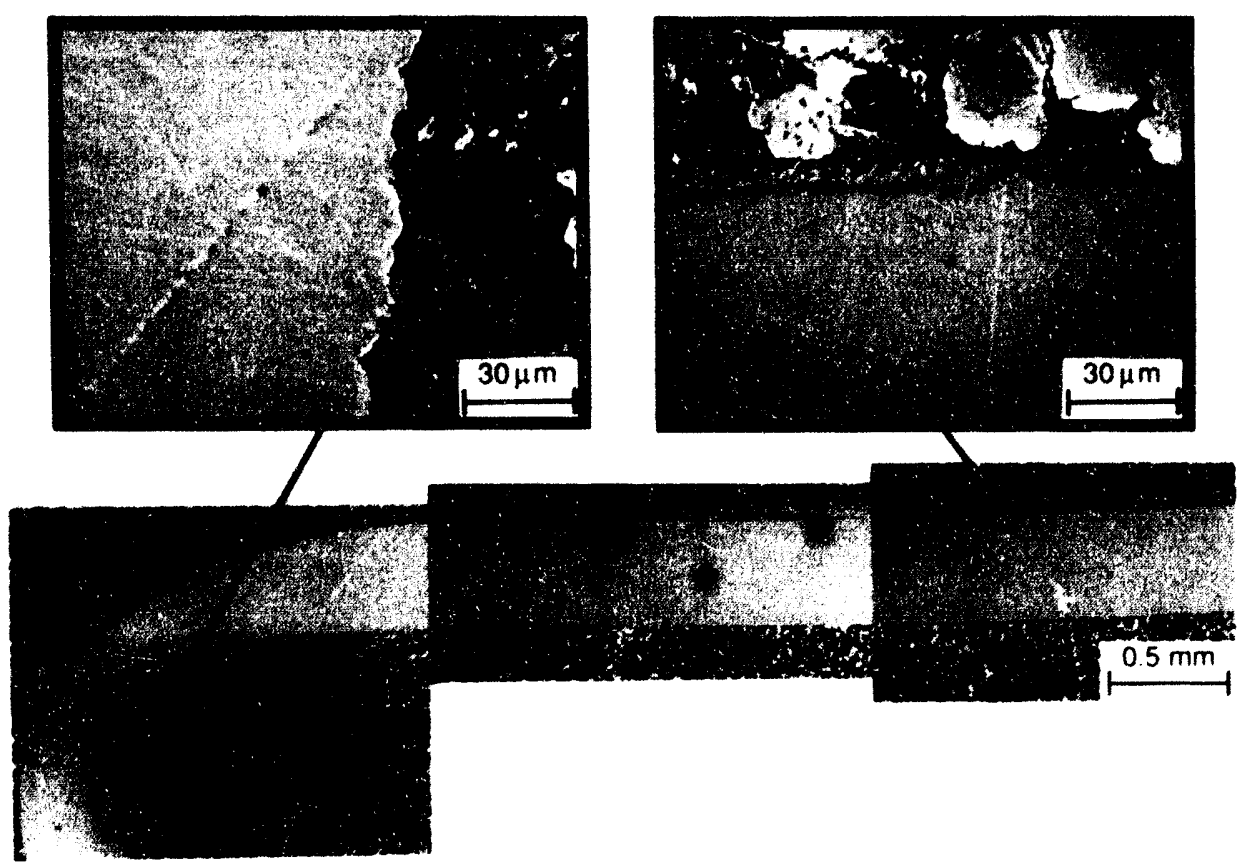

Figure A2. Type $316 \mathrm{SS}$ exposed in gallum for $1000 \mathrm{~h}$ at $200^{\circ} \mathrm{C}$ (SS-2D) 


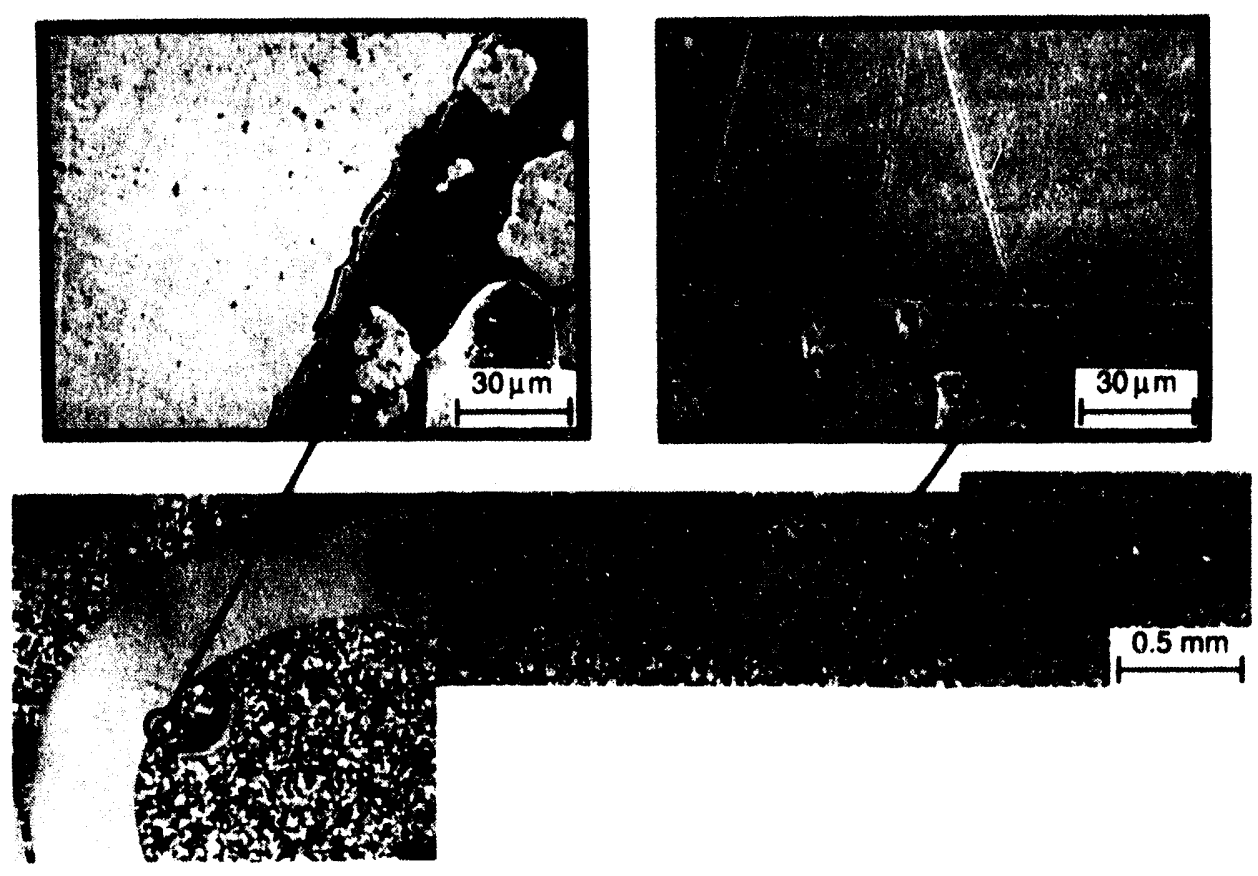

Figure A3. Type 316 SS exposed in gallum for $3000 \mathrm{~h}$ at $200^{\circ} \mathrm{C}$ (SS-2E)

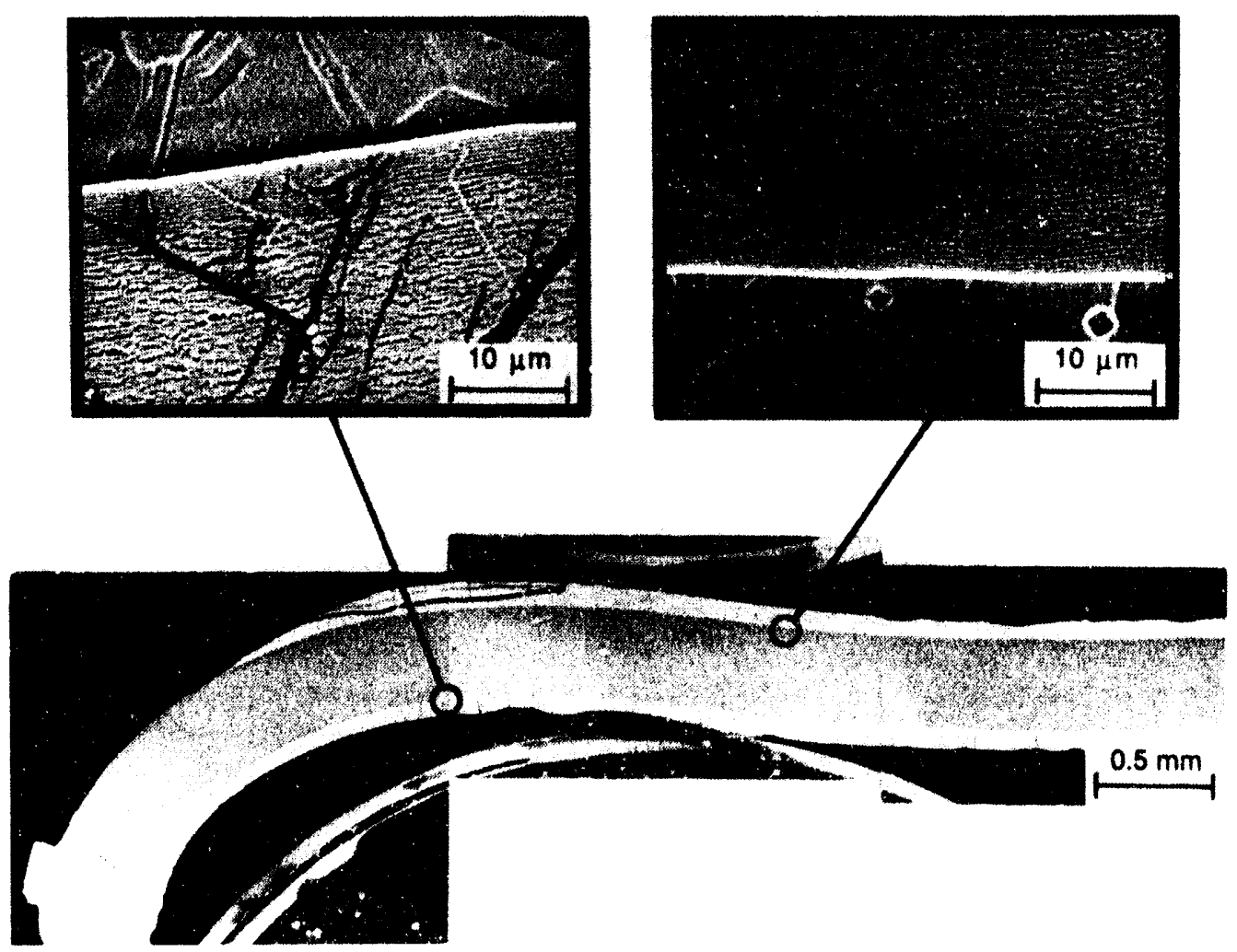

Figure A4. Type $316 \mathrm{SS}$ exposed in gallium for $300 \mathrm{~h}$ at $200^{\circ} \mathrm{C}$ after initial exposure for $24 \mathrm{~h}$ at $400^{\circ} \mathrm{C}$ (SS-24C) 


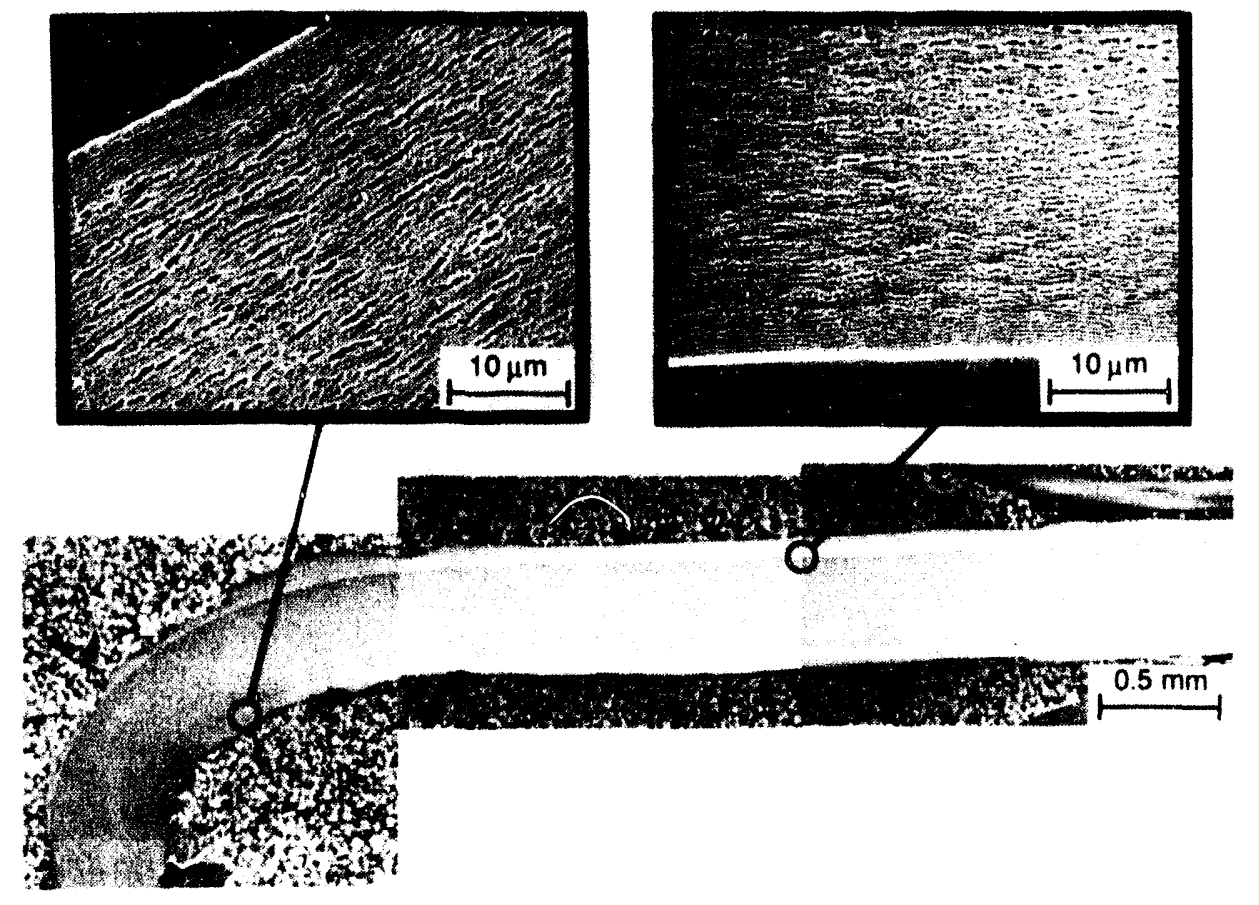

Fyure A5. Type $316 \mathrm{SS}$ exposed in gallum for $1008 \mathrm{~h}$ at $200^{\circ} \mathrm{C}$ after initial exposure for $24 \mathrm{~h}$ at $400^{\circ} \mathrm{C}$ (SS-24D)

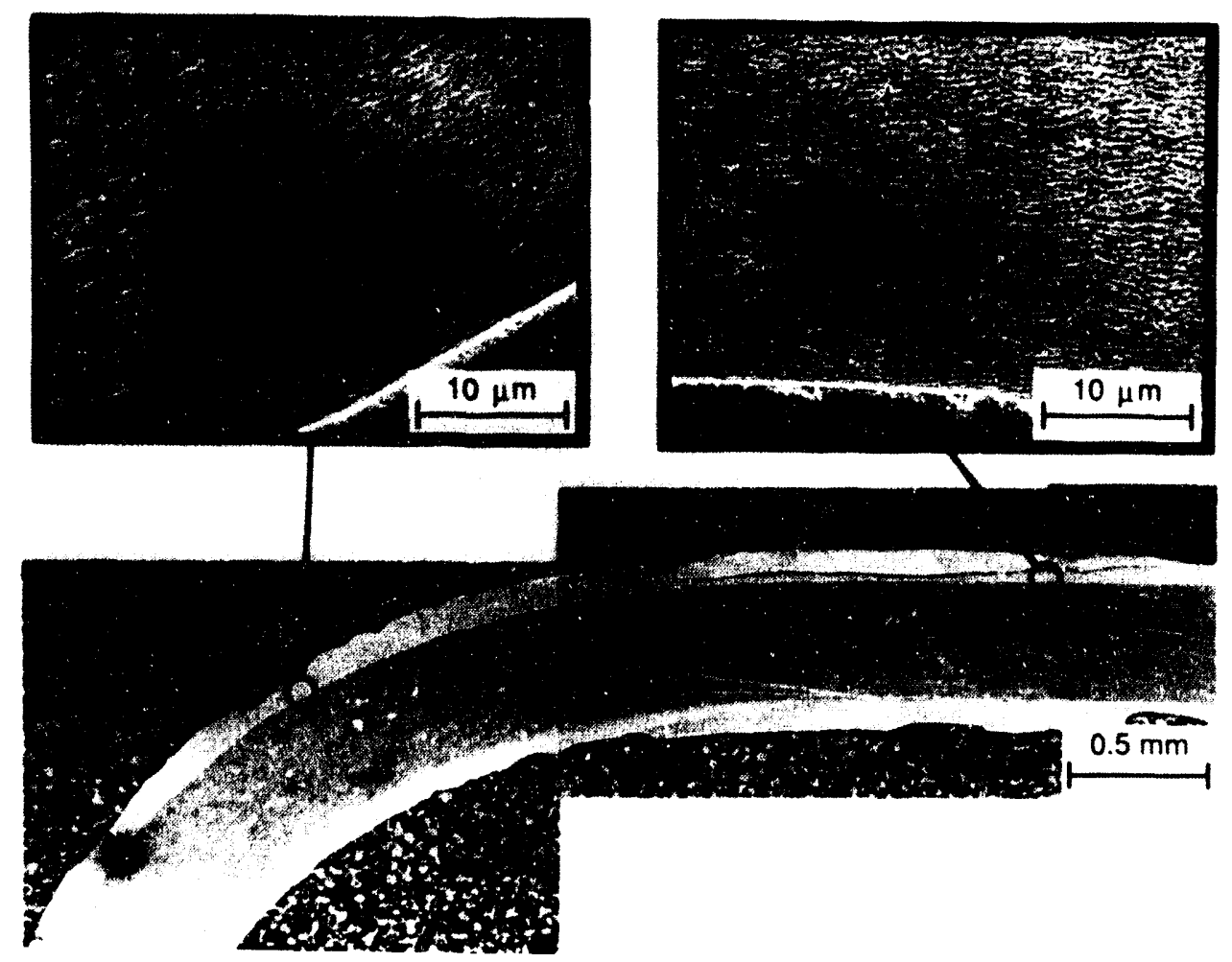

Figure A6. Type $316 \mathrm{SS}$ exposed in gallum for $3000 \mathrm{~h}$ at $200^{\circ} \mathrm{C}$ after initial exposure for $24 \mathrm{~h}$ at $400^{\circ} \mathrm{C}$ (SS-24E) 


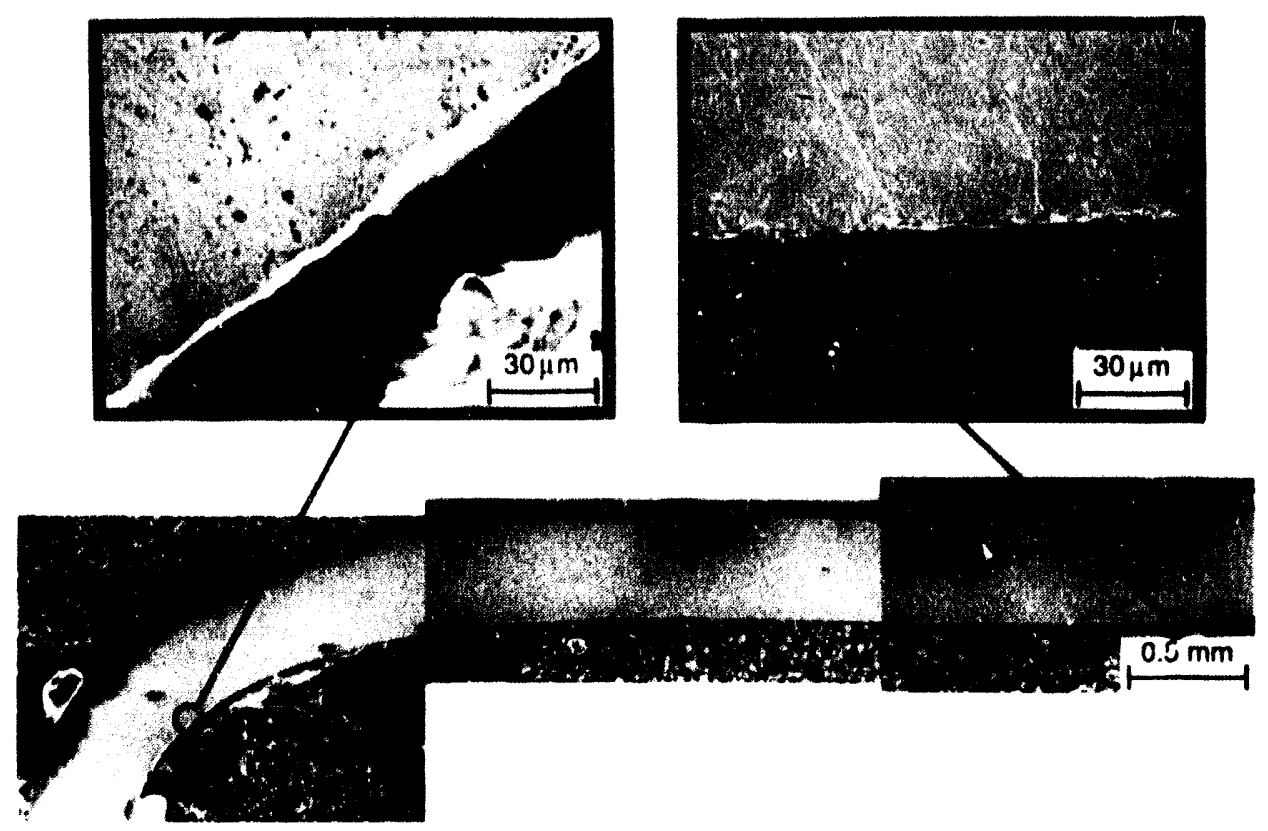

Flgure A7. Type $316 \mathrm{SS}$ exposed in galltum for $100 \mathrm{~h}$ at $300^{\circ} \mathrm{C}$ (SS-3B)

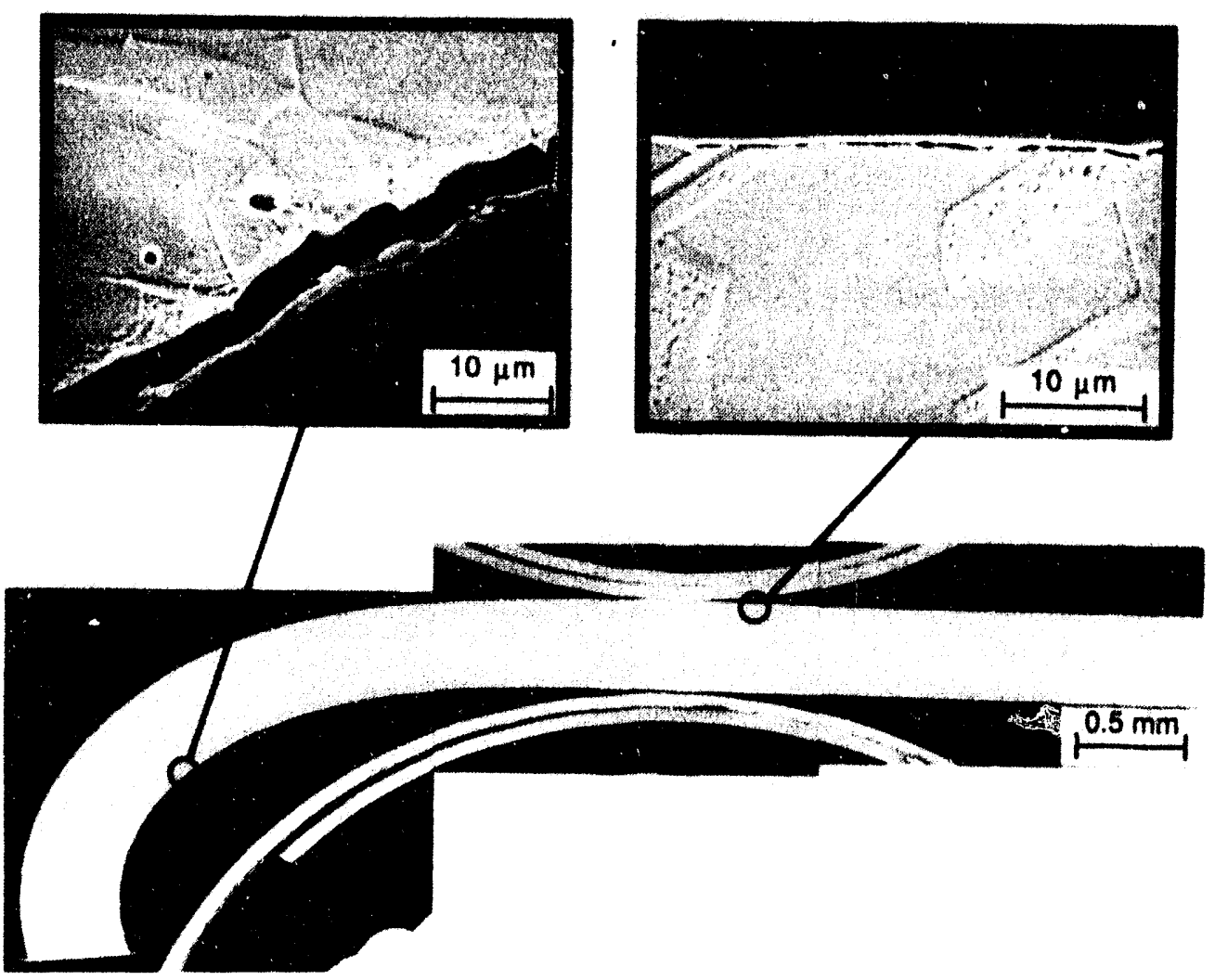

Figure A8. Type $316 \mathrm{SS}$ exposed in gallium for $300 \mathrm{~h}$ at $300^{\circ} \mathrm{C}$ (SS-3C-A) 


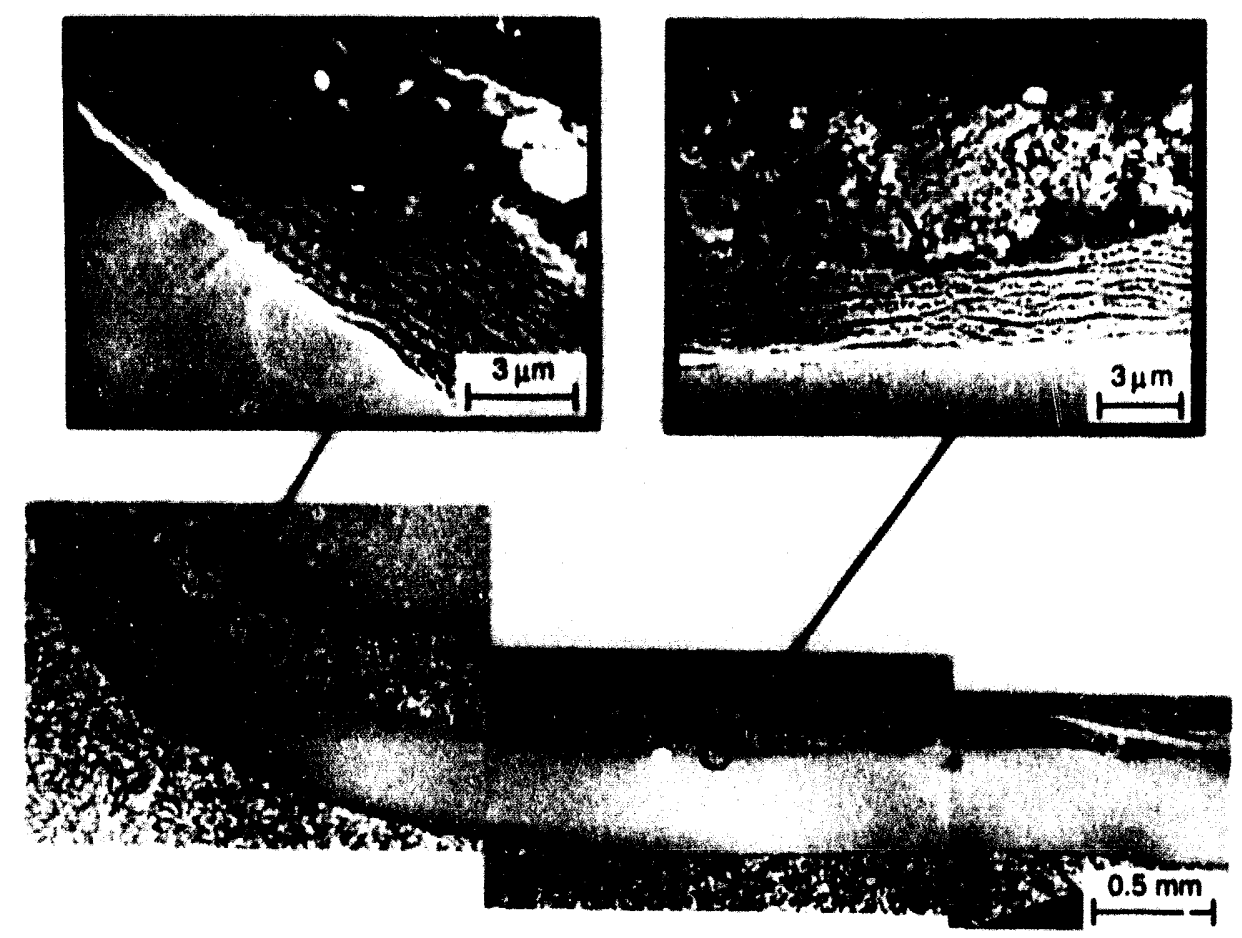

FYgure A9. Type 316 SS exposed in gallium for 1008 h at $300^{\circ} \mathrm{C}$ (SS-3D)

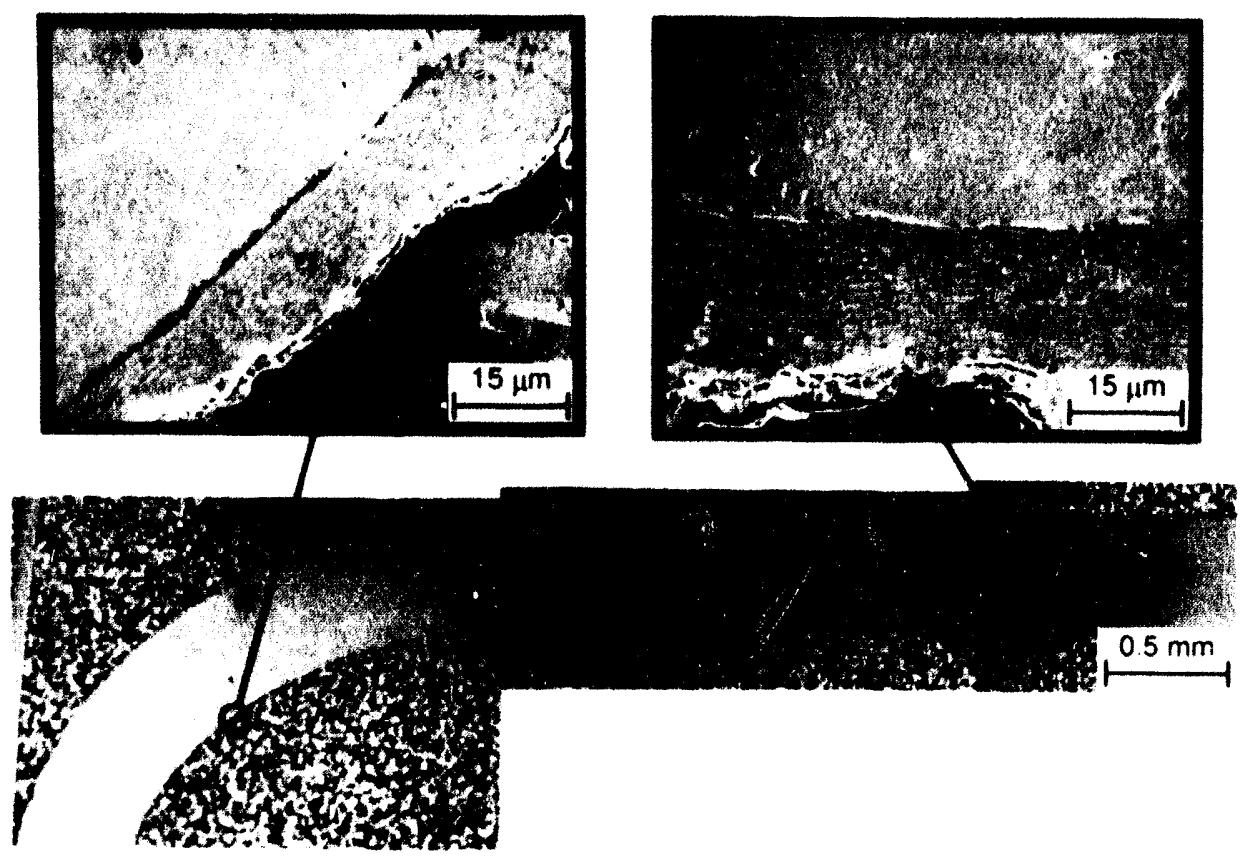

Figure A10. Type $316 \mathrm{SS}$ exposed in gallium for $3000 \mathrm{~h}$ at $300^{\circ} \mathrm{C}$ (SS-3E) 


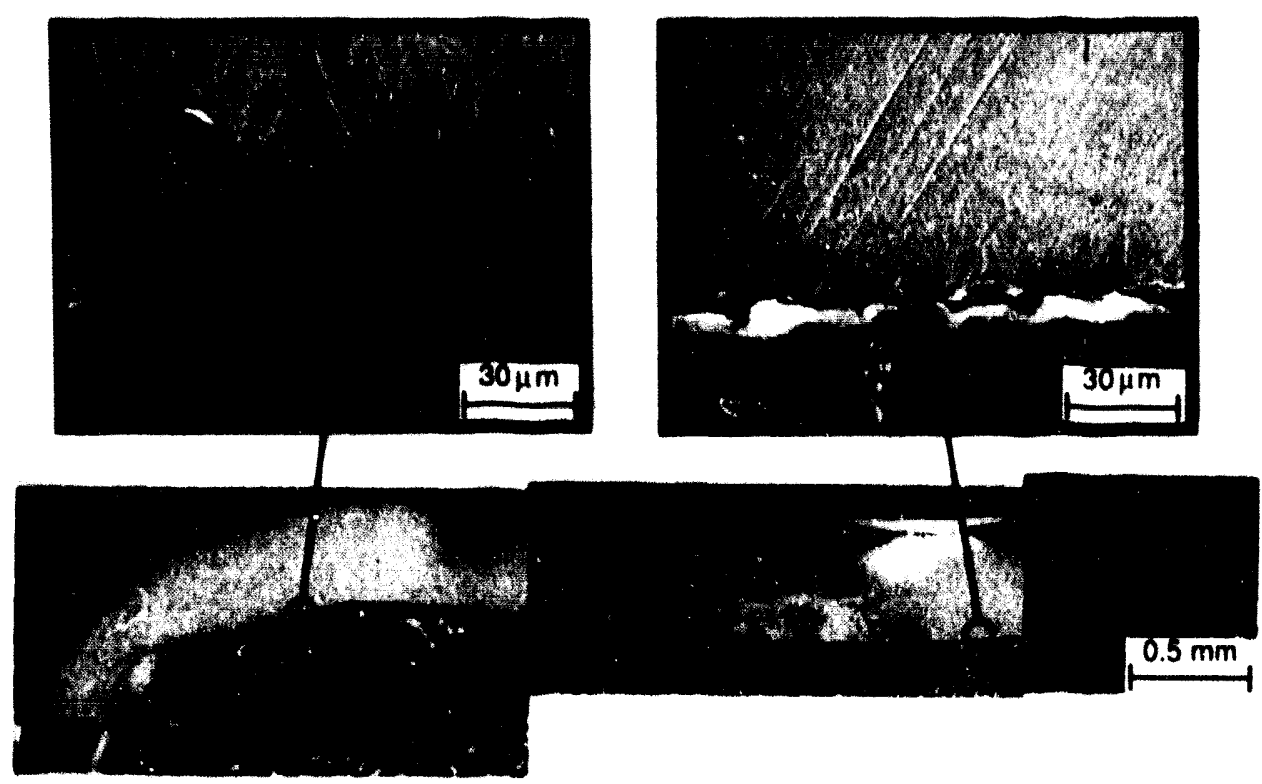

Figure A1 1. Type 316 SS exposed in gallum for $300 \mathrm{~h}$ at $320^{\circ} \mathrm{C}$ (SS-3C-B)

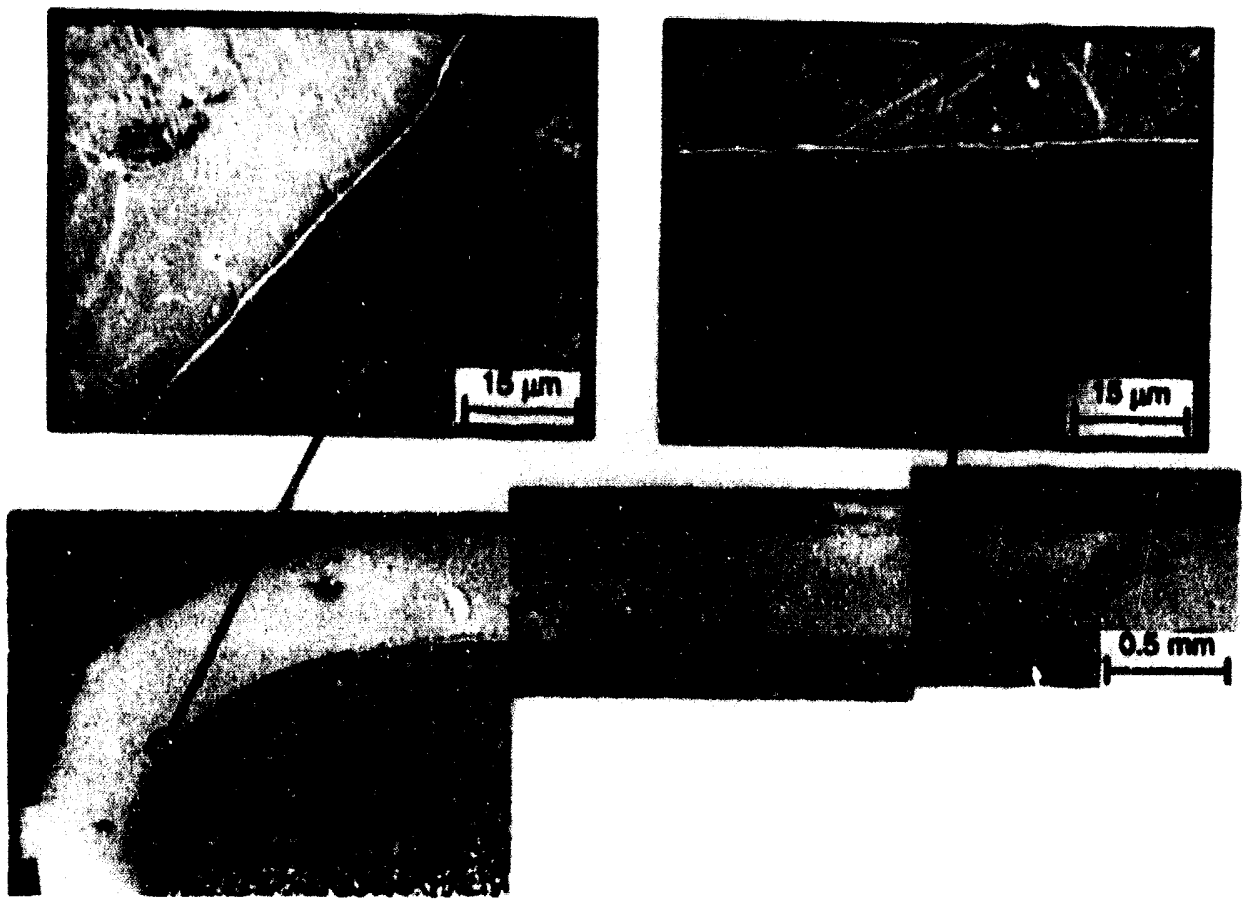

Figure A12. Type 316 SS exposed in gallum for $300 \mathrm{~h}$ at $350^{\circ} \mathrm{C}$ (SS-3C-C) 


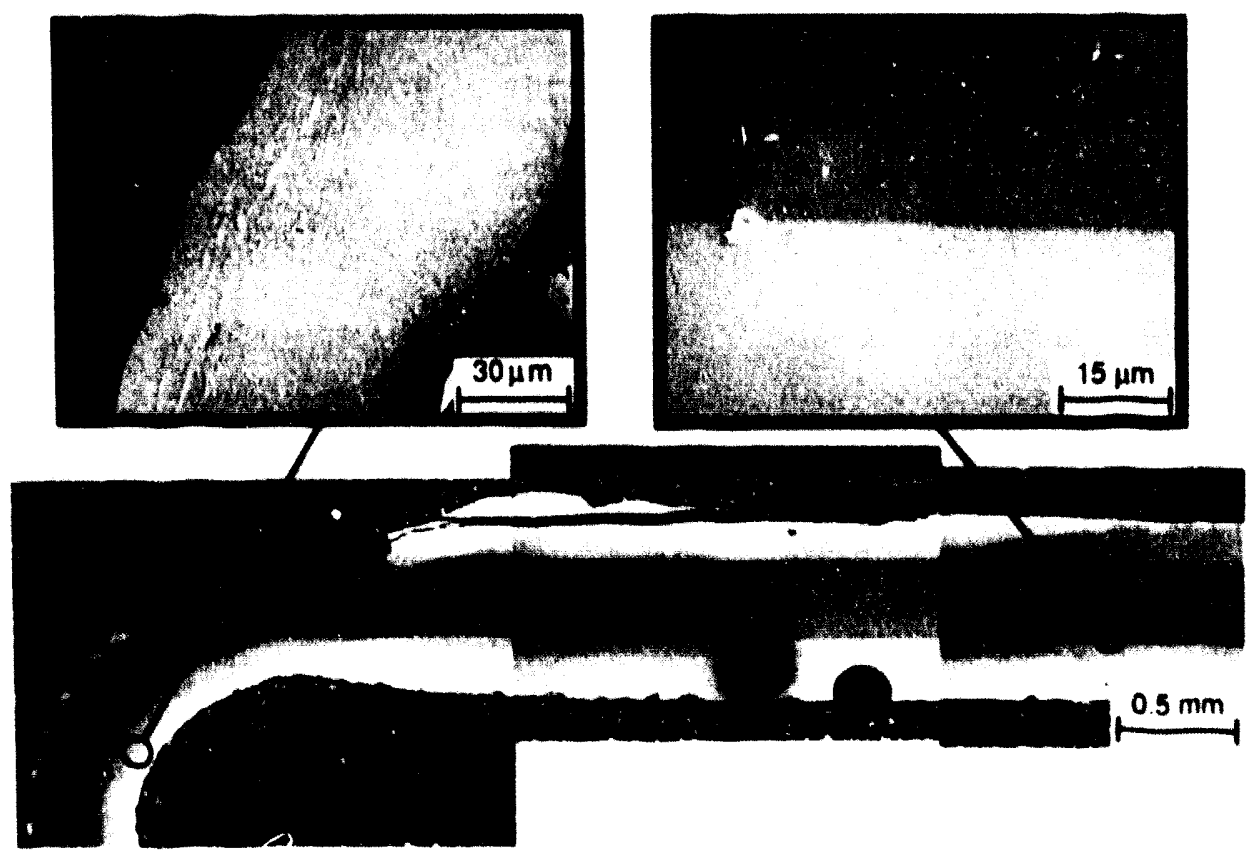

Fyure A13. Type 316 SS exposed in gallium for $300 \mathrm{~h}$ at $375^{\circ} \mathrm{C}$ (SS-3C-D)

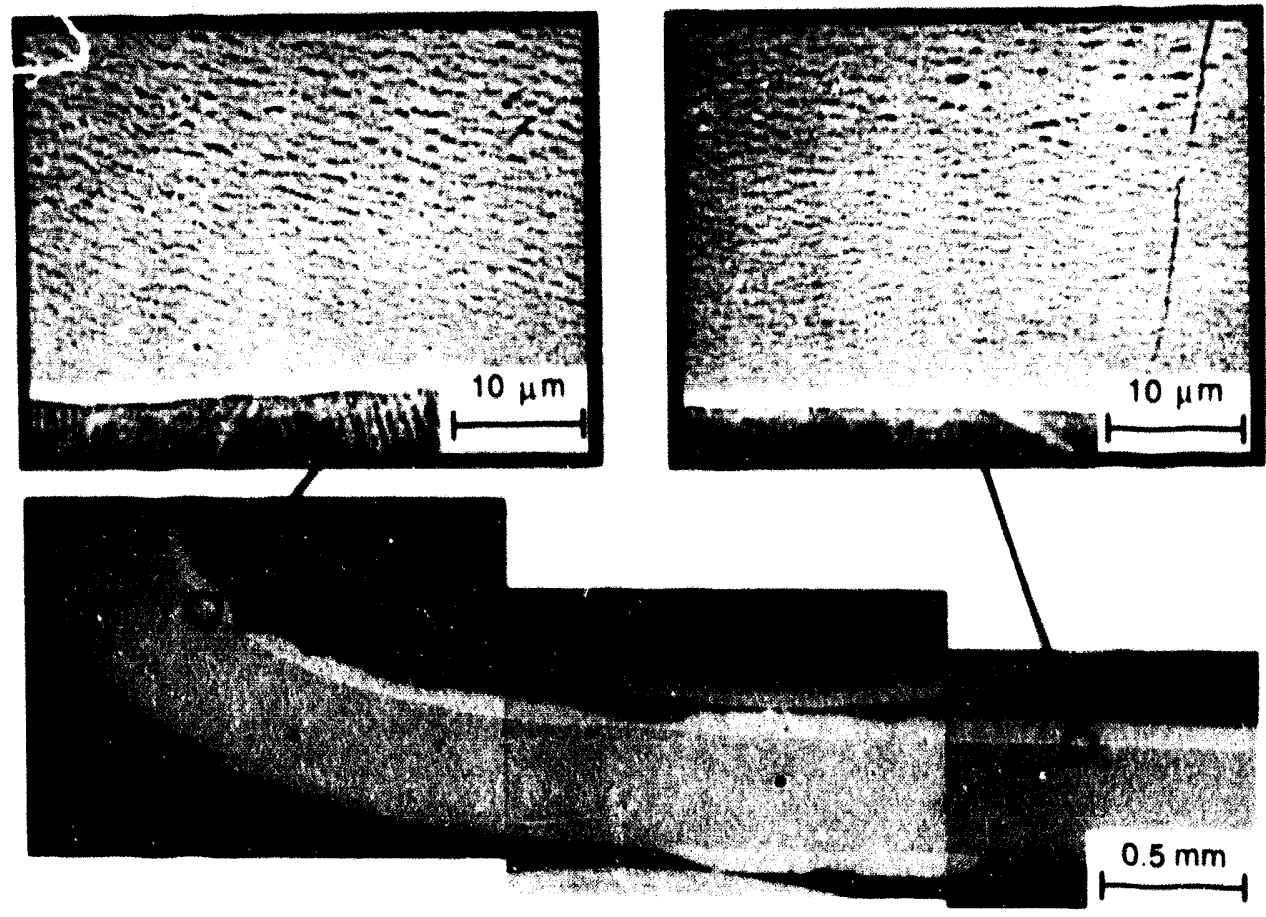

Figure A14. Type 316 SS exposed in gallum for $24 \mathrm{~h}$ at $400^{\circ} \mathrm{C}$ (SS-4A) 


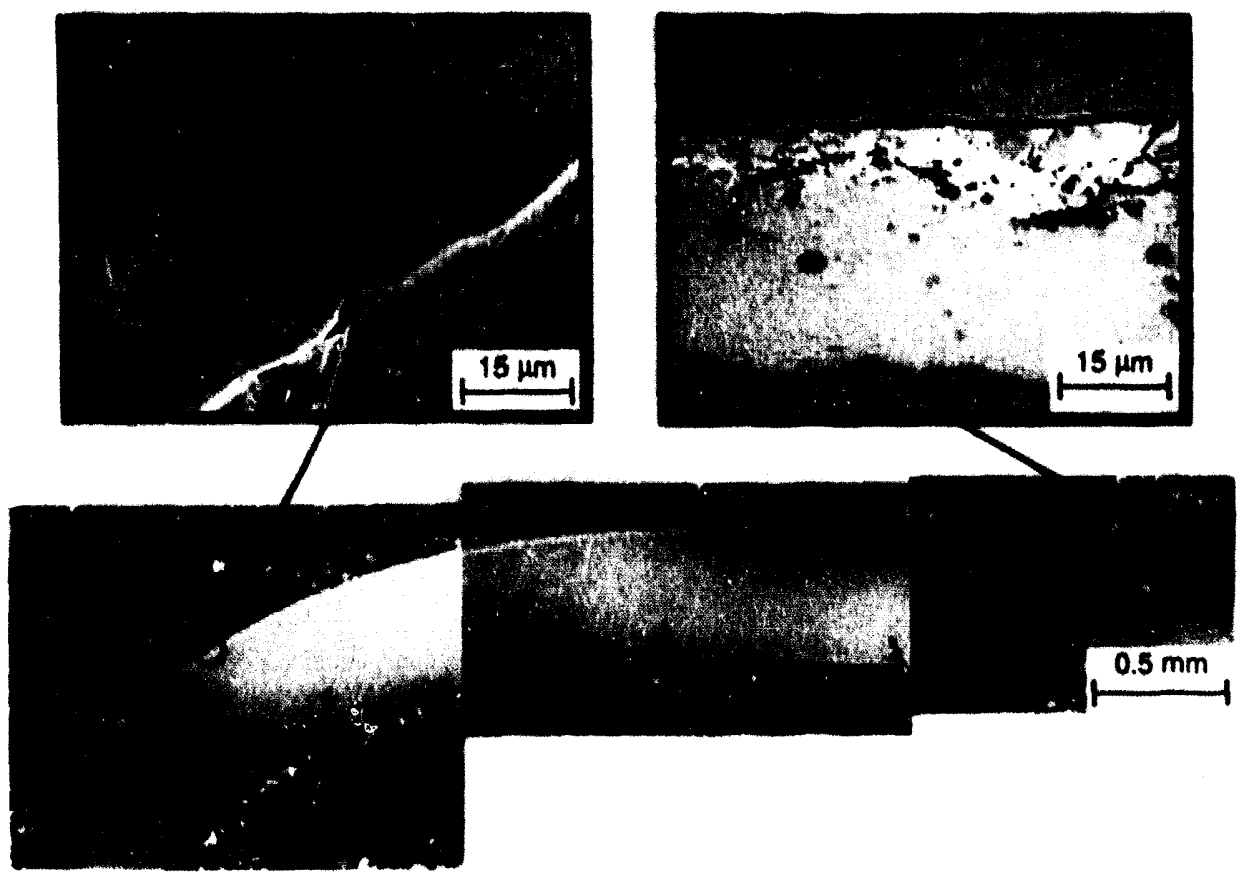

Figure A 15. Type $316 \mathrm{SS}$ exposed in gallum for $48 \mathrm{~h}$ at $400^{\circ} \mathrm{C}$ (SS-4F)

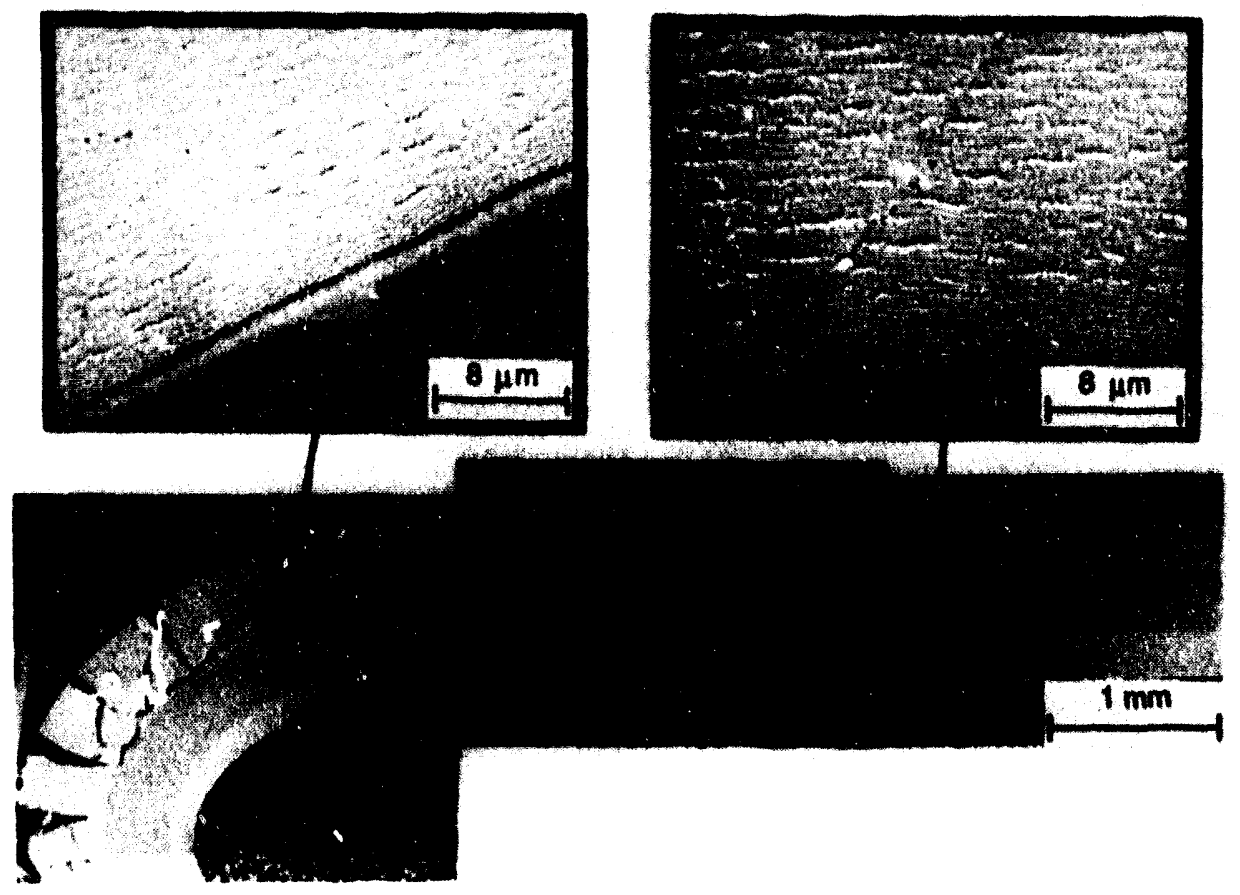

Flgure A16. Type 316 SS exposed in gallium for $100 \mathrm{~h}$ at $400^{\circ} \mathrm{C}$ (SS-4B) 


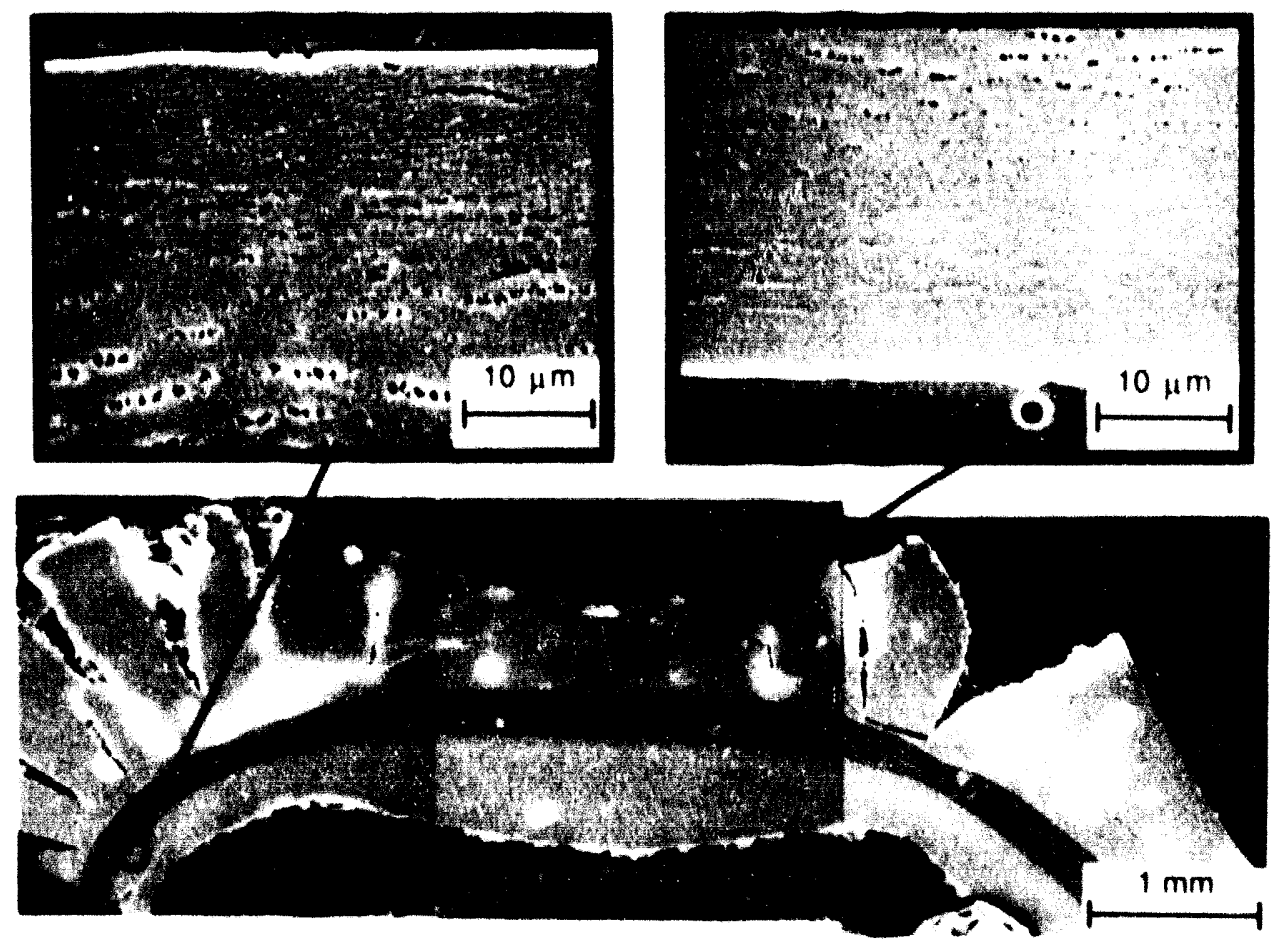

Figure A17. Type $316 \mathrm{SS}$ exposed in gallium for $300 \mathrm{~h}$ at $400^{\circ} \mathrm{C}$ (SS-4C)

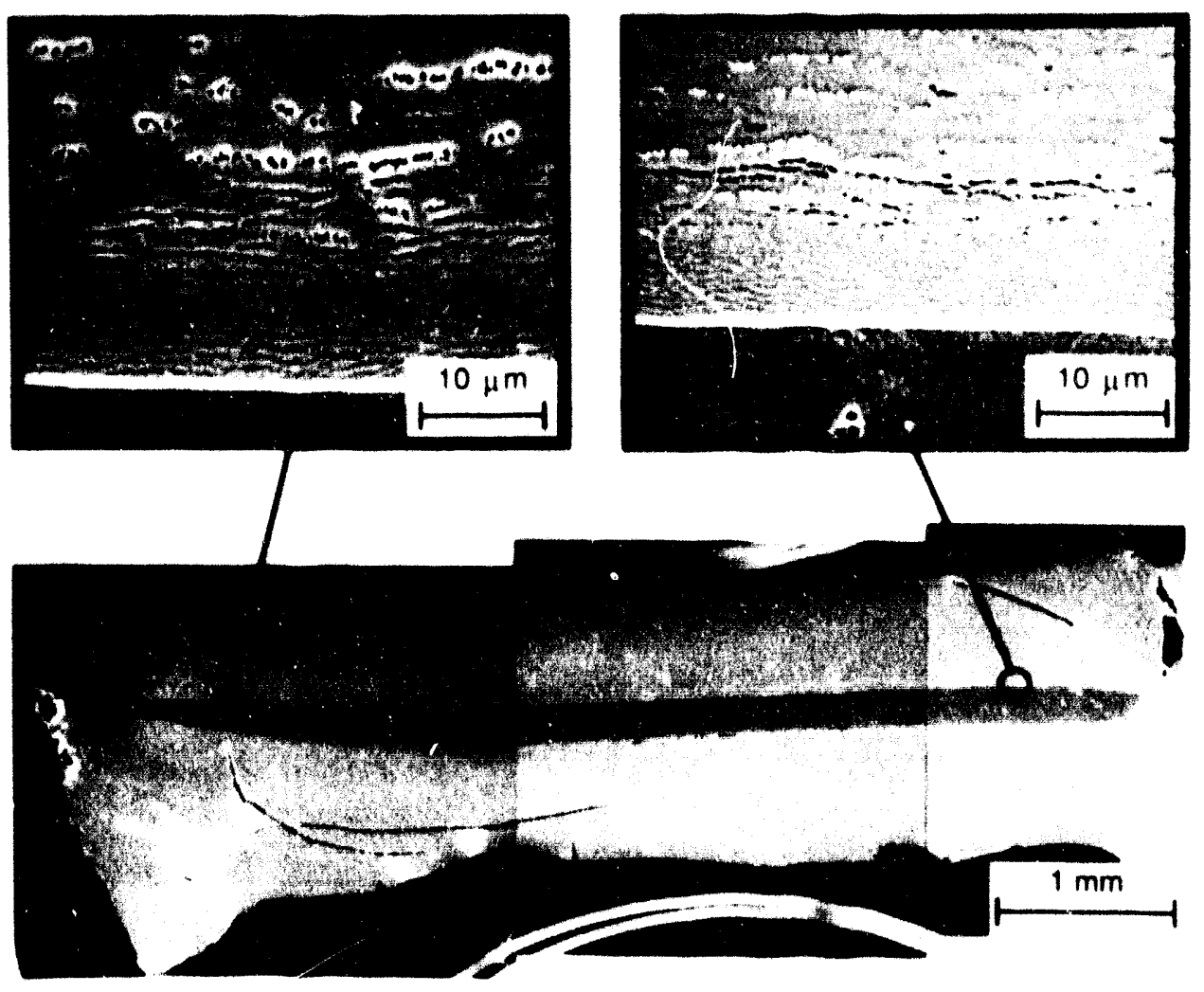

Figure A18. Type $316 \mathrm{SS}$ exposed in gallium for $1076 \mathrm{~h}$ at $400^{\circ} \mathrm{C}$ (SS-4E) 


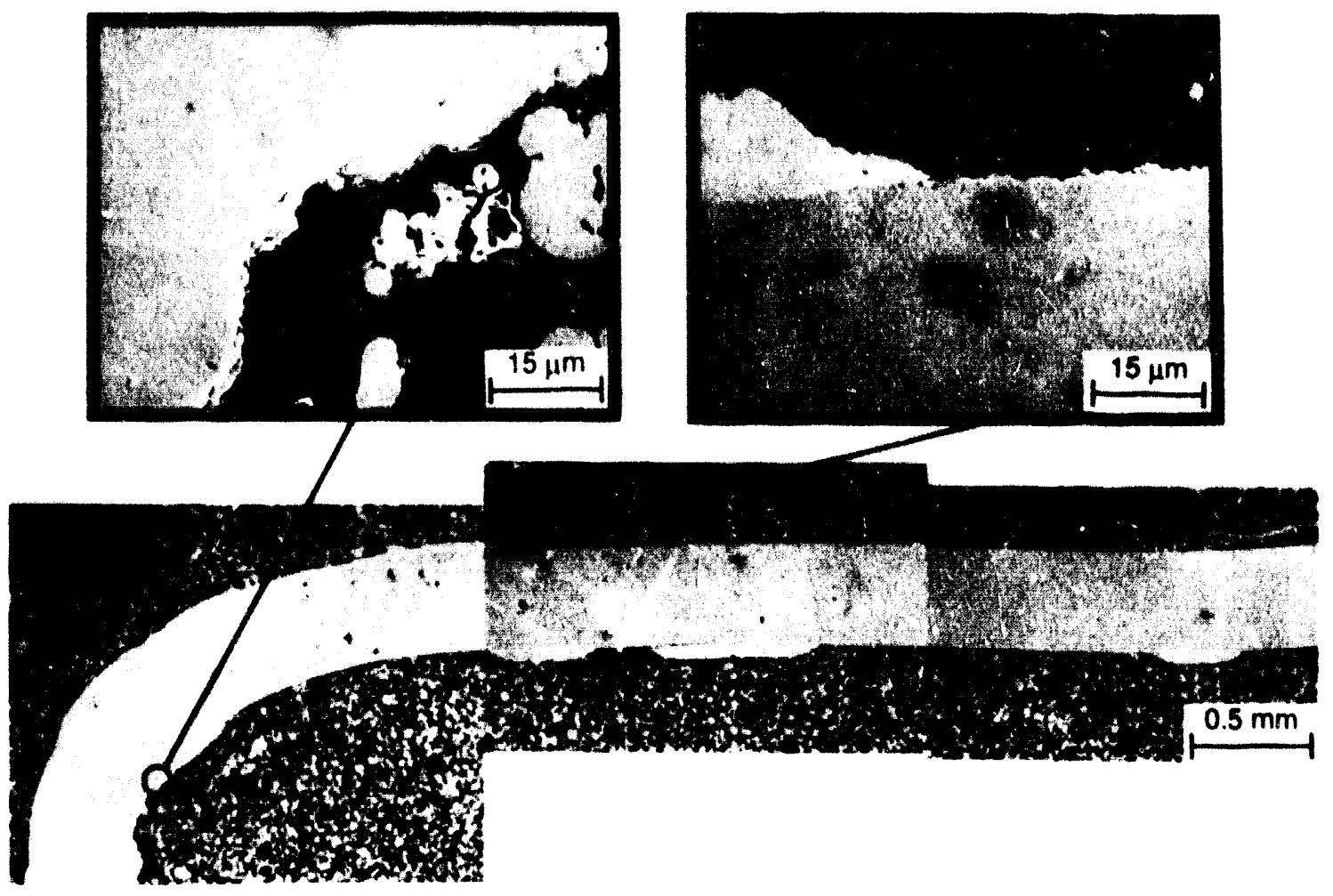

Figure A 19. Type $316 \mathrm{SS}$ exposed in gallium for $100 \mathrm{~h}$ at $400^{\circ} \mathrm{C}$ after axidation in atr for $100 \mathrm{~h}$ at $350^{\circ} \mathrm{C}$ (SSA-4B)

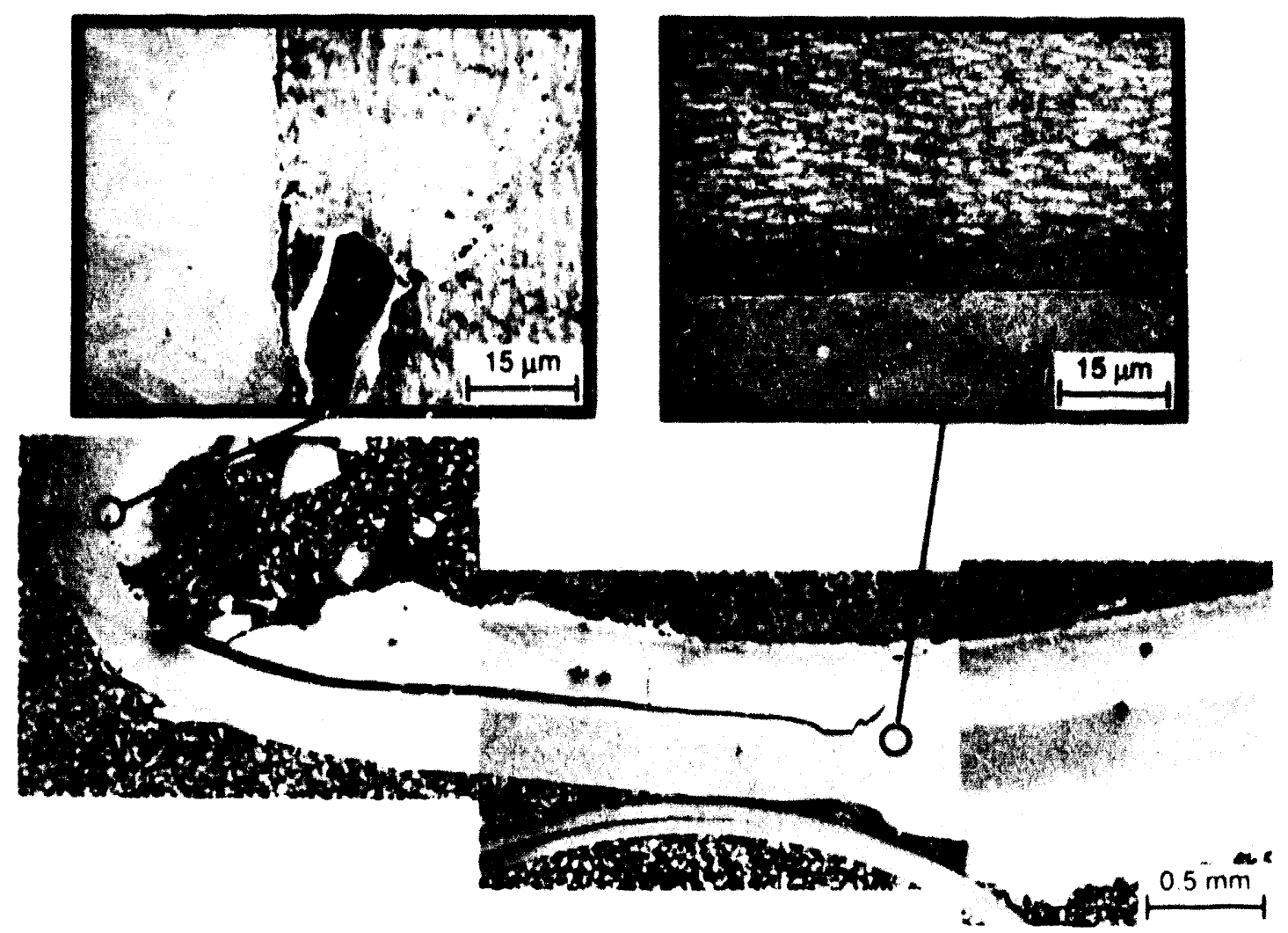

Figure A20. Type $316 \mathrm{SS}$ exposed in gallum for $300 \mathrm{~h}$ at $400^{\circ} \mathrm{C}$ after axidation in air for $100 \mathrm{~h}$ at $350^{\circ} \mathrm{C}$ (SSA-4C) 


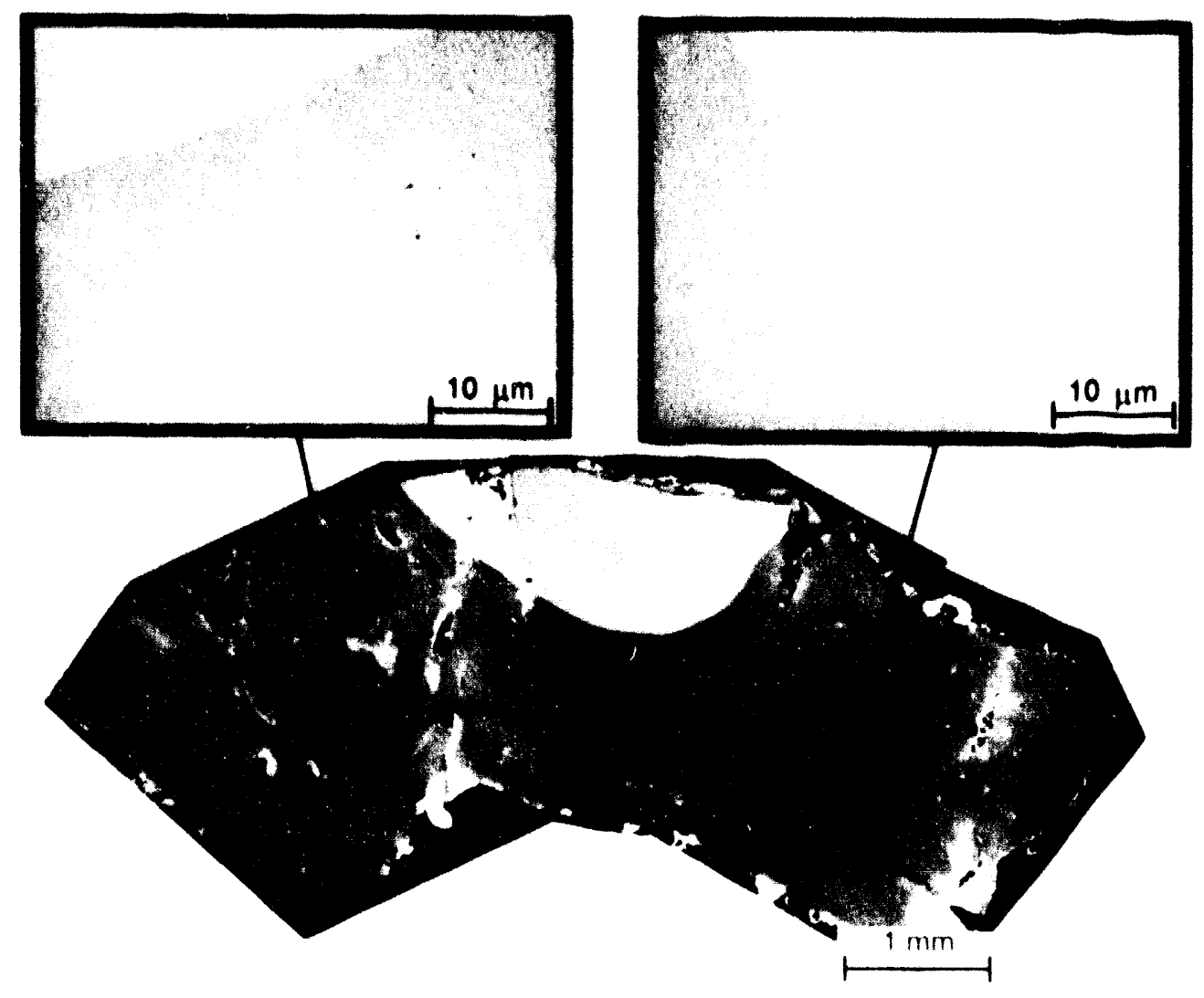

Figure A21. Type $316 \mathrm{SS}$ exposed in gallium for $1000 \mathrm{~h}$ at $400^{\circ} \mathrm{C}$ after aridation in at for $100 \mathrm{~h}$ at $350^{\circ} \mathrm{C}$ (SSA-4D)

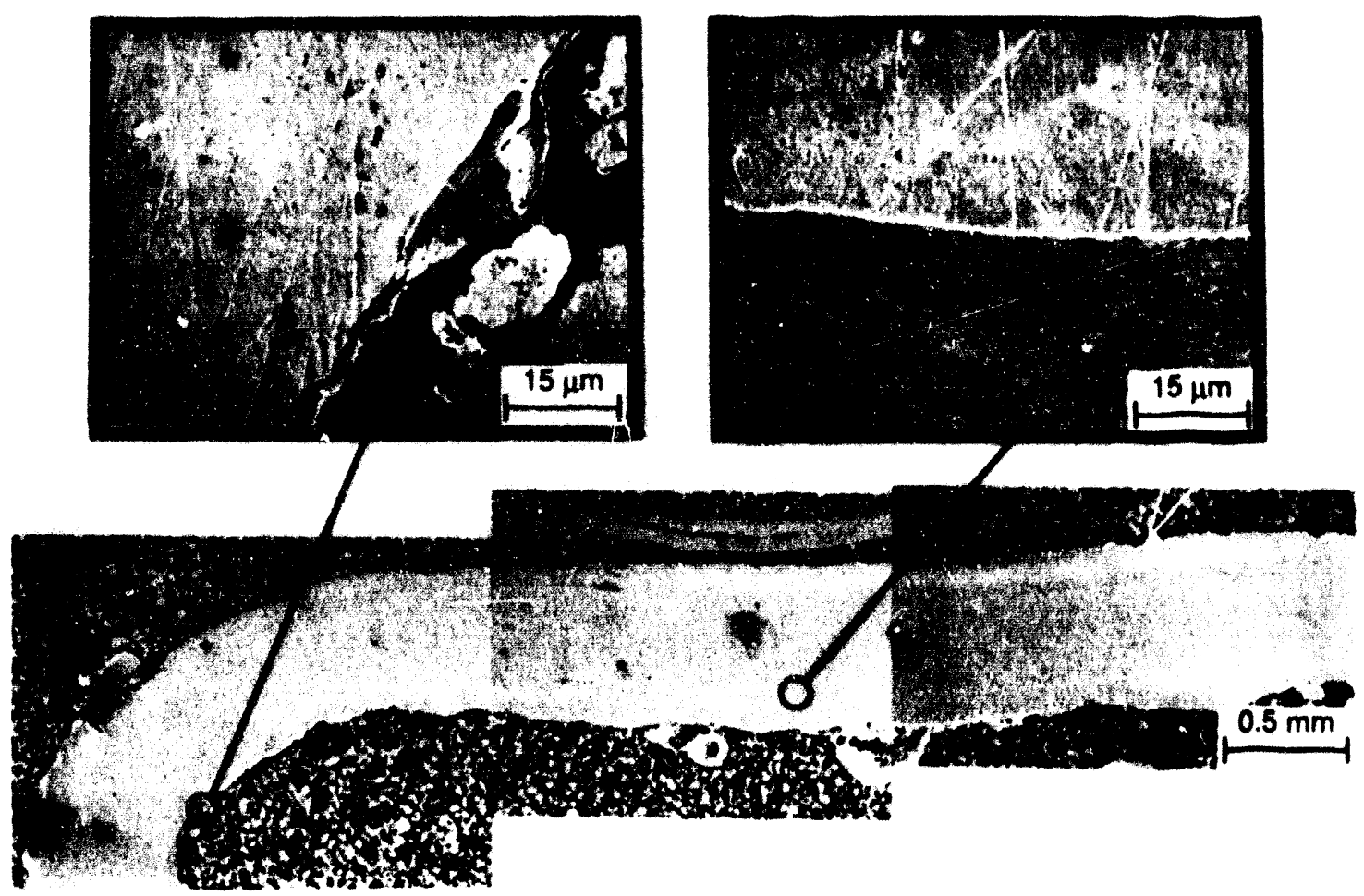

Figure A22. Type $316 \mathrm{SS}$ exposed in gallum for $100 \mathrm{~h}$ at $400^{\circ} \mathrm{C}$ after axidation in water for $100 \mathrm{~h}$ at $290^{\circ} \mathrm{C}$ (SSW-4B) 

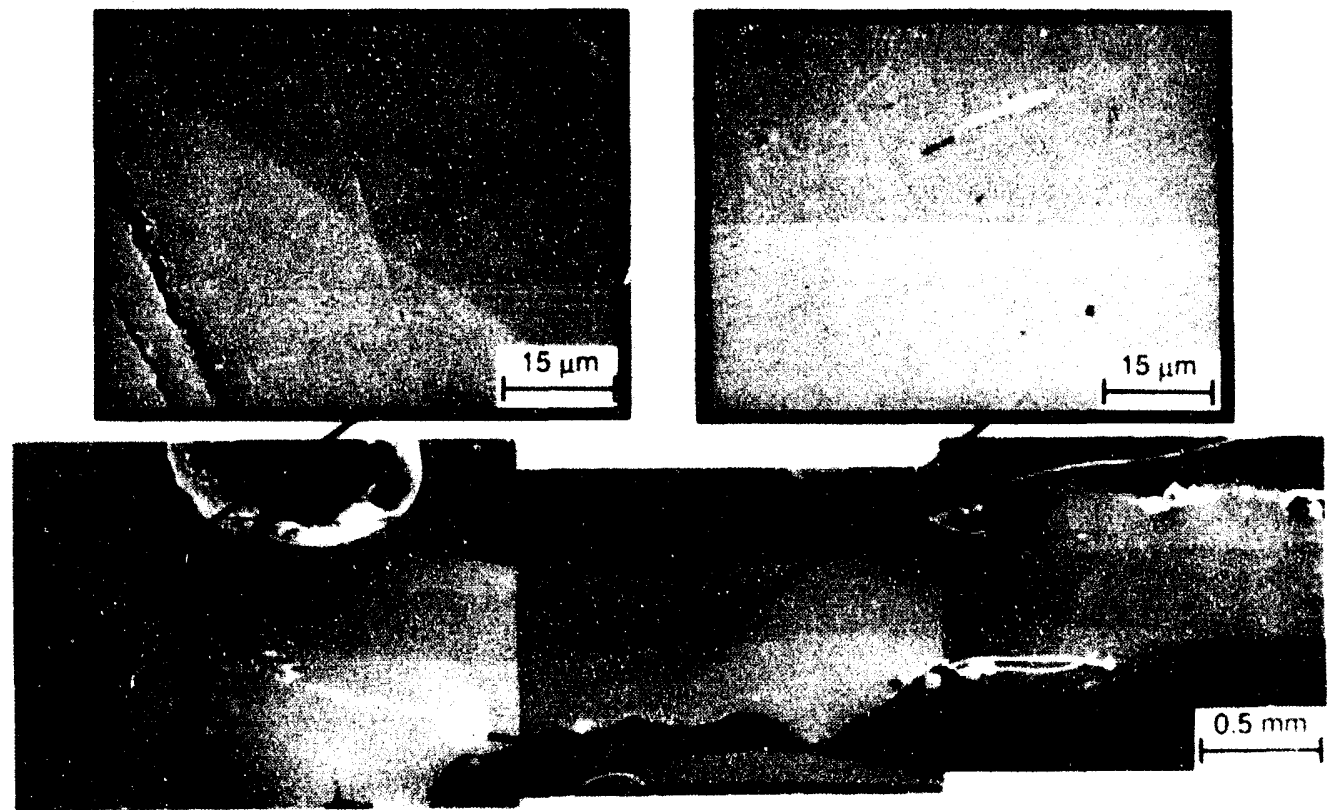

Flgure A23. Type $316 \mathrm{SS}$ exposed in gallum for $300 \mathrm{~h}$ at $400^{\circ} \mathrm{C}$ after axidation in water for $100 \mathrm{~h}$ at $290^{\circ} \mathrm{C}$ (SSW-4C)

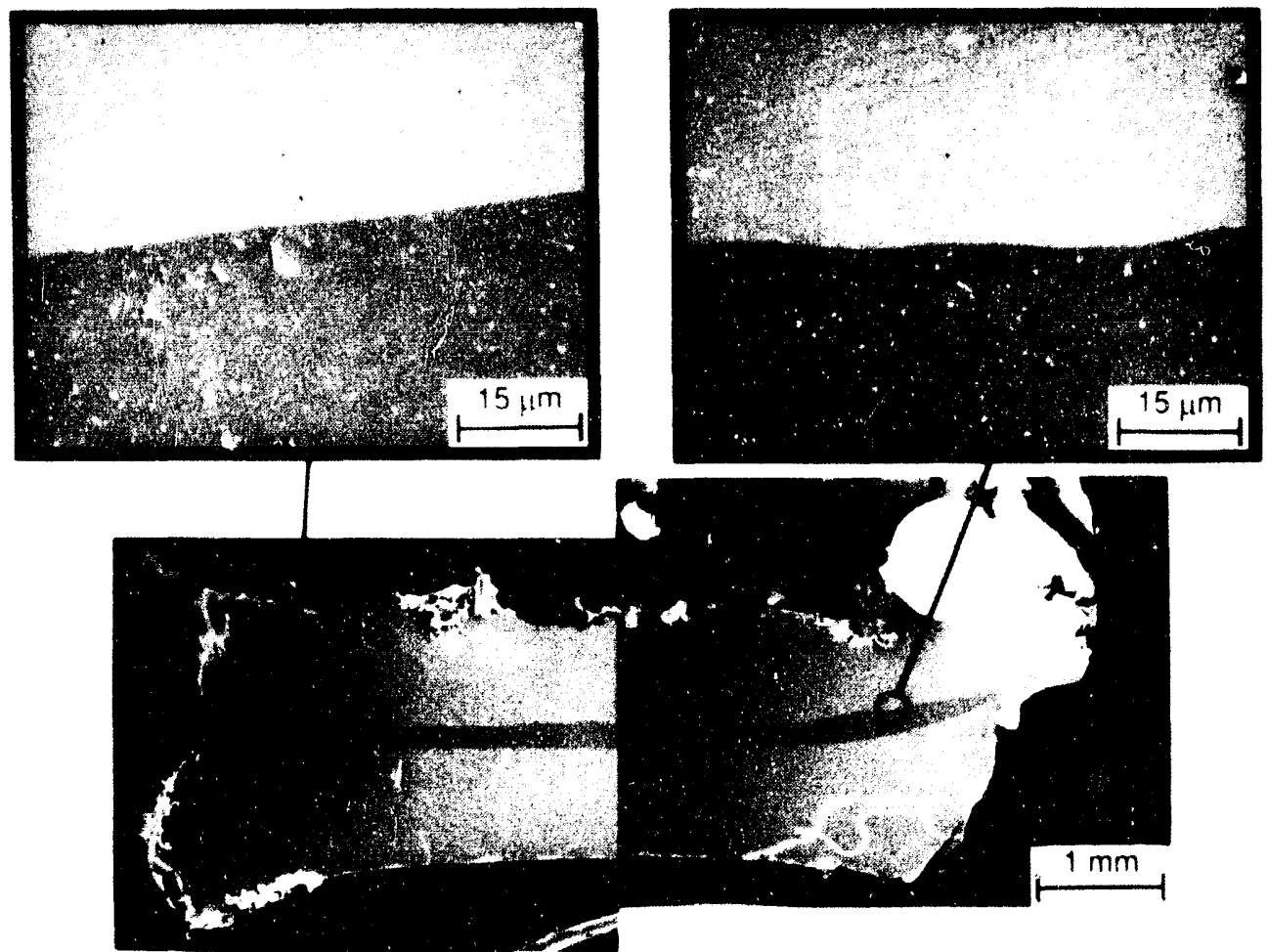

Figure A24. Type 316 SS exposed in gallum for $1000 \mathrm{~h}$ at $400^{\circ} \mathrm{C}$ after axidation in water for $100 \mathrm{~h}$ at $290^{\circ} \mathrm{C}$ (SSW-4D) 


\section{Inconel 625}

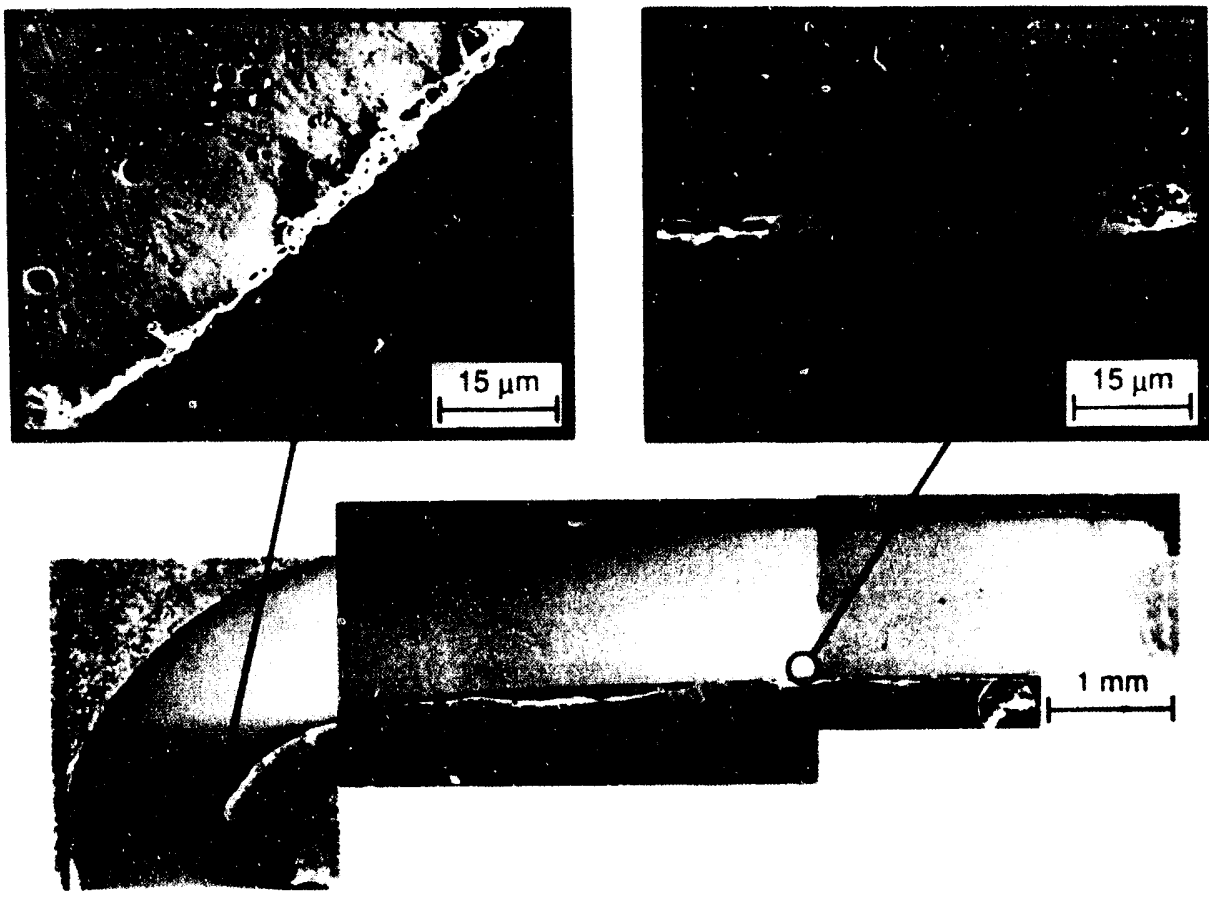

Figure A25. Inconel 625 exposed in gallium for $100 \mathrm{~h}$ at $300^{\circ} \mathrm{C}$ (IN-3B)

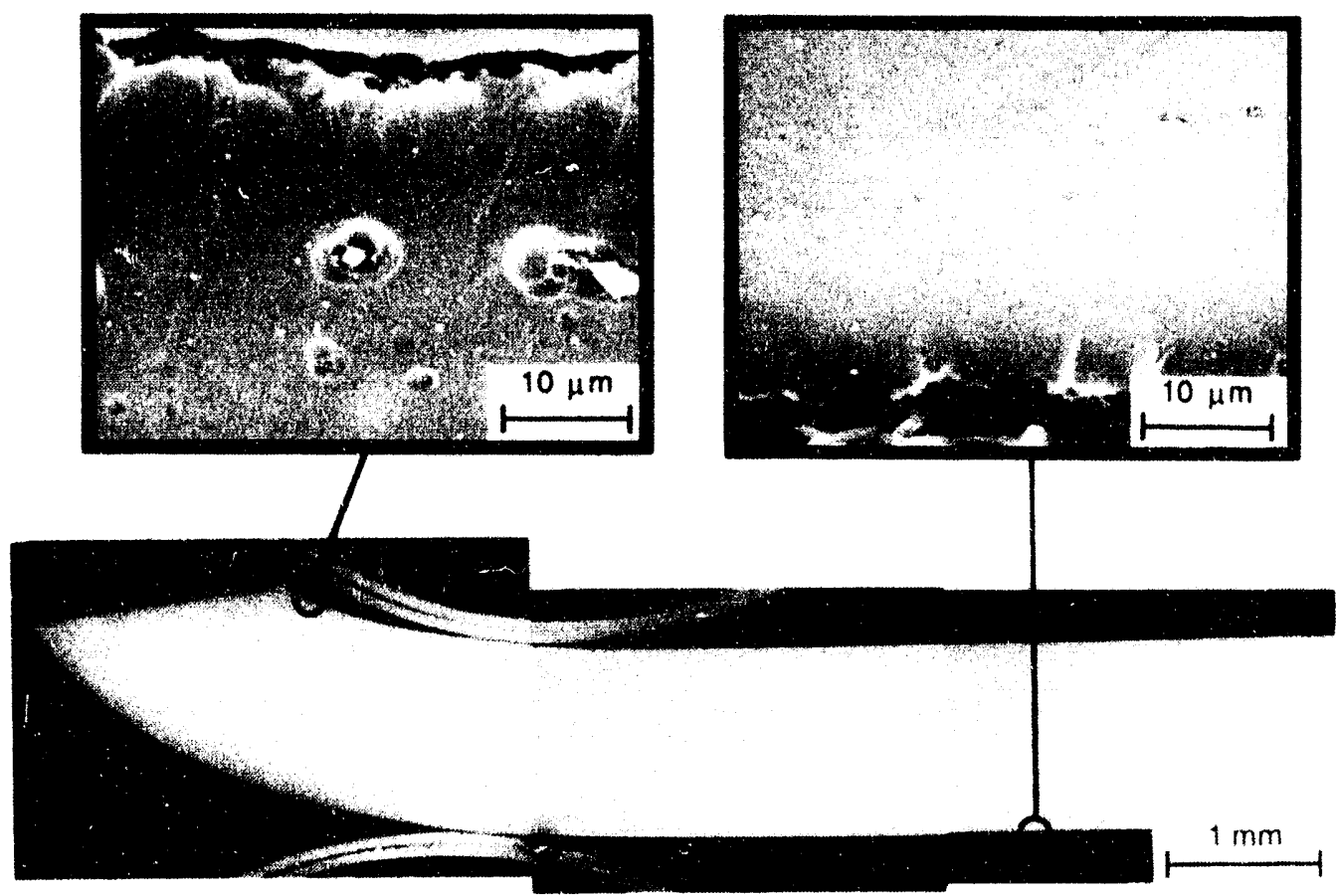

Figure A26. Inconel 625 exposed in gallium for $300 \mathrm{~h}$ at $300^{\circ} \mathrm{C}(\mathrm{IN}-3 \mathrm{C})$ 


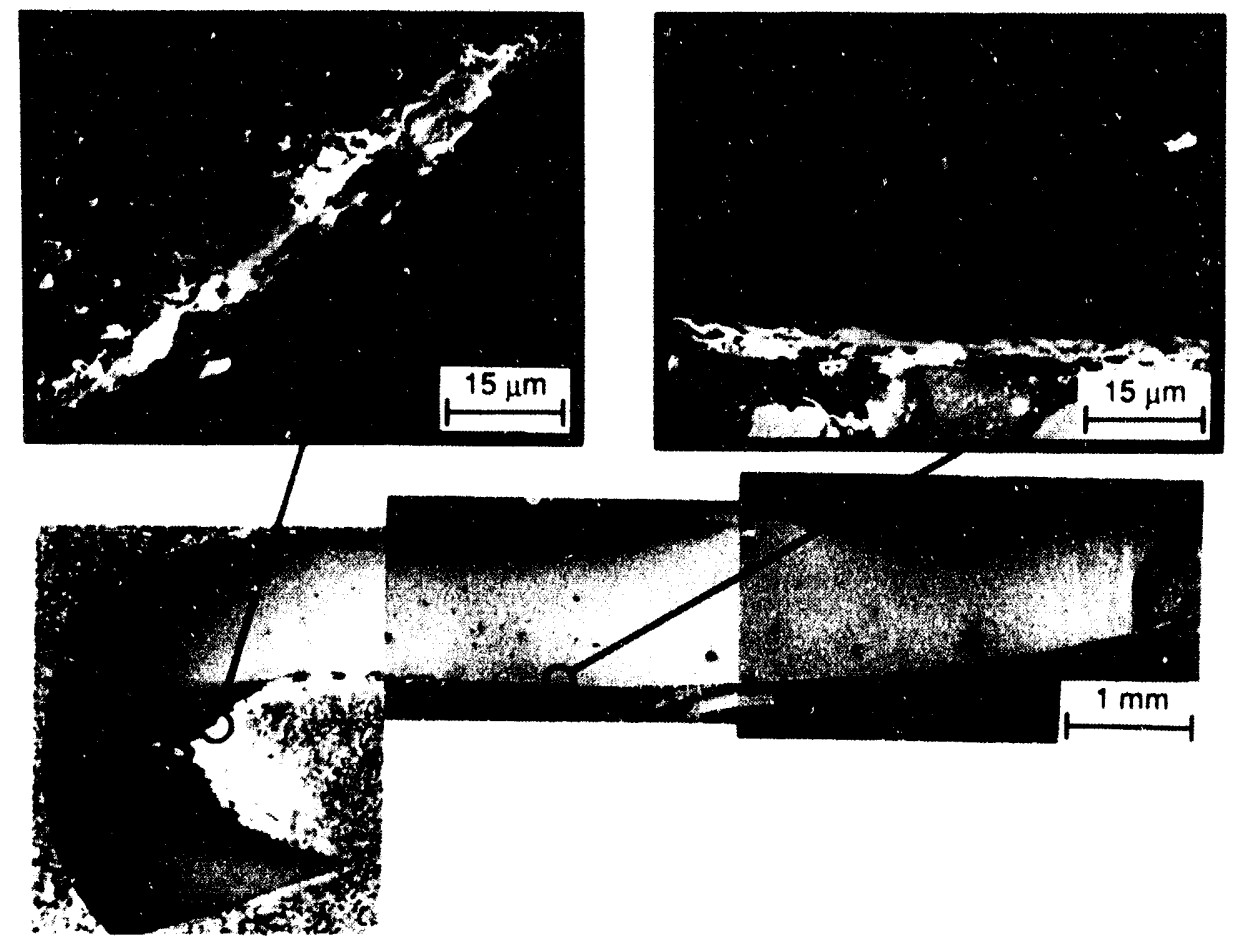

Figure A27. Inconel 625 exposed in gallium for $1008 \mathrm{~h}$ at $300^{\circ} \mathrm{C}$ (IN-3D)

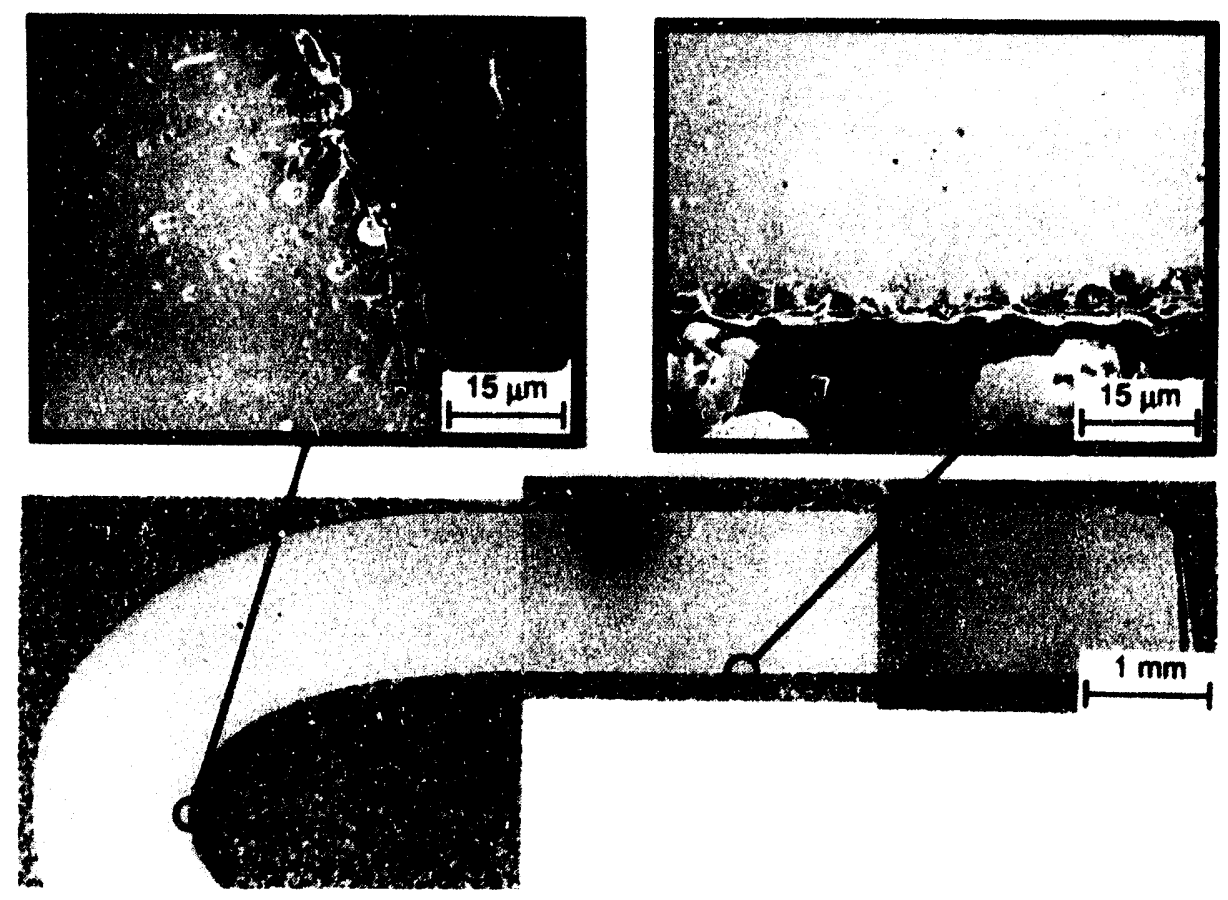

Figure A28. Inconel 625 exposed in gallium for $3000 \mathrm{~h}$ at $300^{\circ} \mathrm{C}$ (IN-3E) 


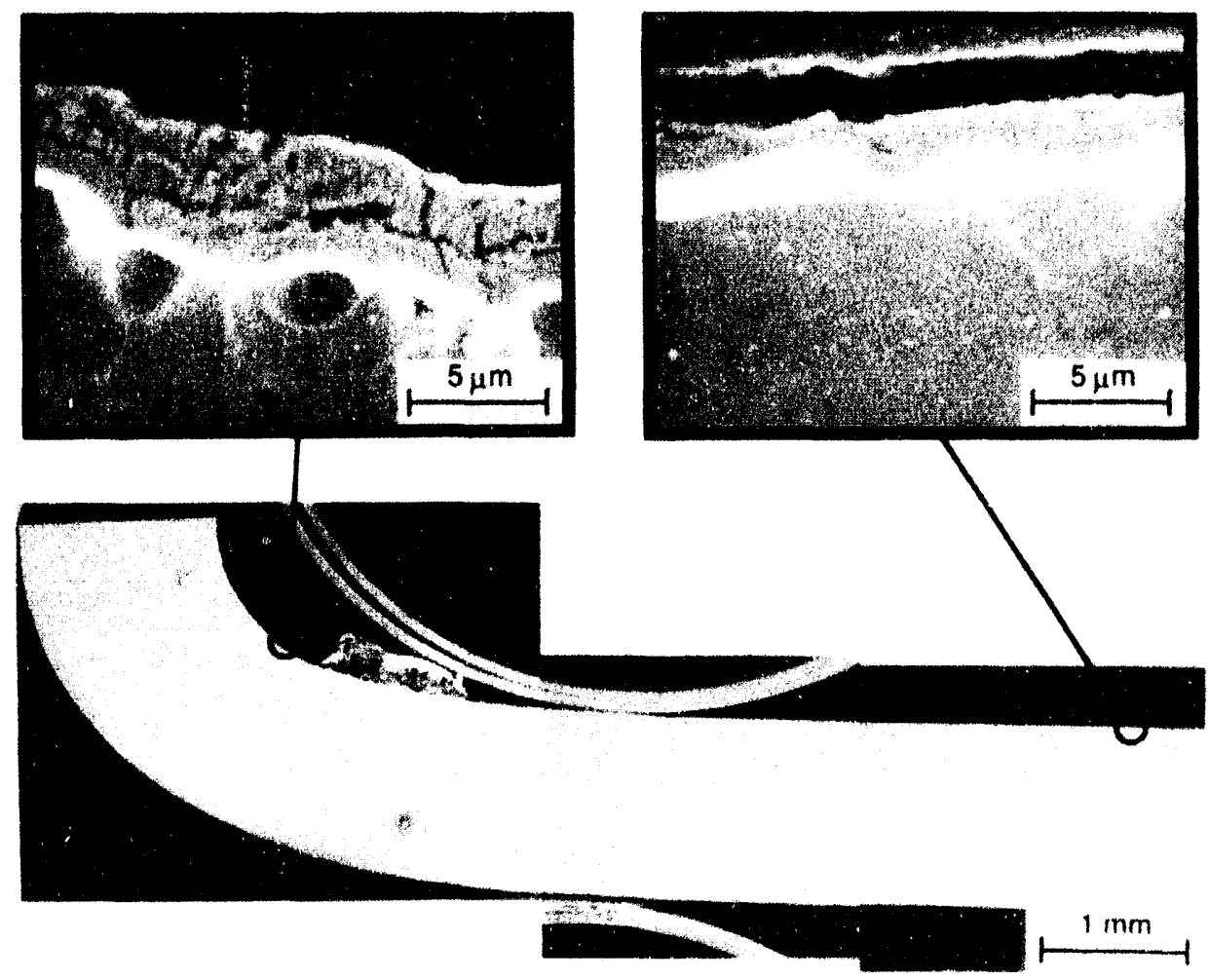

Figure A29. Inconel 625 exposed in gallium for $24 \mathrm{~h}$ at $400^{\circ} \mathrm{C}(\mathrm{IN}-4 \mathrm{~A})$

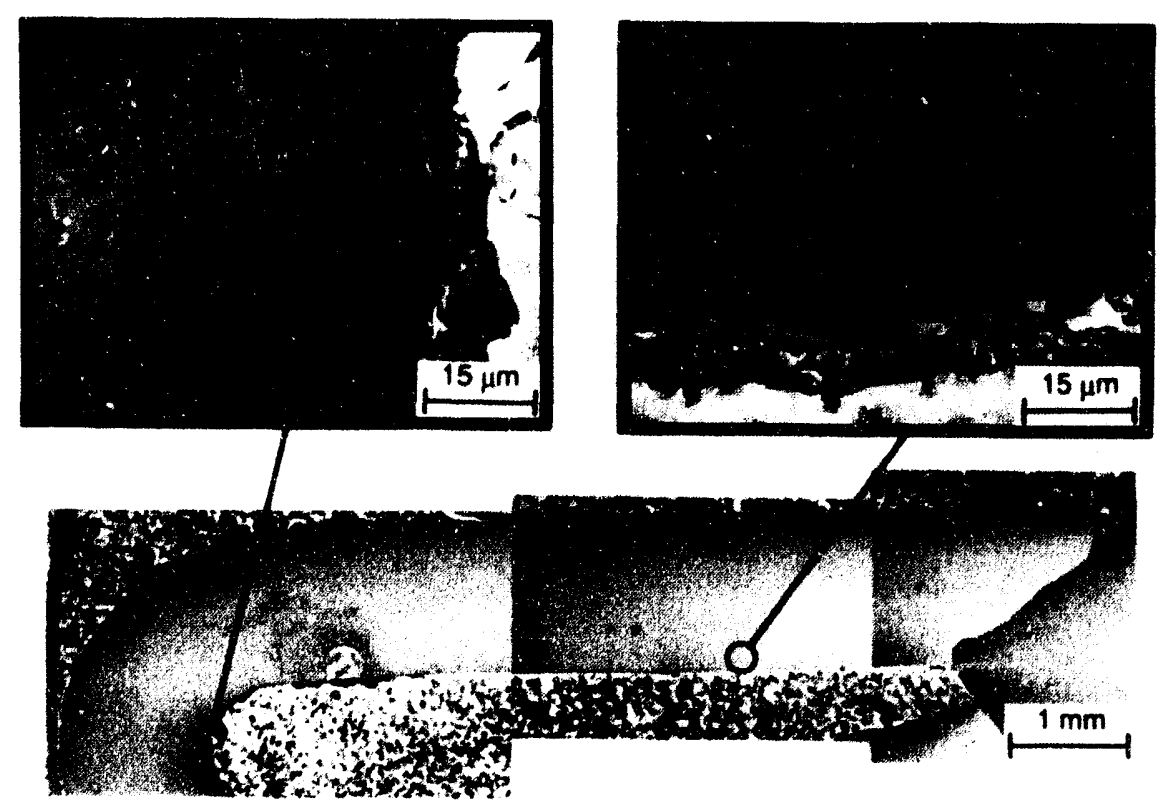

Figure A30. Inconel 625 exposed in gallum for $48 \mathrm{~h}$ at $400^{\circ} \mathrm{C}(\mathrm{IN}-4 \mathrm{~F})$ 


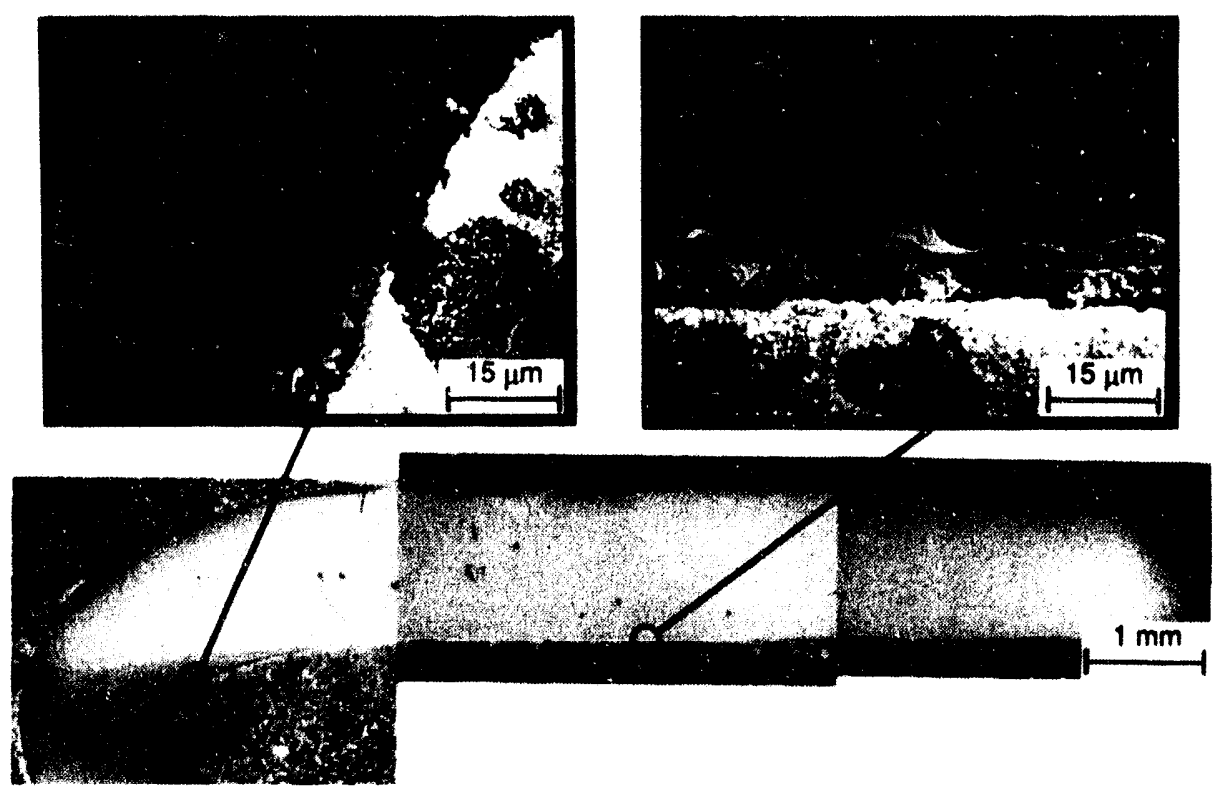

Figure A31. Inconel 625 exposed in gallium for $100 \mathrm{~h}$ at $400^{\circ} \mathrm{C}$ (IN-4B)

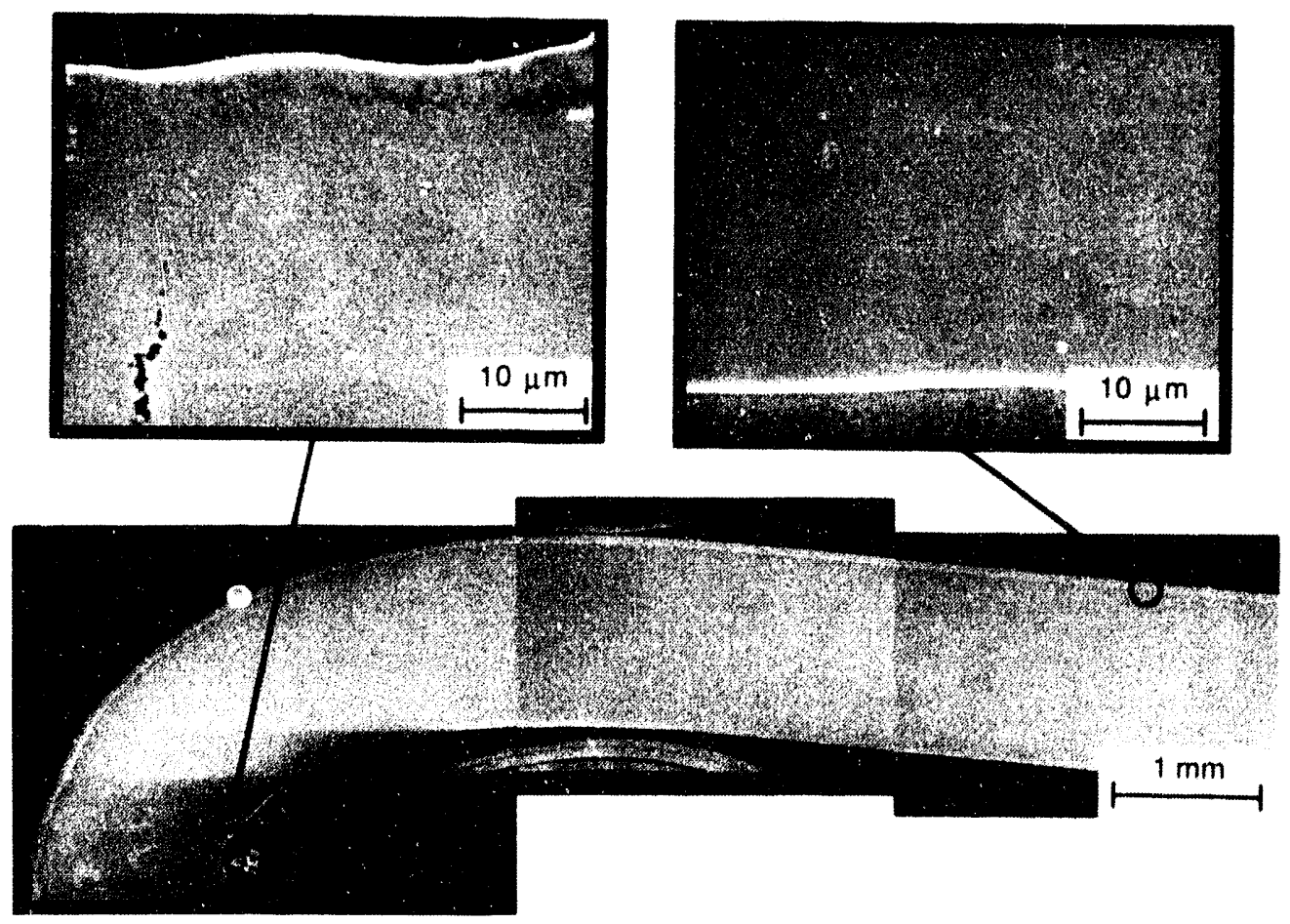

Figure A32. Inconel 625 exposed in gallium for $300 \mathrm{~h}$ at $400^{\circ} \mathrm{C}(\mathrm{IN}-4 \mathrm{C})$ 


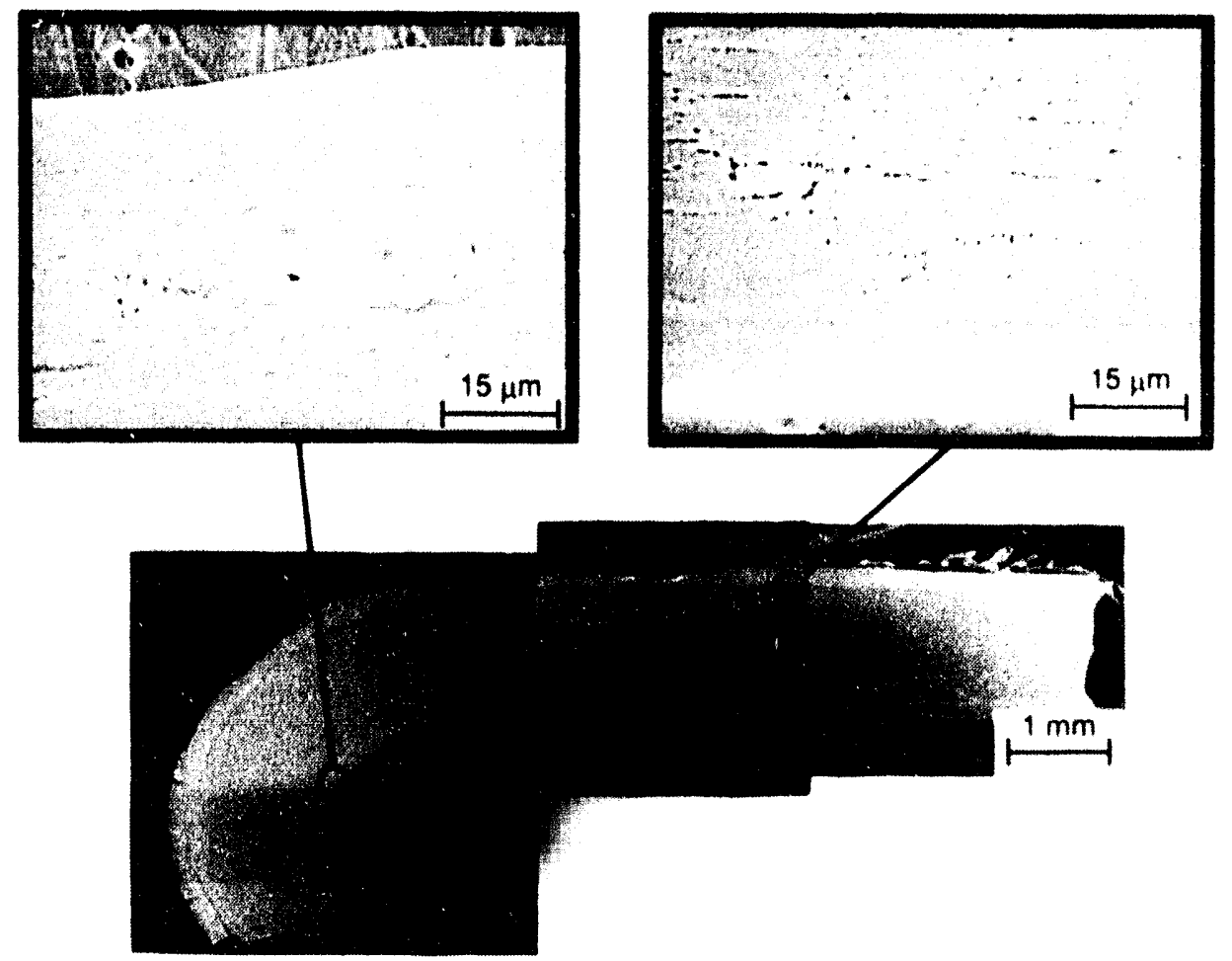

Figure A33. Inconel 625 exposed in gallium for $1076 \mathrm{~h}$ at $400^{\circ} \mathrm{C}(\mathrm{N}-4 \mathrm{E})$ 


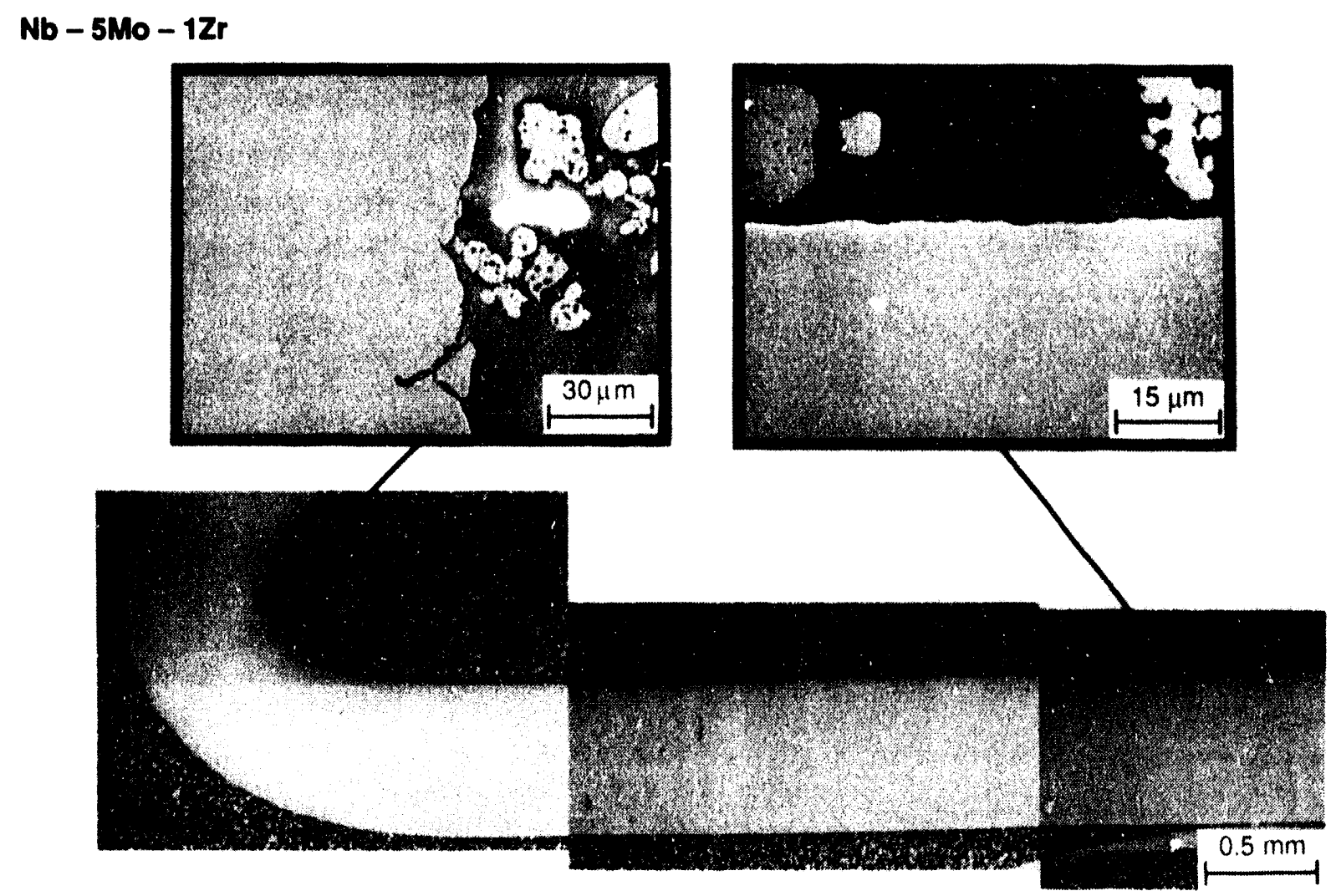

Flgure A34. $\mathrm{Nb}-5 \mathrm{Mo}-1 \mathrm{Zr}$ exposed in gallium for $100 \mathrm{~h}$ at $300^{\circ} \mathrm{C}(\mathrm{NB}-3 \mathrm{~B})$

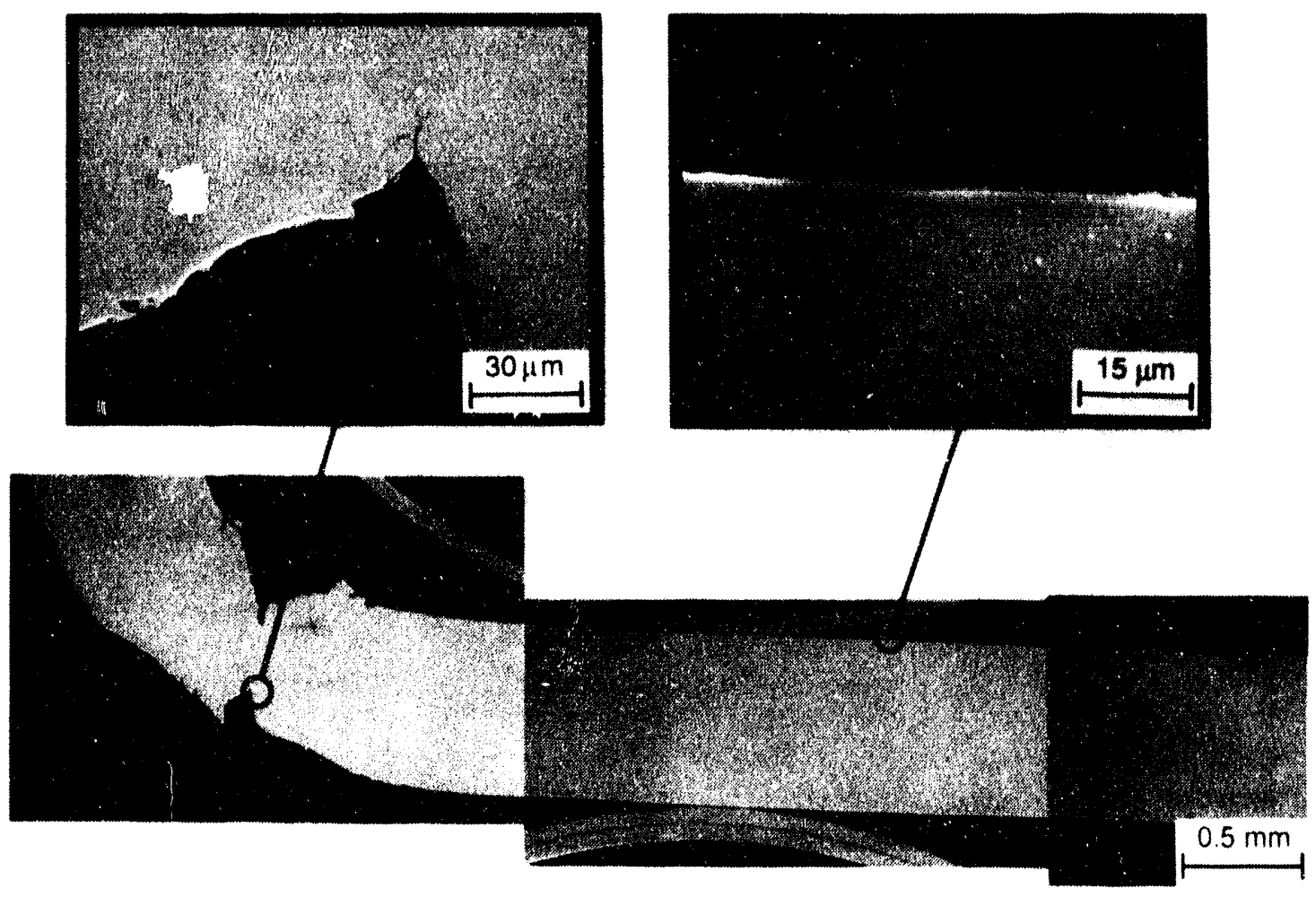

Figure A35. $\mathrm{Nb}-5 \mathrm{Mo}-1 \mathrm{Zr}$ exposed in gallum for $300 \mathrm{~h}$ at $300^{\circ} \mathrm{C}(\mathrm{NB}-3 \mathrm{C})$ 


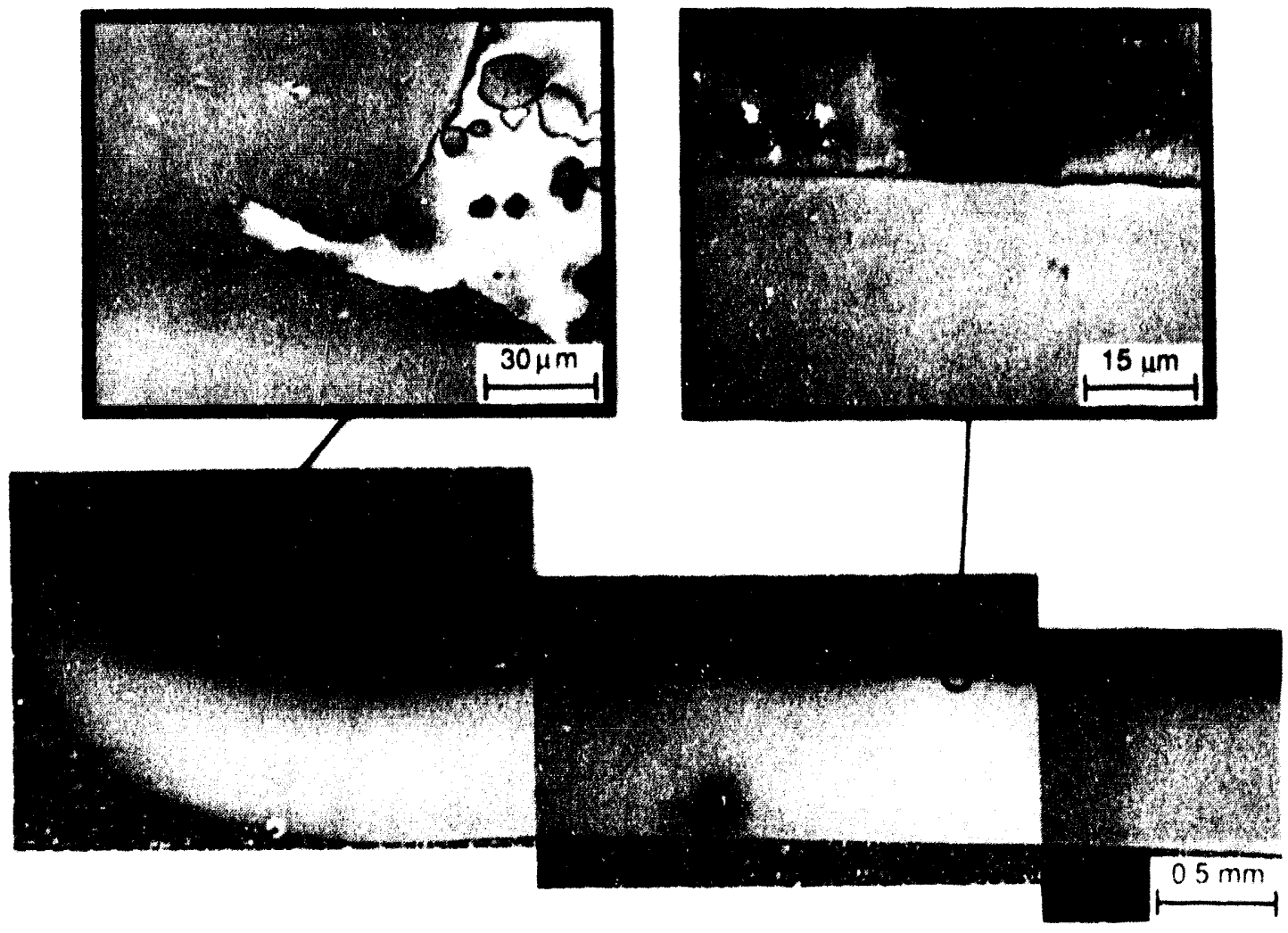

Figure A36. $\mathrm{Nb}-5 \mathrm{Mo}-1 \mathrm{Zr}$ exposed in galltum for $1008 \mathrm{~h}$ at $300^{\circ} \mathrm{C}(\mathrm{NB}-3 \mathrm{D})$

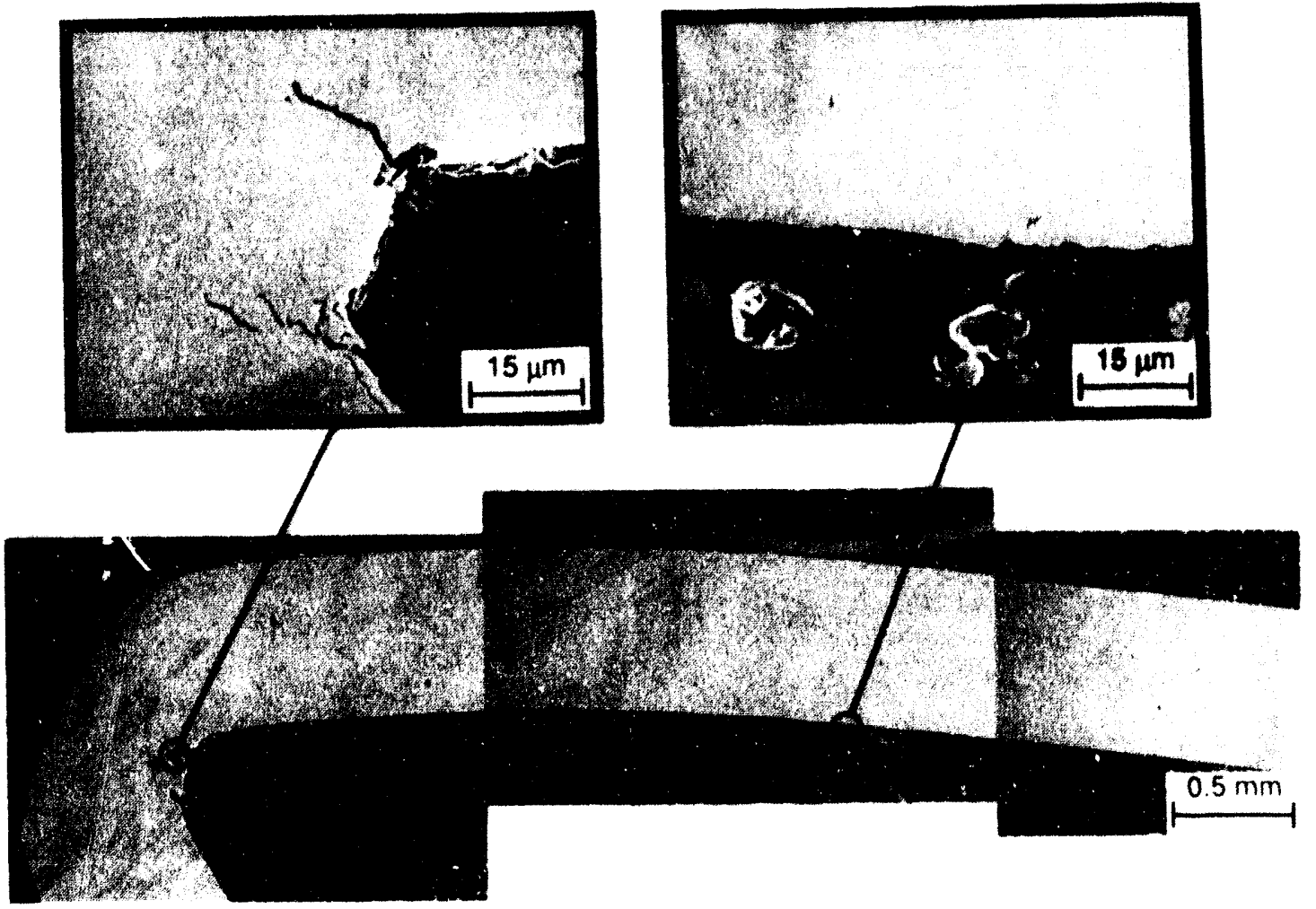

Figure A37. $\mathrm{Nb}-5 \mathrm{Mo}-12 \mathrm{r}$ exposed in gallium for $3000 \mathrm{~h}$ at $300^{\circ} \mathrm{C}$ (NB-3E) 


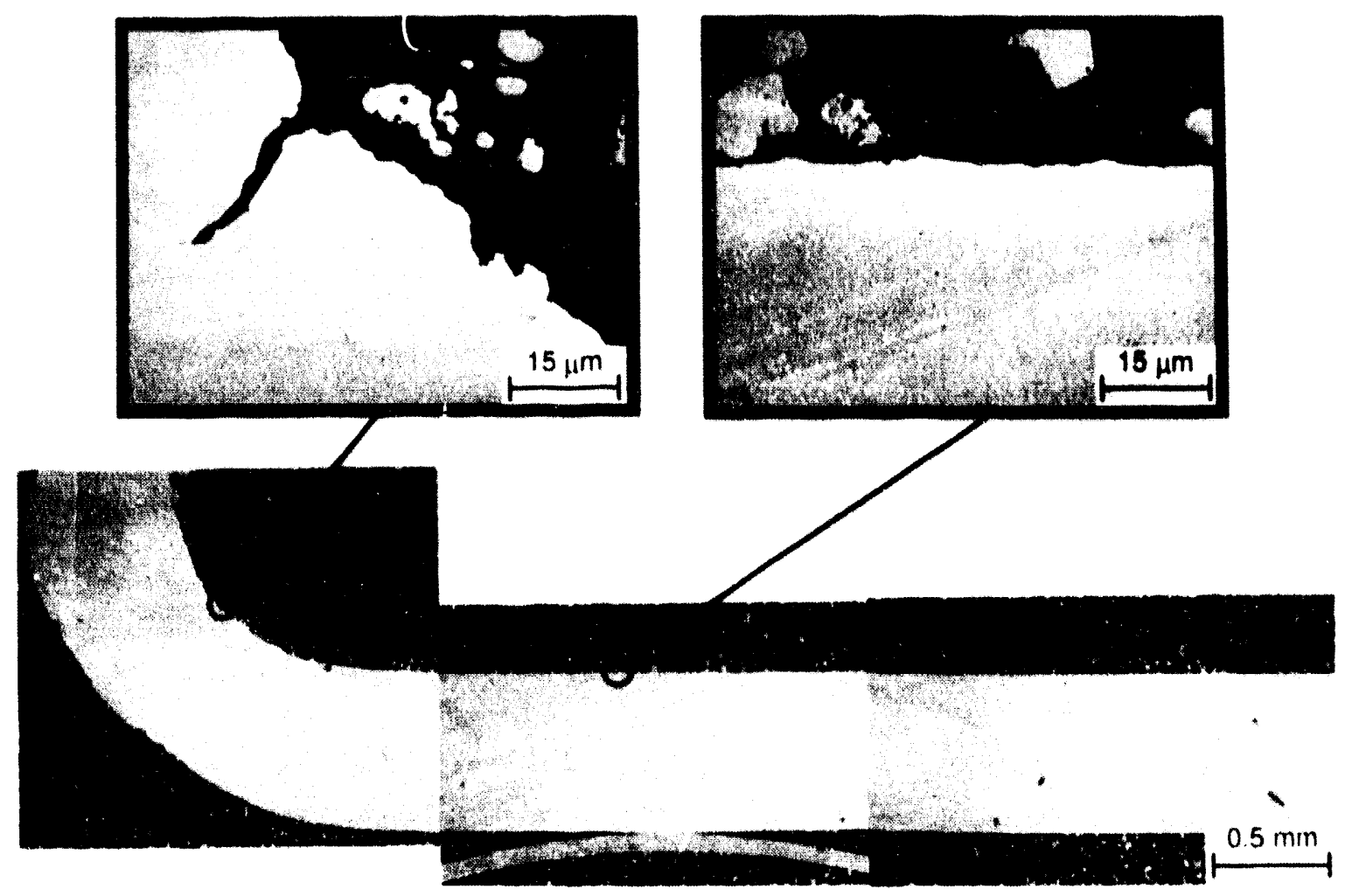

Figure A38. $\mathrm{Nb}-5 \mathrm{Mo}-1 \mathrm{Zr}$ exposed in gallium for $24 \mathrm{~h}$ at $400^{\circ} \mathrm{C}(\mathrm{NB}-4 \mathrm{~F})$

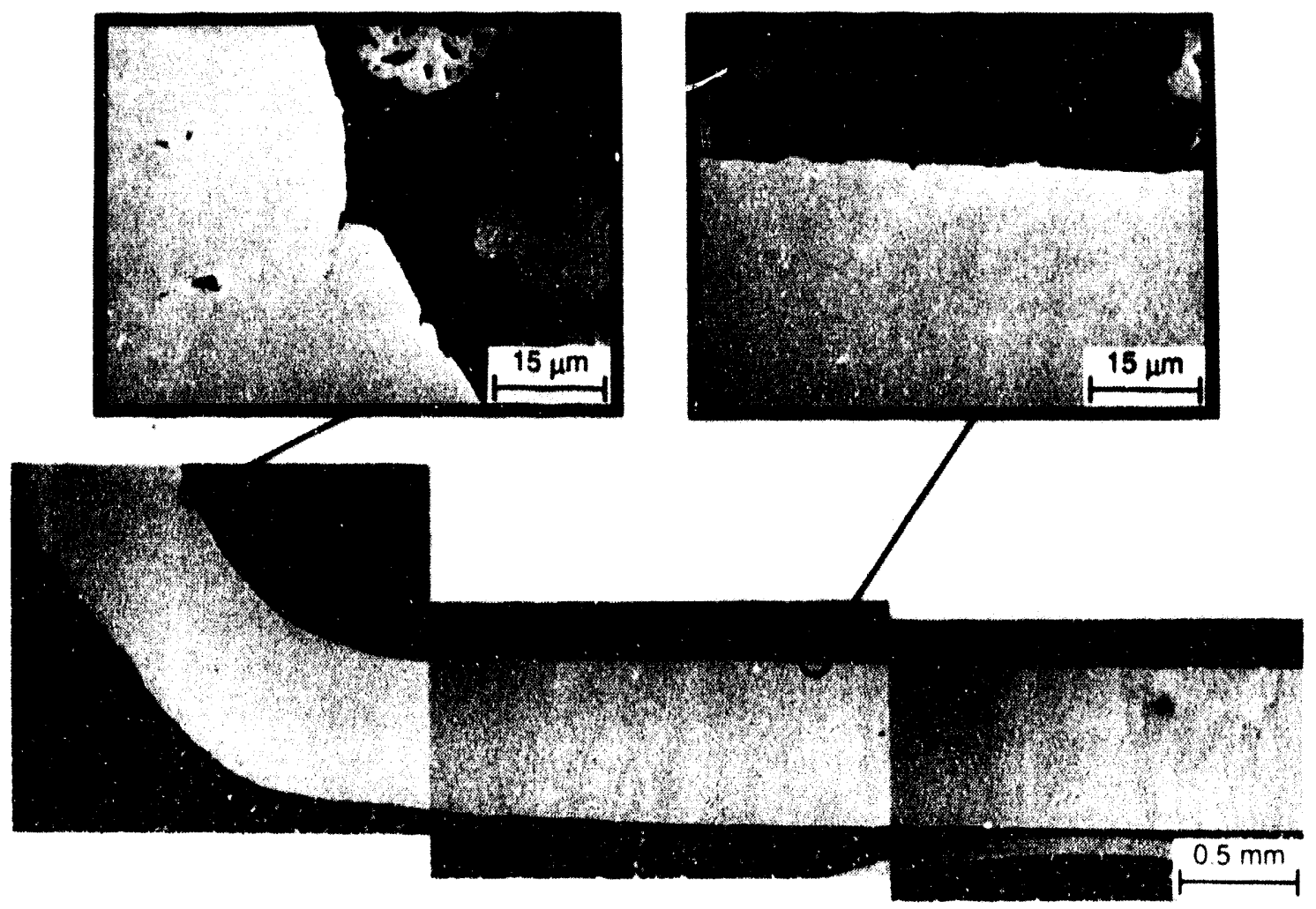

Figure A39. $\mathrm{Nb}-5 \mathrm{Mo}-1 \mathrm{Zr}$ exposed in gallium for $100 \mathrm{~h}$ at $400^{\circ} \mathrm{C}(\mathrm{NB}-4 \mathrm{~B})$ 


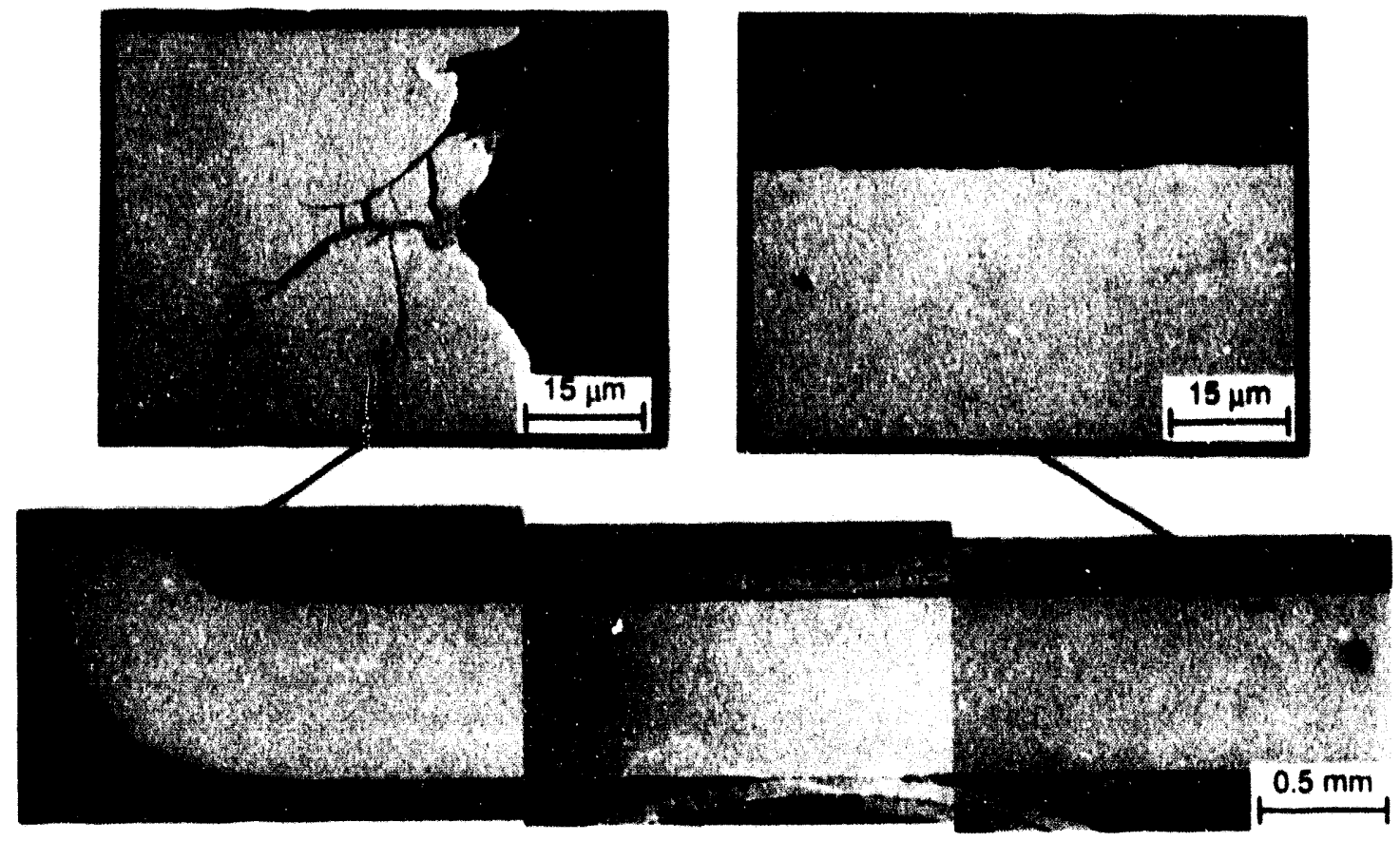

Figure $\mathrm{A40}$. $\mathrm{Nb}-5 \mathrm{Mo}-1 \mathrm{Zr}$ exposed in gallum for $300 \mathrm{~h}$ at $400^{\circ} \mathrm{C}$ (NB-4C)

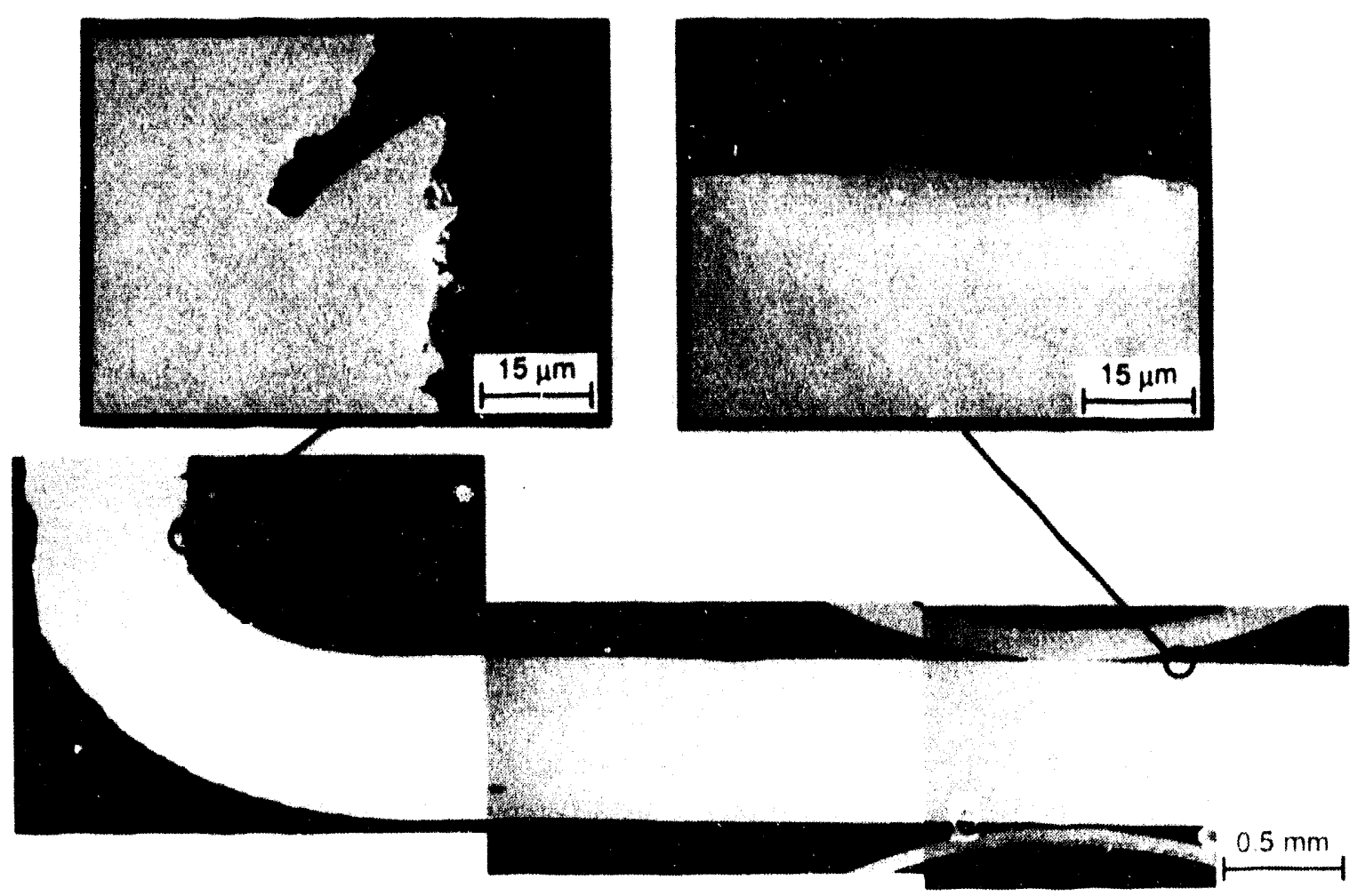

Figure A41. $\mathrm{Nb}-5 \mathrm{Mo}-1 \mathrm{Zr}$ exposed in gallium for $1076 \mathrm{~h}$ at $400^{\circ} \mathrm{C}(\mathrm{NB}-4 \mathrm{E})$ 


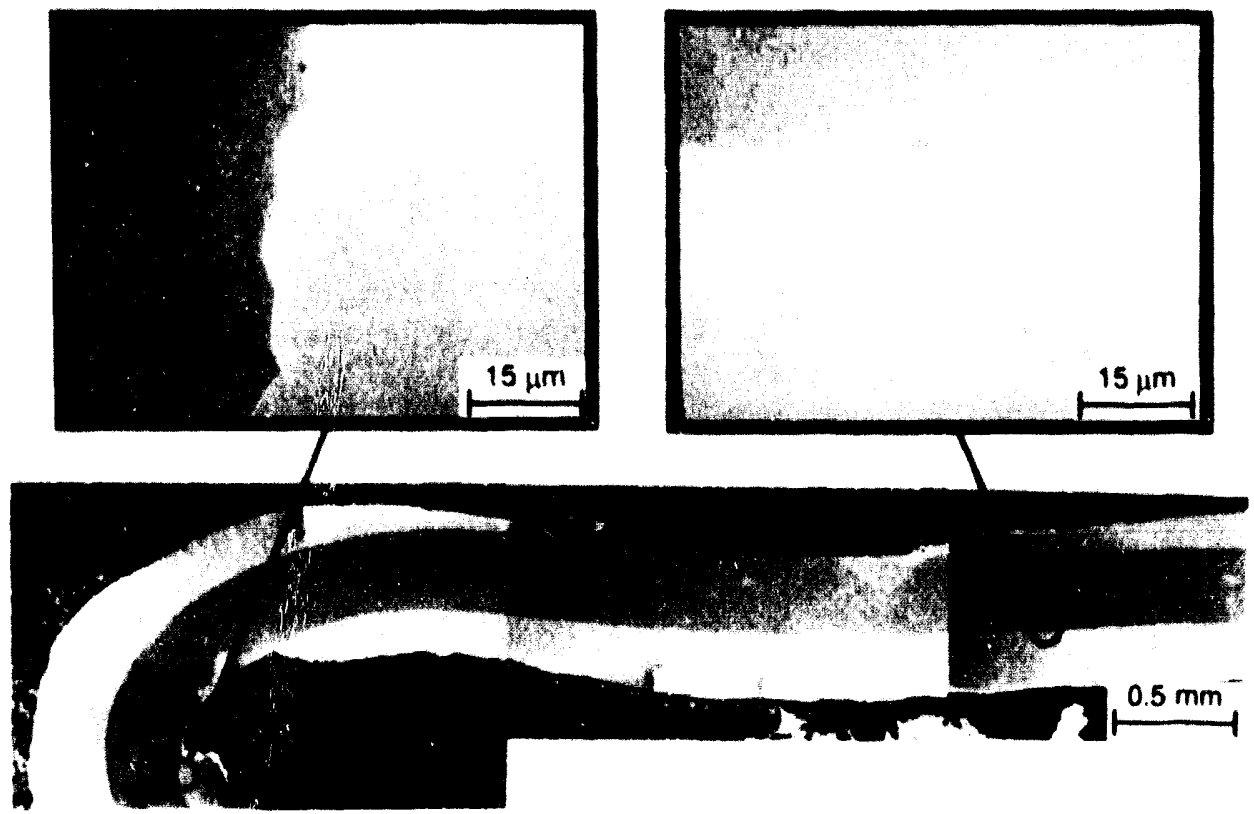

Figure A42. Armco tron exposed in gallium for $100 \mathrm{~h}$ at $300^{\circ} \mathrm{C}$ (FE-3B)

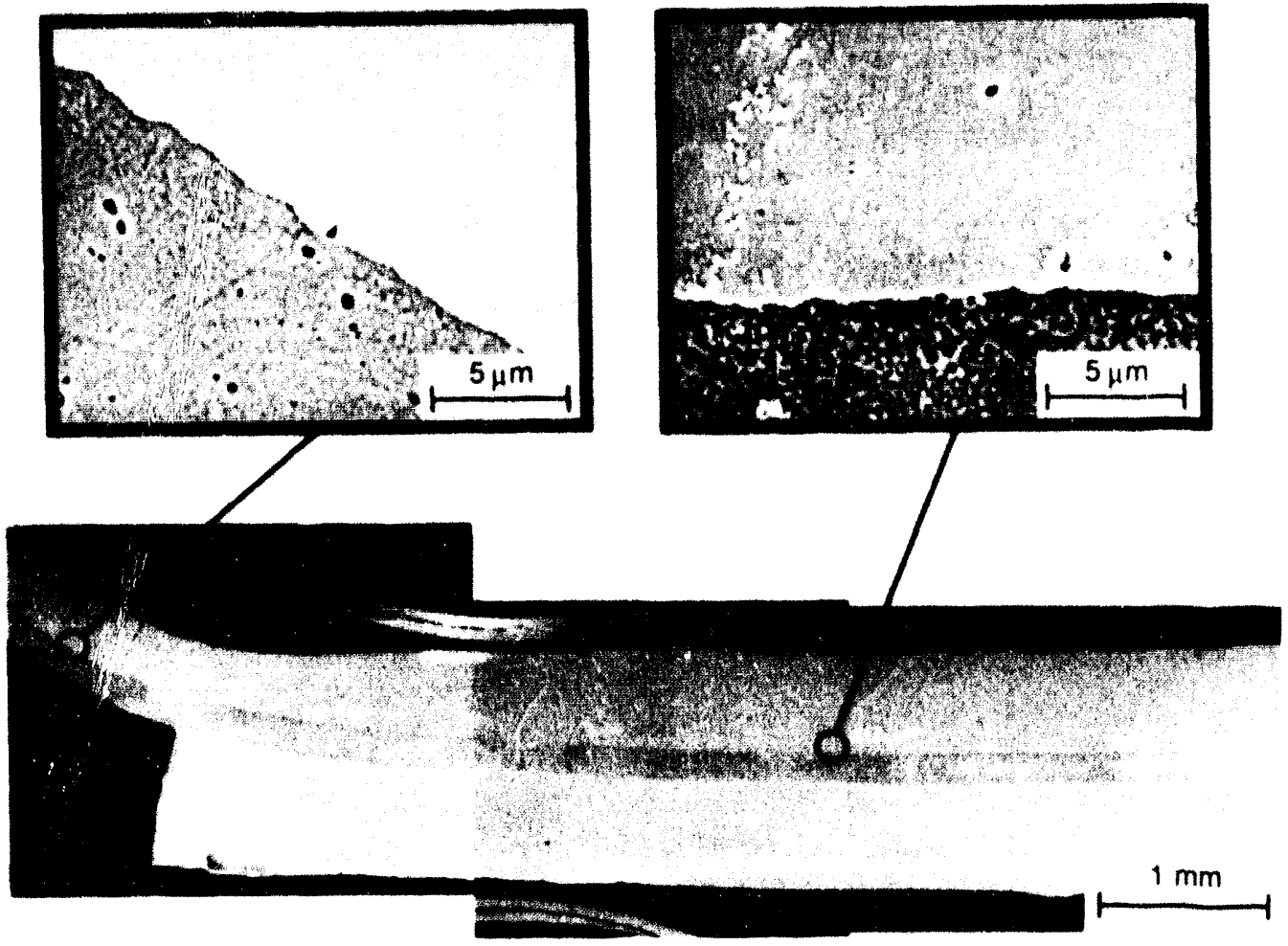

Figure A43. Armco tron exposed in gallum for $300 \mathrm{~h}$ at $300^{\circ} \mathrm{C}$ (FE-3C) 
Nickol 270

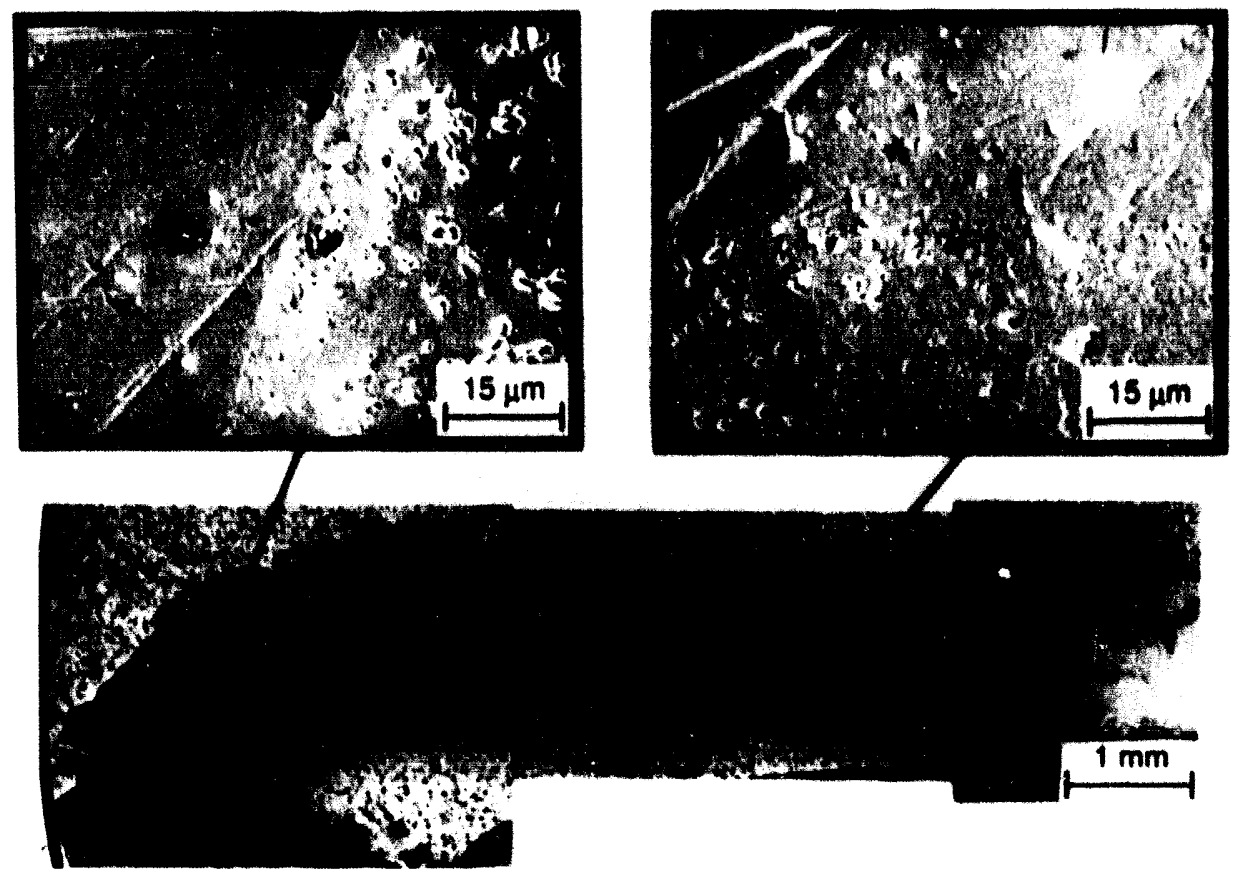

Figure A44. Nickel 270 exposed in gallium for 100 h at $400^{\circ} \mathrm{C}(\mathrm{NI}-4 \mathrm{~B})$ 


\section{APPENDIX B: \\ BIBLIOGRAPHY ON GALLIUM}

\section{Avallability}

F. E. Katrak and J. C. Agarwal, Gallum: Long-Run Supply. J. Met., 33, 33-36 (1981).

D. A. Kramer, Gallium in Minerals Yearbook, U.S. Dept. of the Interlor, Bureau of Mines, 463-467 (1990).

M. C. Munson, Events and Trends in Metal and Mineral Commoditles, J. Met., 45, 22-28 (1993).

\section{Physical and Chemical Properties}

W. D. Wilkinson, Propertles of Gallium: Summary of Published Data on Alloys, Physical Properties, and Chemistry. Argonne National Laboratory Report ANL -4109 (February 1948).

1. A. Sheka, I. S. Chaus, and T. T. Mityureva, The Chemistry of Gallium. Elsevier Publishing Company. Amsterdam (1966).

A. M. Dymov and A. P. Samostin, Analytical Chemistry of the Elements: Gallium. Ann Arbor Science Publishers, Ann Arbor (1970).

J. E. Lewis, The Radiochemistry of Aluminum and Gallium. National Academy of SciencesNational Research Council, Report No. NAS-NS 3032, April 1961.

An. N. Nesmeyanov, Vapour Pressure of the Elements, Publishing House of the U.S.S.R. Academy of Sclences, Moscow (1961).

J. C. Bailar, Jr., H. J. Emelus, R. Nyholm, and A. F. Trotman-Dickenson, Comprehensive Inorganic Chemistry. Pergamon Press, Oxford (1973).

Y. S. Touloukian et al., Thermophysical Properties of Matter, Volumes 1-13, IFI/Plenum Press, New York. (1970).

V. Ya. Prokhırenko, E. A. Ratushnyak, B. I. Stadnyk, V. I. Lakh, and A. M. Korsunshil, Investigation of Liquid Metal Thermosensittue Elements, Originally in Teplofizika Vysokikh Temperatur, 7, 804-806 (1969).

Ya. I. Dutchak and V. Ya. Prokhorenko. Structure-Sensitive Thermoelectric Properties of Liquid Indium and Gallium, Ukrain. Phys. J., 12, 2060-2062 (1967).

L. N. Rykova, V. N. Danilin, and S. P. Yatsenko. Thermodynamic Propertles of Dilute Solutions of Zirconium in Gallium, Russ. J. Phys. Met., 45. 1222-1224 (1971).

D. Chatain, I. Rivollet, and N. Eustathopoulos, Adhésion Thermodynamique Dans Les Systèmes Non-Réactifs Métal Liquide-Alumine. J. Chimie Phys., 83, 561-567 (1986).

M. Inagaki, Metal Gallium-Its Natural Resource, Property, Recovering Process, and Utility. J. Coal Res. Inst. Jpn., 7, 129-139 (1956).

\section{Solubility/Corrosion of Materials}

L. R. Kelman and W. D. Wilkinson, Galltum Study, Argonne National Laboratory Report ANL-4103 (March 1948).

W. D. Wilkinson, Gallium Studies, Argonne National Laboratory Report ANL -4150 (March 1948). 
Wilkinson. W. D., Gallium Alloys, Argonne National Laboratory Report ANL-4188 (June 1948).

L. R. Kelman, W. D. Wilkinson, and F. L. Yaggee. Resistance of Materials to Attack by Liquid Metals, Argonne National Laboratory Report ANL-4417 (July 1950).

W. D. Wilkinson, Effects of Gallium on Materials at Elevated Temperatures Supplementary Report, Argonne National Laboratory Report ANL-4582 (August 1953).

W. D. Wilkinson, Effects of Gallium on Materials at Elevated Temperatures, Argonne National Laboratory Report ANL-5027 (August 1953).

R. I. Jaffee, R. M. Evans, E. A. Fromm, and B. W. Gonser, Gallium in Nuclear Reactors: Considerations for Use as a Primary Coolant. U.S. Atomic Energy Commission Report AECD-3317 (August 1949).

S. P. Yatsenko and Yu. A. Anikin, Solubility of Metals of the Fourth Perlod in Liquid Gallium, Russ. Metall., 4, 118-123 (1970).

S. P. Yatsenko and Yu. A. Anikin. Solubility of Metals of the Fyfth Period in Liquid Gallium. Sov. Mater. Scl., 6, 333-337 (1970).

S. P. Yatsenko, Gallium Interaction With Metals, Nauka, Moscow (1974).

S. P. Yatsenko, L. N. Rykova. Yu. A. Anikin. and E. N. Dieva. The Corrosion of Group VIII Metals in Liquid Gallium. Sov. Mater. Sci., 8, 310-313 (1972).

S. P. Yatsenko, Correlation Between the Physical Properties of Pure Solid Metals and Their Stability in Molten Ga Metal, Russ. J. Phys. Chem., 48, 1095-1098 (1971).

S. P. Yatsenko, E. N. Diyeva, and B. N. Zagrebin, The State of Some Impurtties in Liquid Gallum, Russ. Metall., 3, 77-82 (1972).

S. P. Yatsenko and Yu. A. Anikin, Determination of Limiting Heats of Mixing from Solubility Data in Liquid Metals, Russ. J. Phys. Chem., 46. 1104-1 106 (1971).

C. Guminskd, Solubility of Metals in Liquid Low-Melting Metals, Z. Metallkd., 81, 105-110 (1990).

V. I. Kononenko, A. N. Koznetsov, and S. P. Yatsenko, Method of Studying the Solubility of Solid Materials in Metallic Melts, Zavodskaya Laboratoriya, 41, 806-807 (1975).

Yu. M. Tairov, F. I. Raikhel', and V. F. Tsvetkov, Solubility of Silicon Carbide in Tin and Gallium. Inorg. Mat., 18. 1182-1183 (1982). IOriginally in Akademia Nauk SSSR. Izvestila, Neorganicheskie Materialy, 18, 1390-1391 (1982).I

A. P. Nakhodnova, L. F. Chernysh, and V. G. Pitsyuga, Conditions of Formation and Composition of Aluminium, Gallium, and Indium Vanadates, Russ. J. Inorg. Chem., so. 1287-1290 (1985).

R. L. Fleischer, Statistics of Solubilities of Ternary Elements in Interme'allic Compounds, J. Mater. Sci. Lett., 7, 525-526 (1988).

S. Ochial and T. Suzuki, Solubility Data in $\mathrm{Ni}_{3} \mathrm{Ga}$ with Ternary Additions, Bull. Research Laboratory of Precision Machinery and Electronics, 62, 19-29 (1983).

W. Kroll, Alloys of Gallium, Metallwirtschaft, 11, 435-437 (1932).

V. A. Ponimash. V. Ya. Prokhorenko, and I. S. Slabkovskii, Interaction of Molten Gallium Mixtures with Structural Materials, Sov. Mater. Scl., 16, 505-507 (1980).

S. Tamaki, Y. Tsuchiya, N. E. Cusack, Y. Waseda, and K. T. Jacob, A Derivation of Thermodynamic Quantities of Liquid Alloys From Their Structure Factors, J. Phys. F: Met. Phys., 10, L109-L113 (1980). 
Ya. I. Dutchak, N. M. Klym, V. P. Gal'chak, and S. I. Mudryi, Structure and Features of Mutual Solubility of Components in Stratifying Gallium-Based Melts. Melts (USSR), 2, 4145 (1988).

C. B. Alcock and K. T. Jacob, Solubility and Activity of Oxygen in Liquid Gallium and Gallium-Copper Alloys, J. Less-Comm. Met., 53, 211-222 (1972).

L. B. Pankratz and K. K. Kelley. Thermodynamic Data for Gallium and Scandium Sesquioxides, Report of Investigations 6198, U.S. Bureau of Mines, Washington, DC (1963)

B. Heshmatpour and D. A. Stevenson, An Electrochemical Study of the Solubility and Diffusivity of Oxygen in the Respective Liquid Metals Indium, Gallium, Antimony, and Bismuth. J. Electroanal. Chem. Interfacial Electrochem., 130, 47-55 (1981)

K. A. Klinedinst and D. A. Stevenson, Oxygen Diffusion in Liquid Gallium and Indium. J. Electrochem. Soc.: Solid-State Sci. Technol., 120, 304-308 (1973).

B. Heshmatpour, N. A. D. Parlee, and D. A. Stevenson, Correlations for Thermodynamic and Kinetic Properties of Gas Solutes in Liquid Metal Solvents, High Temp. Sc1., 15, 55-67 (1982).

K. A. Klinedinst, M. V. Rao, and D. A. Stevenson, Determination of the Component Activities in the System In-Ga Using a Solid Oxide Electrolyte Technique, J. Electrochem. Soc.: Solid-State Sci. Technol., 119, 1261-1265 (1972).

A. N. Red'kin, L. G. Dubovitskaya, V. A. Smirnov, and V. S. Dmitriev, The Behavior of Gallium(I) in Aqueous Solution, Russ. J. Inorg. Chem., 33. 640-643 (1988).

\section{Phase Diagrams}

T. B. Massalski, ed., Binary Alloy Phase Diagrams, 2nd Ed., Volume 2, ASM International, 1990.

E. H. Wright and L. A. Willey, Gallium Binary Phase Diagrams, ALCOA Technical Paper No. 16. Pittsburgh (1960).

S. P. Yatsenko, A. A. Semyannikov, B. G. Semenov, and K. A. Chuntonov, Phase Diagrams of Rare Earth Metals with Gallium, J. Less-Comm. Met., 64, 185-199 (1979).

R. Hultgren et al., Ga-Ni System in Selected Values of the Thermodynamic Properties of Binary Alloys, ASM International, pp. 918-919 (1973).

D. S. Easton and J. O. Betterton, Jr., The Eutectoid Region of the Zr-Ga System. Metall. Trans., 1, 3295-3299 (1970).

D. A. Ashby and R. D. Rawlings, The Nb-Rich Part of the Nb-Ga Phase Diagram, J. LessComm. Met. (Switzerland), 50, 111-124 (1976).

E. Hellner, Das System Nickel-Gallium, Z. Metallkd., 41, 480-484 (1950).

H. Meissner and K. Schubert, Zum Aufbau einigerzu T5-Ga homologer und quasihomologer Systeme, Z. Metallkd., 56, 523-530 (1965). 
Internal

\author{
H. M. Attaya \\ M. C. Billone \\ O. K. Chopra (10) \\ H. M. Chung \\ D. Crawford \\ M. Y. A. Gohar \\ I. Gomes \\ T. Q. Hua
}

\author{
T. F. Kassner \\ P. R. Luebbers (10) \\ C. Malefyt \\ R. F. Mattas \\ W. F. Michaud \\ K. Natesan \\ J. H. Park \\ R. B. Poeppel
}

C. Reed

W. J. Shack

D. L. Smith

R. B. Smither

D. K. Sze

C. E. TIII

R. W. Weeks

TIS Files

\section{External}

DOE-OST, for distribution per UC-423

ANL Libraries

ANL-E (2)

ANL-W

DOE Chicago Fleld Office: Manager

Energy Technology Division Review Committee:

H. K. Birnbaum, Untversity of Illinois, Urbana, IL

R. C. Buchanan. University of Cincinnati, Cincinnati, $\mathrm{OH}$

M. S. Dresselhaus, Massachusetts Institute of Technology, Cambridge. MA

B. G. Jones, University of Illinois, Urbana, IL

C.-Y. LI, Cornell University, Ithaca, NY

S.-N. Llu, Fremont, CA

R. E. Smith, ScrTech, Inc., Morrisville, NC

Other Government - University - Industry:

M. G. Barker, Chemistry Department, Nottingham University, U.K.

H. U. Borgstedt, Kernforschungszentrum Karlsruhe, Germany

J. H. DeVan, Oak Ridge National Laboratory

P. Fauvet. CEA, Fontenay-aux-Roses, France

T. Flament, CEA, Fontenay-aux-Roses, France

P. Hubberstey, Chemistry Department, Nottingham University, U.K.

H. Tas, SCK/CEN, Metallurgy Department, Mol, Belglum

P. F. Tortorell, Oak Ridge National Laboratory 

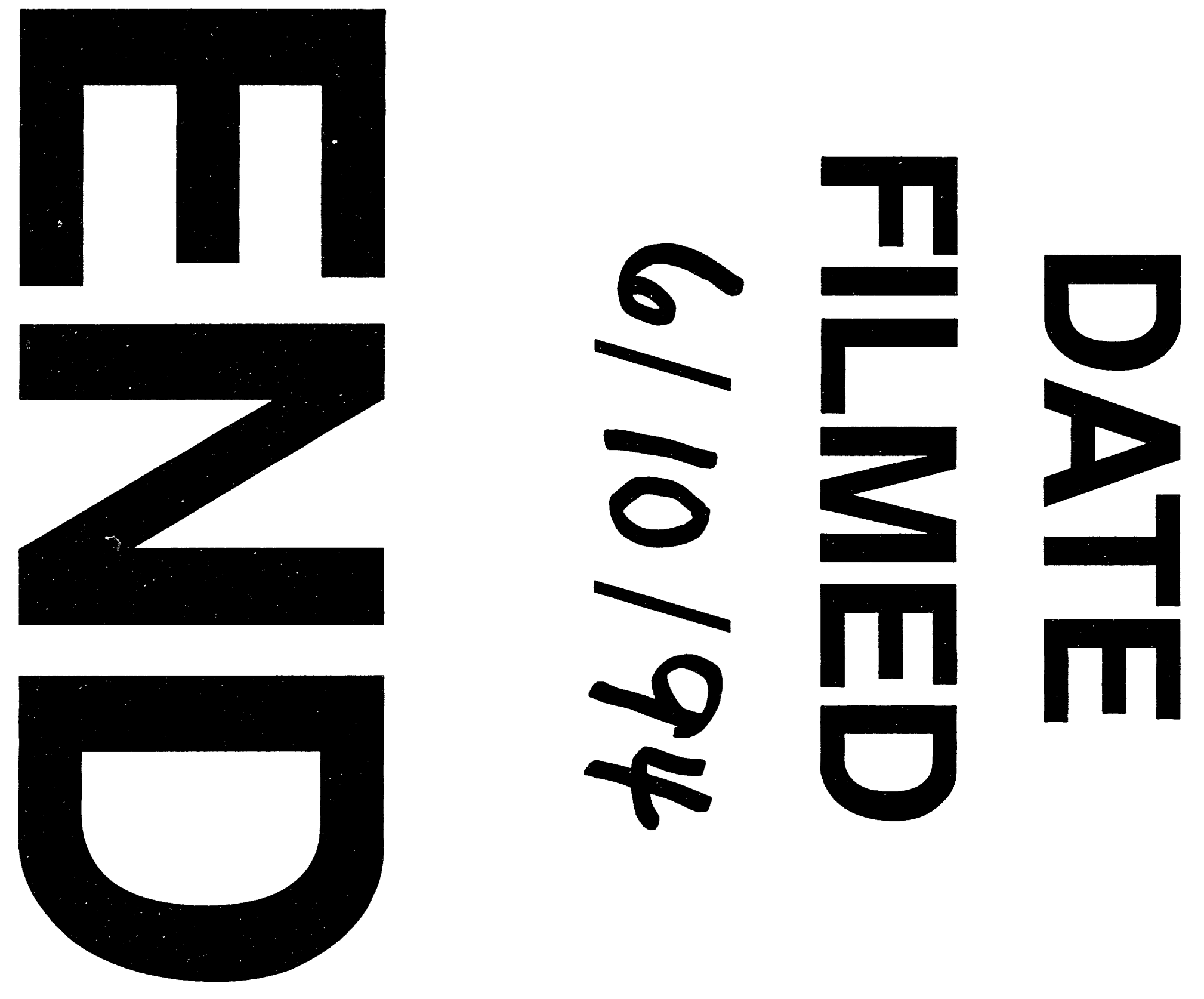


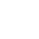

